\title{
Lappeenranta
}

University of Technology

Anshy Oonnittan Plamthottathil

\section{APPLICATION OF ELECTROKINETIC FENTON PROCESS FOR THE REMEDIATION OF SOIL CONTAMINATED WITH HCB}

\footnotetext{
Thesis for the degree of Doctor of Science (Technology) to be presented with due permission for public examination and criticism in the Auditorium of Mikkeli University Consortium on the 4 th of May, 2012, at 12:00.
}

Acta Universitatis

Lappeenrantaensis 468 
Supervisor

Reviewers

Opponent
Prof. Mika Sillanpää Lappeenranta University of Technology Finland

Dr Claudio Cameselle

Associate Professor

Department of Chemical Engineering

University of Vigo

Spain

Prof. Dr. -Ing. Wolfgang Calmano

Hamburg University of Technology

Institute of Environmental Technology and Energy Economics Germany

Dr Claudio Cameselle

Associate Professor

Department of Chemical Engineering

University of Vigo

Spain

ISBN 978-952-265-211-9

ISBN 978-952-265-212-6 (PDF)

ISSN 1456-4491

Lappeenrannan teknillinen yliopisto

Digipaino 2012 


\begin{abstract}
Anshy Oonnittan

Application of electrokinetic Fenton process for the remediation of soil contaminated with HCB Lappeenranta, 2012

$67 \mathrm{p}$.

Acta Universitatis Lappeenrantaensis 468

Diss.Lappeenranta University of Technology

ISBN 978-952-265-211-9, ISBN 978-952-265-212-6 (PDF)

ISSN 1456-4491
\end{abstract}

Electrokinetic remediation coupled with Fenton oxidation, widely called as Electrokinetic Fenton process is a potential soil remediation technique used for low permeable soil. The applicability of the process has been proved with soil contaminated with a wide range of organic compounds from phenol to the most recalcitrant ones such as PAHs and POPs.

This thesis summarizes the major findings observed during an Electrokinetic Fenton Process study conducted for the remediation of low permeable soil contaminated with HCB, a typical hydrophobic organic contaminant. Model low permeable soil, kaolin, was artificially contaminated with HCB and subjected to Electrokinetic Fenton treatments in a series of laboratory scale batch experiments. The use of cyclodextrins as an enhancement agent to mobilize the sorbed contaminant through the system was investigated. Major process hindrances such as the oxidant availability and treatment duration were also addressed. The HCB degradation along with other parameters like soil $\mathrm{pH}$, redox and cumulative catholyte flow were analyzed and monitored. 
The results of the experiments strengthen the existing knowledge on electrokinetic Fenton process as a promising technology for the treatment of soil contaminated with hydrophobic organic compounds. It has been demonstrated that HCB sorbed to kaolin can be degraded by the use of high concentrations of hydrogen peroxide during such processes. The overall system performances were observed to be influenced by the point and mode of oxidant delivery. Furthermore, the study contributes to new knowledge in shortening the treatment duration by adopting an electrode polarity reversal during the process.

Keywords: electrokinetic, electrokinetic Fenton, soil remediation, hexachlorobenzene, cyclodextrin, polarity reversal, hydrogen peroxide.

UDC 502/504:504.5:541.17:628.516 


\section{Acknowledgements}

I extend my heartfelt gratitude to my supervisor Prof. Mika Sillanpää, a veteran and award winner in the field of Environmental Technology, for his support, supervision and guidance throughout my whole $\mathrm{PhD}$ tenure under him. I thank you for giving me an opportunity to work under you and fulfill a lifetime ambition.

I would like to thank my mentor and co-supervisor, Dr Reena A. Shrestha, for giving me courage and guidance, especially during the initial phases of my studies. I express my respect and profound gratitude to my second co-supervisor Dr Pirjo Isosaari for her guidance, suggestions and comments which have helped me to draw major conclusions in many instances. I am indebted to you for giving me a chance to work under you at TKK.

All my colleagues in the laboratory are remembered for their acceptance and cooperation. Special thanks to Heikki Särkkä, who was always there with a helping hand and a smiling face. No words to express my feelings to Thuy Duong (Daisy), the honest and the most self-less being i have ever met.

Special thanks for the financial assistance by the funding bodies arranged by Prof. Mika Sillanpää and the personal grant from Maa- ja vesitekniikan tuki ry (MVTT).

I am very much thankful to my parents, Mr. P. P. Oonnittan and Mrs. Mariyamma Oonnittan as well as my brother, Mr. Anish Oonnittan who have given me the mental support for my stay in Finland and my studies here. My father's highly ambitious expectations for his daughter have encouraged and helped me to achieve this milestone in my career. 
I thank my loving husband, Mr. Hans James, for his continual support without which i would have never achieved my goal. My sweet little angel, Sara, is thanked for being my stress reliever and energy booster. You have made my life brighter and i love you so much! 


\section{LIST OF PUBLICATIONS}

The publications are listed in roman numerals in the text as follows:

I. Anshy Oonnittan, Reena Shrestha, Mika Sillanpää, Remediation of hexachlorobenzene in soil by enhanced electrokinetic Fenton process. Journal of Environmental Science and Health Part A 43 (2008) 894-900.

II. Anshy Oonnittan, Reena Shrestha, Mika Sillanpää. Removal of hexachlorobenzene from soil by electrokinetically enhanced chemical oxidation. Journal of Hazardous Materials 162 (2009) 989-993.

III. Anshy Oonnittan, Reena Shrestha, Mika Sillanpää, Effect of cyclodextrin on the remediation of hexachlorobenzene in soil by electrokinetic Fenton process, Separation and Purification Technology 64 (2009) 314-320.

IV. Anshy Oonnittan, Pirjo Isosaari, Mika Sillanpää, Oxidant availability and its effect on HCB removal during electrokinetic Fenton process, Separation and Purification Technology 76 (2010) 146-150.

V. Anshy Oonnittan, Pirjo Isosaari, Mika Sillanpää, The effect of polarity reversal on HCB removal during electrokinetic Fenton process, submitted.

\section{Author's contribution in the publications}

Planned, designed, carried out all the experiments, analyzed the data, interpreted the results and prepared the first draft of all the manuscripts. 



\section{TABLE OF CONTENTS}

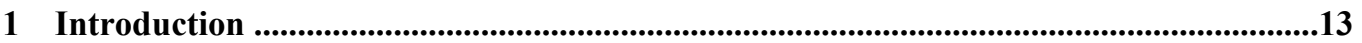

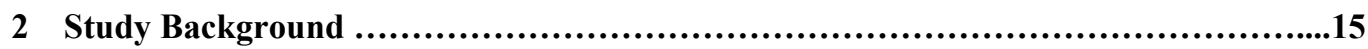

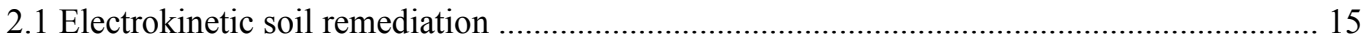

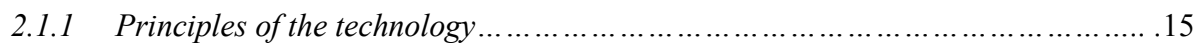

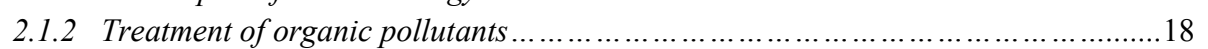

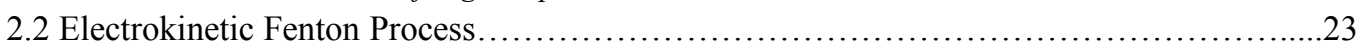

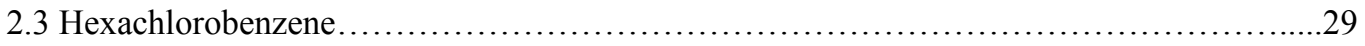

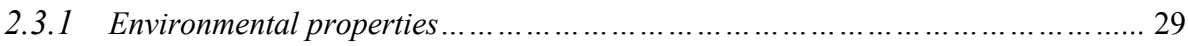

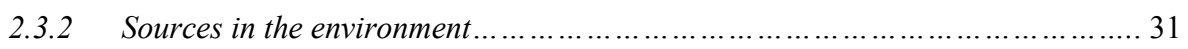

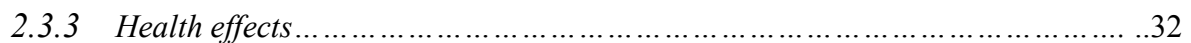

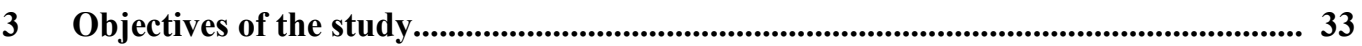

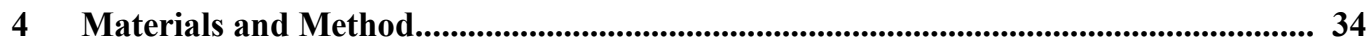

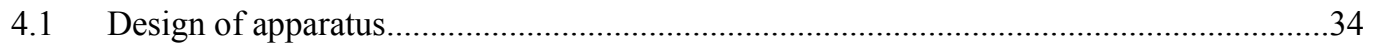

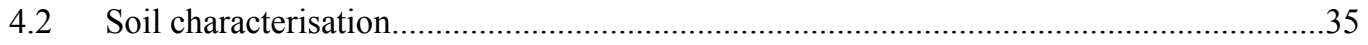

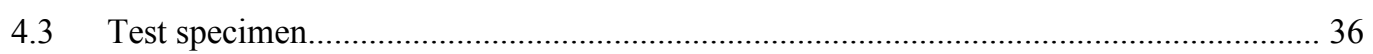

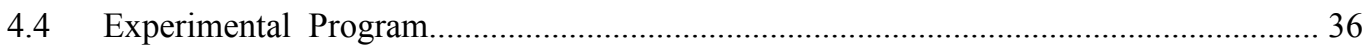

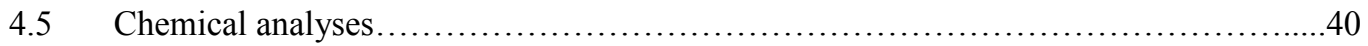

$5 \quad$ Results \& discussions...................................................................42

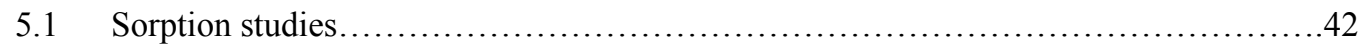

5.2 Feasibility Tests - Electrokinetic and Electrokinetic Fenton Treatments................42

5.3 Electrode positioning / Type 1 and Type 2 apparatus.............................42

5.4 Electrokinetic Fenton Treatment with and without $\beta$-cyclodextrin.....................45

5.5 Oxidant availability - Electrokinetic Fenton Treatment with different modes and points of oxidant addition...................................................... 47

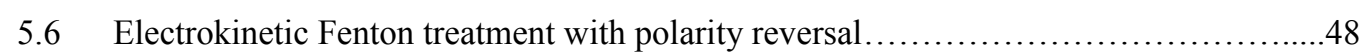

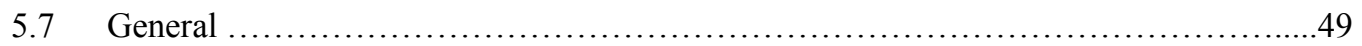

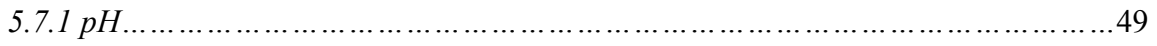

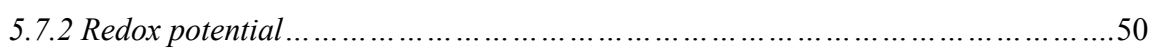

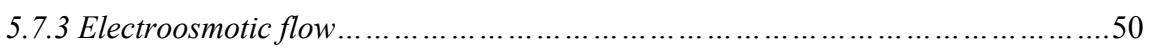




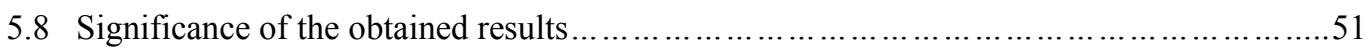

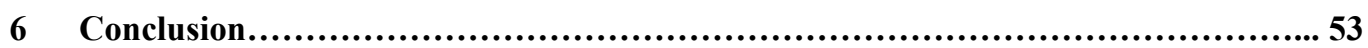

References

Appendix 


\section{Symbols}

q Volume flow rate $\mathrm{m}^{3} / \mathrm{s}$

$\mathrm{K}_{\mathrm{e}} \quad$ electroosmotic permeability of the soil $\mathrm{m}^{2} / \mathrm{Vs}$

E electric field strength $\quad \mathrm{V} / \mathrm{m}$

A cross-sectional area of the soil sample $\mathrm{m}^{2}$

$\mathrm{OH}^{*} \quad$ hydroxyl radical

$\mathrm{HO}_{2}{ }^{*} \quad$ perhydroxyl radical.

$\mathrm{R}^{*} \quad$ organic radical

Q mass of HCB sorbed per unit mass of kaolin $\quad \mathrm{mg} / \mathrm{kg}$

C concentration of HCB in solution at equilibrium $\mathrm{mg} / \mathrm{l}$

$\begin{array}{ll}\text { Abbreviations } & \\ \text { POPs } & \text { persistent organic pollutants } \\ \text { PAHs } & \text { polycyclic aromatic hydrocarbons } \\ \text { HCB } & \text { hexachlorobenzene } \\ \text { TDI } & \text { tolerable daily intake } \\ \text { USEPA } & \text { US Environmental Protection Agency } \\ \text { ATSDR } & \text { Agency for Toxic Substances and Disease Registry } \\ \text { DW } & \text { deionized water } \\ \text { OCPs } & \text { organochlorine pesticides } \\ \text { HPCD } & \text { hydroxypropyl beta cyclodextrin } \\ \text { EDTA } & \text { ethylenediamine tetraacetic acid } \\ \text { DTPA } & \text { diethylenetriamine pentaacetic acid } \\ \text { SDS } & \text { sodium dodecyl sulfate } \\ \text { APG } & \text { alkyl polyglucosides }\end{array}$





\section{INTRODUCTION}

Soil constitutes one of the major parts of the ecosystem. Activities that lead to soil contamination may also disrupt the soil quality. Industrial development and agricultural activities have been pointed out as the major causes for soil contamination so far. The increased awareness about the threats caused by organic contaminants especially POPs have raised concerns and have led the governments and authorities to put stringent regulations on their manufacture and use. Once, POPs get into the soil, they are difficult to remove due to their hydrophobic nature.

Numerous techniques based on physical, chemical and biological methods have been in practice for the remediation purposes. However, they have often proved unsuccessful when the site consisted of heterogeneities or low permeable soil [1].

Electrokinetic technology has been developed and accepted as an effective remediation technique for treating low permeable soils [2]. Electrokinetic remediation has been applied for the removal of a wide range of contaminants, including heavy metals, organics and radionuclides. The use of electrokinetics for the removal of organic contaminants can be beneficial when aimed for the complete destruction/degradation of the contaminants right in the soil itself. This can be accomplished by suitably combining chemical oxidation processes like Fenton oxidation with electrokinetic treatment of soil.

Integrated technologies based on electrokinetics like electrokinetic Fenton process have shown their potential for addressing such technologically challenging situations. Despite the need for such integrated processes for solving the pollution issues, this area remains largely under researched. Therefore, it is of great importance that studies pertaining to the applicability of 
electrokinetic Fenton processes for the degradation of sorbed organic contaminants be carried out. 


\section{STUDY BACKGROUND}

\subsection{Electrokinetic soil remediation}

\subsubsection{Principles of the technology}

Electrokinetics has emerged as one of the most versatile technologies for soil remediation over the past three decades because of its suitability to treat both inorganic and organic pollutants as well as radionuclides, saturated and unsaturated soil matrices, low permeable soil and heterogeneous soil layers.

Electrokinetic treatment has shown its potential also for the simultaneous removal of inorganic and organic species from soil [3, 4]. Electrokinetics is a process that can be used to decontaminate soil by driving the inorganic and organic contaminant species through the soil matrix. The driving force for this species transfer is the applied electric field. Finally, the contaminants are removed by electroplating at the electrode, precipitation or co-precipitation at the electrode, adsorption onto the electrode or complexing with ion exchange resins (heavy metal species) and pumping water near the electrode (organic contaminants) [5].

Several large scale applications of electrokinetics were reported even from late 1970s and early 1980s [6]. These studies were based on the fundamental aspects of the technology without the comprehension of complicated electrochemical phenomena that actually govern the process. However, the results of these applications proved the potential of electrokinetics for the removal of a wide range of inorganic pollutants, soluble organic pollutants and radionuclides $[7,8,9,10$, $11,12]$. Later on, the focus was directed to the enhancement of the processes for better removal rates, including $\mathrm{pH}$ conditioning and surfactant additions $[13,14,15]$. At present, several pilot 
scale trials are being carried out for the removal of organic compounds, heavy metals and radio nuclides from contaminated soil. $[16,17,18]$

The recent developments and the history of electrokinetics, how it emerged and evolved as a remediation technique, have been explained by Yeung [19].

The principles of electrokinetic technology have elaborately been explained and thoroughly understood $[2,5,20,21]$. There are several electrochemical phenomena taking place upon the application of electric field on a soil mass. However, the major transport mechanisms that are relevant from a remediation standpoint are the following:

\section{Electromigration}

2. Electroosmosis

3. Electrophoresis

Electromigration refers to the movement of charged species present in the soil mass under the influence of an externally applied electric field. The charged species move towards the electrodes of opposite polarity. The ionic mobilities of heavy metals at infinite dilution are in the range of $10^{-4} \mathrm{~cm}^{2} /$ Vs. However, taking into account the effective ionic mobility due to the tortuosity in a porous medium like soil, the rate of heavy metal transport in clayey soil is about a few centimeters per day under a unit electric gradient [22].

Electroosmosis is the movement of the pore fluid under an electric field which results from the interaction between the bulk liquid and the diffuse double layer existing at the soil particle /fluid interface. The direction of the electroosmosis depends on the surface charge of the soil particles. Since, a negative surface exists in most soil particles, especially on clayey soil, excess positive charges are distributed adjacent to the soil surface which continuously drags the bulk fluid 
towards the cathode. Therefore, the direction of electroosmosis is always towards the electrode of negative polarity unless, the surface charge of the soil particles are changed. The rate of electroosmotic flow in a porous medium is defined by the Helmholtz-Smoluchowski equation which is explained in latter section.

Electrophoresis is the transport of charged particles (like clay particles or microorganisms) or colloids under an applied electric field. However, electrophoresis has no major role in a compact solid phase, where there is minimal movement of the particles.

A recent review by Mahmoud et al. [23] presents a detailed account of these electrokinetic transportation phenomena.

Highly soluble ionized inorganic species that are present in moist soil environments are transported by electromigration and also by electroosmosis depending upon the species concentration [5]. However, electroosmosis plays the dominant role in the transport of soluble organic species present in the soil.

Besides these transportation processes, the application of voltage also leads to other electrode reactions and the corresponding geochemical reactions in the treated material. The electrode reactions involve the electrolysis of water:

$$
\begin{aligned}
& 2 \mathrm{H}_{2} \mathrm{O}-4 \mathrm{e}^{-}=\mathrm{O}_{2}+4 \mathrm{H}^{+} \quad \text { (anode) } \\
& 2 \mathrm{H}_{2} \mathrm{O}+2 \mathrm{e}-=\mathrm{H}_{2}+2 \mathrm{OH}^{-} \text {(cathode) }
\end{aligned}
$$

The protons and hydroxyl ions generated at the anode and cathode, respectively, are transported through the soil. The mobility of protons under an applied electric field is about two times the mobility of hydroxyl ion [24]. Also, the advance of the basic front developed at the cathode is 
retarded by the counteracting electroosmotic flow. Therefore, the soil $\mathrm{pH}$ that develops during an electrokinetic process depends on the extent of the movement of protons and hydroxyl radicals as well as the geochemical characteristics of the soil such as its buffering capacity [25]. These changes in the soil $\mathrm{pH}$ lead to other geochemical reactions in the soil which include sorptiondesorption reactions, complexation reactions, precipitation -dissolution reactions and oxidationreduction reactions.

These geochemical reactions significantly affect the electrokinetic process and can enhance or retard the process [22].

Several techniques have been proposed to alter the normal geochemical reactions that arise from the electrode reactions to enhance the electrokinetic removal of species from the soil. They are controlling the soil $\mathrm{pH}$ by suitable acid, base, and buffer additions into the anolyte or catholyte, by using specially designed ion selective membranes, or by using enhancement agents which aid in the complexation and removal of species present etc $[15,22]$.

\subsubsection{Treatment of organic pollutants}

A major part of the early research on electrokinetics was devoted to the investigation of heavy metal removal. Removal of organic pollutants by electrokinetic process gained interest and attention only when the role of electroosmosis in transporting the soluble organics was understood.

Among different theories proposed for the electroosmotic flow, including the HelmholtzSmoluchowski theory, Schmid theory, the Spiegler friction model, and ion hydration theory, the 
Helmholtz-Smoluchowski theory is the most common theoretical description of electroosmosis [22]. The rate of electroosmotic flow is controlled by the coefficient of electroosmotic permeability of soil [24]. Ke, as stated by Helmholtz- Smoluchowski equation depends primarily on the porosity and zeta potential of soil and can be assumed as constant during an electrokinetic process as long as there is no change in the concentration of ions or $\mathrm{pH}$ of the pore fluid.

For practical purposes, electroosmotic flow rate is expressed by an equation analogous to Darcy's law of hydraulic flow as:

$\mathrm{q}=\mathrm{k}_{\mathrm{e}} \mathrm{E} A$

The very first reports on the application of electroosmosis for the decontamination of soils contaminated with organic compounds were presented by the research team led by R. F. Probstein $[26,27]$. They demonstrated the feasibility of using electroosmosis for the removal of organic compounds like phenol and acetic acid from saturated clay both theoretically and experimentally.

However, the process had limited application when dealing with insoluble organics sorbed to the soil [2]. This is because electroosmosis is expected to transport only the hydrophilic organic contaminants. The focus then shifted to the removal of hydrophobic organic contaminants, and the use of solubilizing agents to desorb and mobilize insoluble organic contaminants gained attention. Subsequent research on the electrokinetic treatments made use of these enhancement agents like surfactants, cosolvents or cyclodextrins to treat sorbed contaminants [28, 29, 30].

Surfactants are compounds with a polar hydrophilic head and a non polar hydrophobic tail. Based on the hydrophilic head group surfactants are commonly classified as anionic, cationic and non ionic. Among these, nonionic surfactants are generally considered ideal for soil remediation as 
they have higher solubilization capacities and are relatively non-toxic [31]. Surfactants increase the aqueous solubility of organic compounds by lowering the interfacial tension and by micellar solubilization [32]. Cosolvents are organic solvents that are capable of changing the aqueous phase characteristics of organic compounds such as its solubility, sorption kinetics and transport velocity [31]. Cyclodextrins, formed by the degradation of starch by bacteria, are linear chain glucose molecules with their ends joined to form a cyclic structure. They form inclusion complexes with hydrophobic organic compounds by partitioning them to the center of their ring, thus significantly enhancing the aqueous solubility of organic compounds [33]. Recently there have been more interest towards cyclodextrin based enhancements. This is because they are non toxic and biodegradable when compared to toxic surfactant micelles and cosolvents at higher concentrations [34]. Moreover, cyclodextrins have been proved effective for the mobilization of PAHs and other HOCs in contaminated soil $[3,35]$.

Electroosmotic flushing of solubilizing agents through the soil can be used as such to remove soil-bound organic contaminants. A summary of some of the studies undertaken during the last decade in electrokinetic remediation of organic compounds using these kinds of enhancement agents is presented in Table 1. 
Table 1. Summary of electrokinetic soil remediation studies using enhancement agents.

\begin{tabular}{|c|c|c|c|c|}
\hline Contaminant & $\begin{array}{l}\text { Soil } \\
\text { Type/Source }\end{array}$ & $\begin{array}{l}\text { Enhancement } \\
\text { agent used }\end{array}$ & Relevant Results & Reference \\
\hline Gas oil & Natural soil & Rhamnolipid & $\begin{array}{l}\text { A maximum of } 86.7 \% \text { removal with } \\
\text { the highest dose used. }\end{array}$ & {$[36]$} \\
\hline $\begin{array}{l}\text { HCB, Heavy } \\
\text { metals }\end{array}$ & $\begin{array}{l}\text { Aged } \\
\text { sediment }\end{array}$ & HPCD & $\begin{array}{l}\text { Nearly } 40 \% \text { HCB removal } \\
\text { efficiency obtained with } 2.6 \text { pore } \\
\text { volumes. }\end{array}$ & {$[37]$} \\
\hline Diesel oil & $\begin{array}{l}\text { Petrol station } \\
\text { soil }\end{array}$ & $\begin{array}{l}\text { EDTA, n-propanol, } \\
\text { Tergitols }\end{array}$ & $\begin{array}{l}\text { EDTA alone enhanced the removal } \\
\text { of aliphatic and aromatic } \\
\text { compounds in the soil. A } \\
\text { combination of n-propanol and } \\
\text { EDTA enhanced the hydrocarbon } \\
\text { removal efficiency. }\end{array}$ & {$[38]$} \\
\hline Phenanthrene & $\begin{array}{l}\text { collected } \\
\text { from specific } \\
\text { waste site }\end{array}$ & $\begin{array}{l}\text { Triton X - } 100 \text { and } \\
\text { Rhamnolipid }\end{array}$ & $\begin{array}{l}\text { Rhamnolipid found to be more } \\
\text { efficient than Triton X-100 }\end{array}$ & {$[39]$} \\
\hline $\begin{array}{l}\text { Phenanthrene, } \\
\text { Nickel }\end{array}$ & Kaolin & $\begin{array}{l}\text { Igepal CA-720, } \\
\text { Tween } 80\end{array}$ & $\begin{array}{l}\text { Complete removal observed using } 5 \\
\% \text { Igepal CA-720 }\end{array}$ & {$[40]$} \\
\hline $\begin{array}{l}\text { Phenanthrene, } \\
\text { Lead, Zinc }\end{array}$ & MGP soil & $\begin{array}{l}\text { Igepal CA-720, } \\
\text { Tween } 80, \mathrm{n}- \\
\text { butylamine, } \\
\text { tetrahydro furan, } \\
\text { EDTA. }\end{array}$ & $\begin{array}{l}\text { Effective removal of phenanthrene } \\
\text { observed with different } \\
\text { concentrations of Igepal CA- } 720 \\
\text { and Tween } 80 \text {. }\end{array}$ & {$[41]$} \\
\hline $\begin{array}{l}\text { Phenanthrene, } \\
\text { Nickel }\end{array}$ & Kaolin & n-butylamine & $\begin{array}{l}\text { Significant solubilisation of } \\
\text { phenanthrene with increasing } \\
\text { concentrations of the cosolvent. }\end{array}$ & {$[42]$} \\
\hline Phenanthrene & Kaolin & APG, Brij 30, SDS & $\begin{array}{l}\text { APG found to be the best among } \\
\text { three in terms of removal efficiency } \\
\text { and electroosmotic flow. }\end{array}$ & {$[43]$} \\
\hline DDT & Sandy loam & Tween 80, SDBS & $\begin{array}{l}\text { Though both surfactants showed } \\
\text { similar solubilization potentials for } \\
\text { DDT, electrokinetics transport with } \\
\text { SDBS yielded better results. }\end{array}$ & {$[44]$} \\
\hline $\begin{array}{l}\text { PAH mixture, } \\
\text { Heavy metals }\end{array}$ & MGP soil & $\begin{array}{l}\text { Tween } 80 \text {, Igepal } \\
\text { CA-720, n- } \\
\text { butylamine, HPCD }\end{array}$ & $\begin{array}{l}\text { Though highest electroosmotic flow } \\
\text { was observed with cosolvents, } \\
\text { Igepal CA } 720 \text { resulted in the } \\
\text { highest removal efficiency. }\end{array}$ & {$[45]$} \\
\hline $\mathrm{HCB}$ & Kaolin & $\begin{array}{l}\beta \text {-cyclodextrin, } \\
\text { Tween } 80\end{array}$ & $\begin{array}{l}\text { Better removal with } \beta \text {-cyclodextrin } \\
\text { than with Tween } 80 \text {. }\end{array}$ & [35] \\
\hline $\begin{array}{l}2,4 \\
\text { dinitrotoluene }\end{array}$ & $\begin{array}{l}\text { Kaolin, } \\
\text { Glacial till }\end{array}$ & HPCD & $\begin{array}{l}\text { Higher degradation with HPCD in } \\
\text { kaolin. }\end{array}$ & {$[46]$} \\
\hline $\begin{array}{l}\text { Phenanthrene, } \\
\text { Nickel }\end{array}$ & Kaolin & HPCD & $\begin{array}{l}\text { Phenanthrene removal was high } \\
\text { when using } 1 \% \text { HPCD compared to } \\
10 \% \text { HPCD. However, the overall } \\
\text { removal was not high due to the low } \\
\text { concentration of HPCD. }\end{array}$ & [3] \\
\hline
\end{tabular}


Table contd.

\begin{tabular}{|c|c|c|c|c|}
\hline Contaminant & $\begin{array}{l}\text { Soil } \\
\text { Type/Source }\end{array}$ & $\begin{array}{l}\text { Enhancement } \\
\text { agent used }\end{array}$ & Relevant Results & Reference \\
\hline $\begin{array}{l}\text { Phenanthrene, } \\
\text { Lead, Zinc }\end{array}$ & MGP soil & $\begin{array}{l}\text { Igepal CA-720, n- } \\
\text { butylamine, } \\
\text { tetrahydrofuran, } \\
\text { EDTA, DTPA }\end{array}$ & $\begin{array}{l}\text { Surfactants, Igepal CA-720 and } \\
\text { Tween } 80 \text {, effective in removing } \\
\text { phenanthrene. }\end{array}$ & {$[47]$} \\
\hline Phenanthrene & Kaolinite & APG, Calfax 16L-35 & $\begin{array}{l}\text { Though both showed similar } \\
\text { solubilisation potentials, } \\
\text { electrokinetics movement of } \\
\text { phenanthrene with increasing } \\
\text { concentrations of APG resulted in } \\
\text { higher removal. }\end{array}$ & {$[48]$} \\
\hline Ethybenzene & $\begin{array}{l}\text { Clayey } \\
\text { natural soil }\end{array}$ & $\begin{array}{l}\text { Mixture of SDS, } \\
\text { PANNOX } 110\end{array}$ & $\begin{array}{l}\text { A removal efficiency of } 63-98 \% \\
\text { observed. }\end{array}$ & {$[28]$} \\
\hline $\begin{array}{l}\text { Phenanthrene, } \\
\text { Nickel }\end{array}$ & Kaolin & $\begin{array}{l}\text { Surfactants (Igepal } \\
\text { CA-720, Tween 80), } \\
\text { Cosolvents (n- } \\
\text { butylamine, } \\
\text { tetrahydrofuran), } \\
\text { cyclodextrins } \\
\text { (HPCD, } \beta \text { - } \\
\text { cyclodextrin } \\
\text { hydrate), chelating } \\
\text { agents (EDTA, } \\
\text { DTPA) }\end{array}$ & $\begin{array}{l}\text { Surfactants and cosolvents were } \\
\text { found to be effective for the } \\
\text { removal of phenanthrene. }\end{array}$ & [49] \\
\hline Phenanthrene & $\begin{array}{l}\text { Kaolin, } \\
\text { Glacial till }\end{array}$ & $\begin{array}{l}\text { Igepal CA-720, } \\
\text { Triton X-100, } \\
\text { Tween } 80 \text {, ethanol, } \\
\text { ethanol-Igepal } \\
\text { mixture. }\end{array}$ & $\begin{array}{l}\text { Highest desorption and } \\
\text { solubilization observed with the } \\
\text { surfactant solutions. }\end{array}$ & {$[50]$} \\
\hline Phenanthrene & $\begin{array}{l}\text { Kaolin, } \\
\text { Glacial till. }\end{array}$ & Tween 80 , ethanol & $\begin{array}{l}\text { Contaminant desorption possible by } \\
\text { surfactant or cosolvent solution. }\end{array}$ & {$[51]$} \\
\hline Phenanthrene & Glacial till & $\begin{array}{l}\text { n-butylamine, } \\
\text { tetrahydrofuran, } \\
\text { acetone }\end{array}$ & $\begin{array}{l}43 \% \text { phenanthrene removal after } \\
127 \text { days or } 9 \text { pore volumes. }\end{array}$ & {$[52]$} \\
\hline
\end{tabular}

The application of these electrokinetic processes made a major leap forward when organic contaminants were successfully removed and degraded/destroyed from the soil matrix. This was made possible by coupling electrokinetics with other remediation techniques like biodegradation and chemical oxidation. Electrokinetics coupled with bioremediation is an effective technique if the treatment duration is not a primary concern for the remediation project. However, it fails when the target contaminant is toxic and present at high concentrations. Integrated technologies 
based on advanced oxidation processes have proved to be very successful in treating organic contaminants, especially toxic ones. A comprehensive study on integrated electrokinetic chemical oxidation processes using different oxidants such as sodium persulfate and Fenton's reagent was performed by Isosaari et al [53]. They observed that during the electrokinetic treatment with persulfate oxidation, $35 \%$ of the total PAH mixtures were removed from the soil near the anode section in 8 weeks. However, electro Fenton test did not result in a better performance than electrokinetics alone. Electrokinetic- permanganate oxidation for the removal of phenol was studied by Thepsithar \& Roberts [54]. According to their results, $90 \%$ of phenol was removed from the soil during a 5 days treatment with a voltage gradient of $1 \mathrm{~V} / \mathrm{cm}$. Another study by Pham et al [55] used Ultrasound as an enhancement during the electrokinetic removal of phenanthrene, fluoranthene and HCB. Their results were encouraging and proved the effectiveness of ultrasonically enhanced electrokinetic remediation of soil. However, the results indicate that $\mathrm{HCB}$ was the most difficult to treat, probably because of its extremely stable nature. Yang \& Yeh [56] recently reported the feasibility of electrokinetically enhanced persulfate oxidation for the destruction of TCE in a spiked sandy clay soil. Also, the role of nanoscale $\mathrm{Fe}_{3} \mathrm{O}_{4}$ for activating persulfate was investigated. By doing so, they have achieved the target concentration well below the regulatory threshold values in the soil as well as in the electrode chambers. However, limited studies were done so far for the remediation of stable and recalcitrant organic compounds like OCPs. Moreover, degradation of stable OCPs necessitates the application of aggressive and rigorous chemical oxidation processes such as the Fenton process.

\subsection{Electrokinetic Fenton Process}


Electrokinetic Fenton process is an integrated technology incorporating chemical oxidation by Fenton's process with the electrokinetic treatment of soil. The applicability of iron-catalyzed $\mathrm{H}_{2} \mathrm{O}_{2}$ as an oxidizing agent was first reported by H. J. H. Fenton [57]. Several works have been documented on the use of Fenton's process for the oxidation of organic compounds including recalcitrant contaminants $[58,59,60,61,62,63]$. The use of Fenton's process is favored also due to the fact that the final reaction products are environmentally benign.

The primary reactions in the Fenton's process are:

$$
\begin{aligned}
& \mathrm{H}_{2} \mathrm{O}_{2}+\mathrm{Fe}^{2+} \rightarrow \mathrm{OH}^{*}+\mathrm{OH}^{-}+\mathrm{Fe}^{3+} \\
& \mathrm{H}_{2} \mathrm{O}_{2}+\mathrm{Fe}^{3+} \rightarrow \mathrm{HO}_{2}^{*}+\mathrm{H}^{+}+\mathrm{Fe}^{2+} \\
& \mathrm{OH}^{*}+\mathrm{Fe}^{2+} \rightarrow \mathrm{OH}^{-}+\mathrm{Fe}^{3+} \\
& \mathrm{HO}_{2}{ }^{*}+\mathrm{Fe}^{3+} \rightarrow \mathrm{O}_{2}+\mathrm{H}^{+}+\mathrm{Fe}^{2+} \\
& \mathrm{H}_{2} \mathrm{O}_{2}+\mathrm{OH}^{*} \rightarrow \mathrm{H}_{2} \mathrm{O}+\mathrm{HO}_{2}{ }^{*}
\end{aligned}
$$

In the presence of organic substrate the reactions include:

$$
\begin{aligned}
& \mathrm{RH}+\mathrm{OH}^{*} \rightarrow \mathrm{R}^{*}+\mathrm{H}_{2} \mathrm{O}+\mathrm{HO}_{2}{ }^{*} \\
& \mathrm{R}^{*}+\mathrm{Fe}^{3+} \rightarrow \mathrm{Fe}^{2+}+\text { degradation products }
\end{aligned}
$$

Thus Fenton's oxidation is an effective mechanism for the decomposition of toxic organic compounds $[64,65,66,67,68]$. However, when applied alone, Fenton's process fails to treat low permeable soil. This is because effective contact between the oxidant and the contaminant is a primary requirement for a successful treatment which is not possible in matrices of low 
permeability. This drawback can be overcome by integrating electrokinetics with Fenton's process. In electrokinetic Fenton process, hydrogen peroxide passes through low permeable soil from anode to cathode by electroosmosis and decomposes the contaminants in the soil in the presence of iron present in the soil. The attractiveness of this coupled technology is that it addresses one of the major shortcomings of eletrokinetic remediation by removing as well as destroying/degrading the contaminants, thus avoiding a further treatment or disposal of the waste stream.

The application of electrokinetic Fenton technology for the remediation of contaminated soil was first reported by Yang and Long [69]. In their study a saturated sandy loam containing phenol as pollutant was treated by electrokinetic Fenton by incorporating a permeable reactive bed containing scrap iron powder into the soil bed and $\mathrm{H}_{2} \mathrm{O}_{2}$ was flushed from the anode reservoir. This was followed by a more elaborate study on the performance of electrokinetic Fenton technology for the oxidation of TCE in two types of soil [70]. The results were interpreted for two different types of electrodes and the form and type of iron catalyst used. These studies formed the basis of several successive research based on electrokinetic Fenton process for soil remediation by different research groups. A summary of these studies is presented in Table 2 .

The hydroxyl radicals generated in Fenton's reaction are generated in aqueous solutions and are capable of oxidizing the contaminants in aqueous solution [71]. Therefore they are unable to attack the contaminants sorbed to the soil. However, it has been documented that oxidation of sorbed contaminants in the subsurface can actually be promoted by using a high concentration of $\mathrm{H}_{2} \mathrm{O}_{2}(>2 \%)[58,67]$. 
This is because the use of high concentrations of $\mathrm{H}_{2} \mathrm{O}_{2}$ favors the generation of highly reactive species other than hydroxyl radical like hydroperoxide radicals $\left(\mathrm{HO}_{2}{ }_{2}\right)$, superoxide anions $\left(\mathrm{O}_{2}{ }^{{ }^{*}}\right)$ and hydroperoxide anions $\left(\mathrm{HO}_{2}{ }^{*}\right)$ which are capable of degrading even the most recalcitrant compounds in the sorbed form $[72,73]$.

$\mathrm{H}_{2} \mathrm{O}_{2}+\mathrm{OH}^{*} \rightarrow \mathrm{H}_{2} \mathrm{O}+\mathrm{HO}_{2}^{*}$

$\mathrm{HO}_{2}^{*} \rightarrow \mathrm{O}_{2}^{*}+\mathrm{H}^{+}$

$\mathrm{HO}_{2}{ }_{2}+\mathrm{Fe}^{+} \rightarrow \mathrm{HO}^{*}{ }^{*}+\mathrm{Fe}^{3+}$

Studies by Ferrarese et al. [72] and Rivas [73] suggest that the generation of non/hydroxyl radicals such as hydroperoxide radicals $\left(\mathrm{HO}^{*}\right)$, superoxide anions $\left(\mathrm{O}_{2}{ }^{{ }_{-}}\right)$and hydroperoxide anions $\left(\mathrm{HO}_{2}{ }^{*}\right)$ are responsible for the aggressive chemical reactions which ultimately lead to the oxidation of sorbed contaminants.

Another explanation is that a high concentration $\mathrm{H}_{2} \mathrm{O}_{2}$ first desorbs the contaminants from the soil surface and then oxidizes them. Kawahara et al. [74] proposed that high concentration of $\mathrm{H}_{2} \mathrm{O}_{2}$ has the ability to extract PAHs from clays. The mechanism they have explained is that the electron exchange by structural iron in clay mineral results in the swelling of clay layers and this swelling increases the space between the layers and release the sorbed contaminants. All these studies have established the effectiveness of high concentration of $\mathrm{H}_{2} \mathrm{O}_{2}$ in the remediation of soil contaminated with sorbed contaminants. Also, these studies reveal that sorbed hydrophobic contaminants can be treated without any enhancing agents if high concentrations of $\mathrm{H}_{2} \mathrm{O}_{2}$ are used. 
As seen from Table 2, most of the studies on electrokinetic Fenton treatments were focused on the remediation of soluble organics and relatively insoluble $\mathrm{PAH}$ mixtures. Studies on remediation of soil polluted with OCPs like $\mathrm{HCB}$ by electrokinetic oxidation treatment are limited.

The success and performance of such in situ processes rely on certain key factors including oxidant selection, oxidant loading and oxidant delivery. Numerous studies have been conducted on the oxidant loading or in other terms the dosing of Fenton's reagent for the oxidation of a variety of soil contaminants like phenanthrene, pyrene, chrysene etc [73]. On the other hand, little attention has been given on the studies on oxidant delivery, especially during electrokinetic treatment of soil. Oxidant delivery is important since it determines the extent to which the contaminated soil comes into contact with the oxidant. Therefore, the oxidant should be delivered to the soil in such a way so as to facilitate effective soil-oxidant interaction. It was also pointed out by Isosaari et al [53] that higher oxidation rates were observed near the oxidation injection points in their experiments. This emphasizes the importance of oxidant delivery during these processes.

The environmental impacts of Fenton treatment as discussed by Yap et al [75] show how important it is to restore the soil properties in the post treated soil in order to sustain the microbial activities and soil vegetation. This is because, electrokinetically treated soils in most cases result in an acidic soil which may lead to metal dissolution and also unavailability of plant nutrients at low $\mathrm{pH}$ [76]. Non-uniform electrokinetics induced by reversing the electrode polarity has been studied for maintaining the soil $\mathrm{pH}$ and also for improving the mobility of organic pollutants [77, 78]. Therefore, such a polarity reversal can be adopted to enhance the electrokinetic Fenton 
process by propagating the oxidant through the soil matrix in a better way and also result in a more uniform $\mathrm{pH}$ throughout the soil section.

Table 2. Summary of electrokinetic Fenton based research in soil remediation.

\begin{tabular}{|c|c|c|c|c|c|c|}
\hline Contaminant & Soil Type & $\begin{array}{l}\text { Applied } \\
\text { Voltage } \\
(\mathrm{V} / \mathrm{cm})\end{array}$ & $\begin{array}{l}\% \text { of } \\
\mathrm{H}_{2} \mathrm{O}_{2} \\
\text { used }\end{array}$ & $\begin{array}{l}\text { Duration } \\
\text { (days) }\end{array}$ & Relevant results & Reference \\
\hline Phenol & $\begin{array}{l}\text { Sandy } \\
\text { loam }\end{array}$ & 1 & 0.3 & 10 & $\begin{array}{l}\text { A maximum of } 99.7 \% \\
\text { destruction of the } \\
\text { contaminant was obtained }\end{array}$ & [69] \\
\hline TCE & $\begin{array}{l}\text { Loamy } \\
\text { sand and } \\
\text { Sandy } \\
\text { loam }\end{array}$ & 1 & $\begin{array}{l}<4000 \\
\mathrm{mg} / \mathrm{l}\end{array}$ & 10 & $\begin{array}{l}\text { A maximum destruction of } \\
59.4 \% \text { achieved. }\end{array}$ & {$[70]$} \\
\hline Phenanthrene & Sandy soil & 1.2 & 5 & 21 & $\begin{array}{l}\text { A maximum removal of } 81.6 \\
\% \text { achieved. }\end{array}$ & {$[80]$} \\
\hline Phenanthrene & kaolinite & 1.5 & 7 & 10 & $\begin{array}{l}\text { A maximum of } 74 \% \\
\text { removal with acid ingestion. }\end{array}$ & [81] \\
\hline Phenanthrene & $\begin{array}{l}\text { Hadong } \\
\text { clay and } \\
\text { EPK } \\
\text { kaolin }\end{array}$ & 1.5 & 7 & 22 & $\begin{array}{l}\text { A maximum of about } 50 \% \\
\text { removal attained even at the } \\
\text { cathode region when } \mathrm{H}_{2} \mathrm{SO}_{4} \\
\text { was also used in the analyte. }\end{array}$ & [82] \\
\hline Phenanthrene & $\begin{array}{l}\text { Hadong } \\
\text { clay }\end{array}$ & 1.5 & 7 & $10-22$ & $\begin{array}{l}\text { Better treatment efficiency } \\
\text { observed with the use of } \\
\text { phosphate stabilizer and an } \\
\text { anionic surfactant. }\end{array}$ & [83] \\
\hline PAH mixture & $\begin{array}{l}\text { Creasote } \\
\text { contaminat } \\
\text { ed real } \\
\text { clay }\end{array}$ & $\begin{array}{l}0.48 \text { and a } \\
10 \% \mathrm{AC} \\
\text { component }\end{array}$ & 3 & 60 & $\begin{array}{l}\text { No significant benefit } \\
\text { observed from Electrokinetic } \\
\text { Fenton treatment }\end{array}$ & {$[53]$} \\
\hline $\begin{array}{l}\text { Phenanthrene, } \\
\text { Nickel }\end{array}$ & Kaolin & 1 & $\begin{array}{l}5,10,20 \\
30\end{array}$ & 30 & $\begin{array}{l}\text { A maximum of } 56 \% \\
\text { oxidation of phenanthrene } \\
\text { with } 30 \% \mathrm{H}_{2} \mathrm{O}_{2} \text {. }\end{array}$ & [83] \\
\hline PAHs & $\begin{array}{l}\text { Kaolin, } \\
\text { MGP soil }\end{array}$ & 2 & $5-10$ & $\begin{array}{l}5-8 \text { for } \\
\text { kaolin, } 25 \\
\text { for MGP } \\
\text { soil }\end{array}$ & $\begin{array}{l}\text { A maximum of } 90.5 \% \\
\text { phenanthrene oxidation in } \\
\text { kaolin when ethanol was } \\
\text { pre-flushed and then treated } \\
\text { with } 5 \% \mathrm{H}_{2} \mathrm{O}_{2} \text { from anode } \\
\text { and } 1.4 \mathrm{mM} \mathrm{Fe}-E D T A \text { from } \\
\text { the cathode. }\end{array}$ & [84] \\
\hline Diesel & $\begin{array}{l}\text { Subsurface } \\
\text { layer soil }\end{array}$ & 4 & $0,4,8$ & 60 & $\begin{array}{l}\text { A maximum of } 42 \% \text { with } \\
\text { the highest } \mathrm{H}_{2} \mathrm{O}_{2} \\
\text { concentration used. }\end{array}$ & {$[85]$} \\
\hline Phenanthrene & Kaolinite & 3 & 10 & 14 & $\begin{array}{l}\text { An overall extraction and } \\
\text { destruction efficiency of } 99 \\
\% \text { was achieved when both } \\
\text { the electrode reservoirs were } \\
\text { filled with } \mathrm{H}_{2} \mathrm{O}_{2} \text {. }\end{array}$ & {$[86]$} \\
\hline
\end{tabular}




\subsection{Hexachlorobenzene}

\subsubsection{Environmental properties}

POPs are organic compounds categorized as a special group based on their salient properties. These salient features which make an organic compound a POP are its:

- Persistence - POPs are extremely resistant to physical, chemical and biological degradation. They have long half lives in soil, water and air.

- Bioaccumulation - They accumulate in the organism to a level which can be harmful to the human health and environment.

- Ability for long range transport - It can be transported by the environmental media to far sites where they have never been used or produced, such as in the Arctic regions.

- Toxicity - POPs are extremely toxic and pose a threat both to the human health and the environment.

Some of their physical and chemical properties which determine their fate in the environment are their low water solubility, high lipid solubility, high molecular mass and low volatility.

The organic pollutants that constitute the POPs can be broadly classified into two categories, intentionally manufactured POPs and unintentionally produced byproducts [87].

HCB is a typical POP which can be regarded as a representative compound for studies. It comes under both the classifications of POPs, since it was previously manufactured on a large scale and still produced as a byproduct during the manufacture of other chlorinated solvents. It is also one of the 12 priority pollutants listed by the Stockholm convention on POPs [88]. 
Hexachlorobenzene is a white crystalline solid that is practically insoluble in water. Its chemical structure is as shown in Figure 1. Physical and chemical properties of Hexachlorobenzene are shown in Table: 3

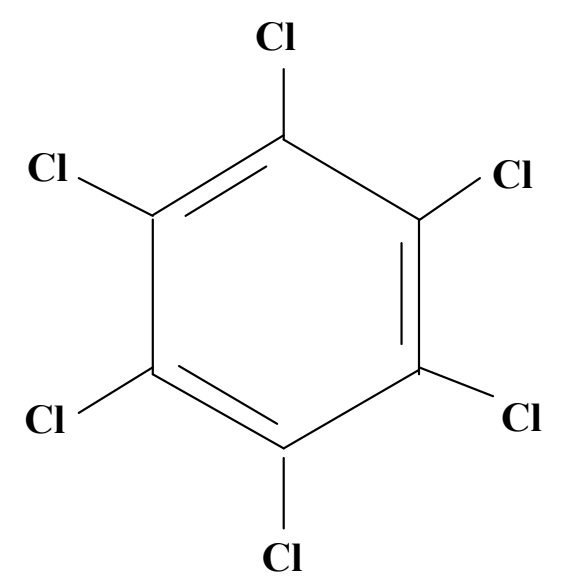

Fig: 1 Structure of HCB

Table : 3 Physical and chemical properties of HCB.

\begin{tabular}{ll}
\hline \multicolumn{1}{c}{ Property } & \multicolumn{1}{c}{ Value } \\
\hline Molecular mass & 284.78 \\
Melting point ${ }^{\circ} \mathrm{C}$ & 231 \\
Boiling point ${ }^{\circ} \mathrm{C}$ & 325 \\
Vapour pressure $\mathrm{mm} \mathrm{Hg}$ at $20{ }^{\circ} \mathrm{C}$ & $1.09 \times 10^{-5}$ \\
Water solubility $\mathrm{mg} /$ /itre at $20{ }^{\circ} \mathrm{C}$ & 0.005815 \\
Log octanol $/$ water partition coefficient & 5.73 \\
Density at $23^{\circ} \mathrm{C} \mathrm{g} / \mathrm{cm}^{3}$ & 2.044 \\
Flash point ${ }^{\circ} \mathrm{C}$ & 242 \\
\hline
\end{tabular}




\subsubsection{Sources in the environment}

$\mathrm{HCB}$ was used in the past as fungicide, wood preservative, intermediates in organic syntheses, synthetic rubber peptizing agent and so on [89]. HCB was first introduced in 1945 for its agricultural use as a fungicide [90]. The peak HCB production was during the late 1970s and early 1980s when the annual production was about 10,000 tonnes per year from 1978 to 1981 [90]. However, it was recognized as a hazardous chemical following an episode of massive human poisoning in Turkey 1959 which resulted from the consumption of bread prepared from wheat contaminated with HCB. The global production of HCB marked its decline due to several restrictions on its use and from 1970s several countries declared a ban on its production. At present, there is a global ban existing on its manufacture. However, the release of HCB still continues as it is produced as a byproduct during the manufacture of several chlorinated hydrocarbons as well as other sources. An estimate given by Bailey in 2000 indicates that a total of about $23000 \mathrm{~kg}$ per year of new HCB added to the environment which comes mainly from trace contamination of pesticides, combustion, manufacturing and biomass burning. However, this sum would be exclusive of the sources of HCB still existing in developing countries [87].

$\mathrm{HCB}$ is widely dispersed in the environment. Though significant quantities of $\mathrm{HCB}$ are present in the atmosphere, the surface oceans and the soil, the major environmental reservoir of HCB was identified as the soil $[90,91]$. This is because of the hydrophobic nature of HCB which allows itself to partition into soil and plant surfaces. Therefore, soil serve as a sink by receiving these pollutants through numerous pathways including direct pesticide application, atmospheric deposition, application of sewage sludge or compost, spills, erosion from nearby 
contaminated areas and contaminated water irrigation [90]. Some examples of HCB contaminated area are an industrial area at Bitterfeld, Germany and Lake Päijänne, Finland $[92,93]$.

From all these, it is evident that HCB is very persistent in the environment and draws concern for its removal from the environment, especially soil.

\subsubsection{Health effects}

Some of the harmful health effects associated with chronic exposure to HCB are porphyria, thyroid imbalances and cancer [94]. It is directly linked to reproductive, developmental, behaviourial, neurological, and endocrine mal functions $[95,96]$. TDI values for HCB have been suggested by various governmental agencies such as the USEPA and ATSDR and vary in the range $1.6 \mathrm{E}-04 \mathrm{mg} / \mathrm{kg}$ d to $5 \mathrm{E}-05 \mathrm{mg} / \mathrm{kg} \mathrm{d}$ [97]. There have been several studies on the association between liver, immunological and renal effects and human exposure to HCB by inhalation and oral ingestion. However, no data could be found regarding the health effects in humans and animals upon dermal exposure to HCB [98] 


\section{OBJECTIVES OF THE STUDY}

The objective of this research was to investigate and further develop a method for the removal of sorbed organic contaminants from low permeable soil. For that, a stepwise and methodological approach was adopted to carry out a series of experiments for evaluating the process performance and contaminant removal efficiency during the electrokinetic Fenton process. Kaolin was used as the model low permeable soil and the representative hydrophobic organic compound chosen for the study was HCB.

The scope of this research included;

I Investigating the feasibility of electrokinetic and electrokinetic Fenton processes for the removal of HCB from soil (Paper I).

II Studying the influence of electrode positions in electrokinetic Fenton system (Paper II).

III Studying the effect of cyclodextrin as an enhancing agent (Paper III).

IV Studying the soil-oxidant interaction at different conditions (Paper IV).

$\mathrm{V}$ Studying the effect of electrode polarity reversal on the contaminant removal (Paper V). 


\section{MATERIALS AND METHODS}

\subsection{Design of apparatus}

The apparatus designed for carrying out the experiments had to meet the following requirements:

1. Allow the handling and processing of the test specimen without actually disturbing the whole system.

2. Resemble a practical field unit rather than a laboratory set-up

3. Enable the scale-up of the actual set-up

4. Provide a safe working condition

Three different designs were used for the present study. The designs, basically of same structural type differed only by certain features which were incorporated to suit the experimental conditions as the studies proceeded (Fig: 2).

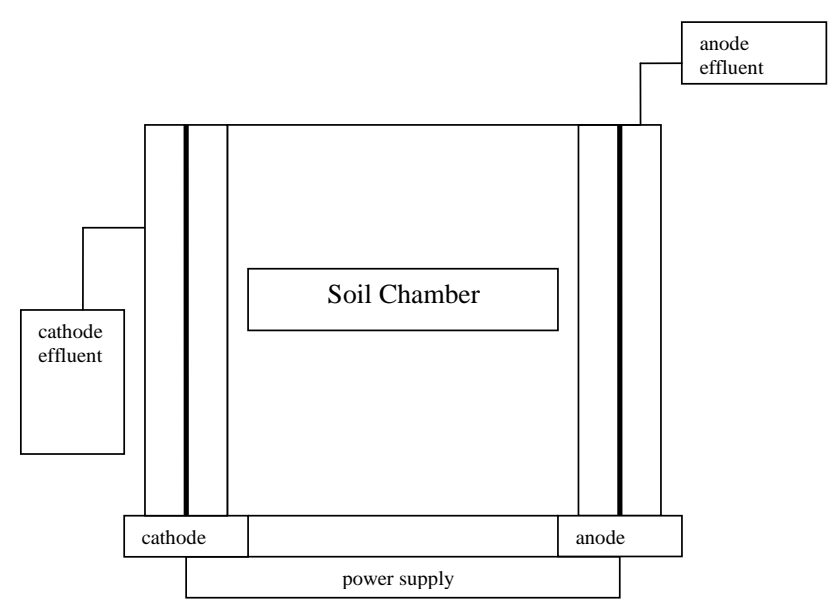

Fig: 2 Basic structure of the apparatus designed for the experiments

Type 1 apparatus consisted of three parts: two electrode chambers filled with electrolyte or oxidant solutions and a soil chamber in between. Type 2 apparatus consisted of a single soil 
chamber in which the electrodes were immersed. Oxidants and DW were directly applied on the soil surface. Type 3 apparatus was similar to Type 1, but with injection wells incorporated to them. Injection wells $(2 \mathrm{~cm}$ diameter) were made of perforated polyvinyl chloride tubes and covered with nylon cloth and then inserted to the soil chamber.

Type 1 and 3 apparatus were made of glass or acrylic and type 2 of HDPE. The electrode chambers were separated from soil chamber using filter cloth or nylon cloth. This allowed the permeation of fluid while preventing soil to pass through them. The chambers were closed using a removable lid with openings to insert electrodes which also served as gas vents. Inert electrodes made of titanium and coated with platinum were used for all experiments. The electrodes were connected to a DC power supply providing a constant voltage of 1.5 or $2.0 \mathrm{~V} / \mathrm{cm}$.

\subsection{Soil characterisation}

Commercially obtained kaolin was used as the model soil for the experiments. The physical and chemical characterization of kaolin was performed in the laboratory following the methods described by Rowell [99] and is presented in Table 4 .

Table 4: Kaolin characteristics

\begin{tabular}{|c|c|}
\hline Properties & Values \\
\hline \multicolumn{2}{|l|}{ Mineralogy } \\
\hline Kaolin & $100 \%$ \\
\hline Paricle size distribution & \\
\hline Gravel \% & 0 \\
\hline Sand \% & 7 \\
\hline Silt \% & 17 \\
\hline Clay \% & 76 \\
\hline Specific Gravity & 0.508 \\
\hline Carbonate content $\%$ & 5.5 \\
\hline $\mathrm{pH}$ & 5.2 \\
\hline Electrical conductivity $(\mu S)$ & 189.2 \\
\hline Cation exchange capacity (m mol $100 \mathrm{~g})$ & 3 \\
\hline
\end{tabular}




\subsection{Test specimen}

Contaminated kaolin used as the test specimen was prepared by artificially spiking the kaolin with $\mathrm{HCB}$. For this, $\mathrm{HCB} /$ hexane solution was prepared. It was then added to dry kaolin so as to get a target concentration of $100 \mathrm{mg} / \mathrm{kg}$, mixed well and left in the fume hood till all the hexane had evaporated and the soil was dry. The dry contaminated soil was thoroughly mixed to get a homogeneous mixture and then brought to the required moisture content of approximately $40 \%$ by adding DW. The test specimen was then stacked into the soil chamber and samples were taken from different points to determine the initial $\mathrm{pH}$ and $\mathrm{HCB}$ concentration.

\subsection{Experimental Program}

The experimental program is summarized as a schematic diagram and shown in Fig. 3. The experiments were divided into five different phases with specific objectives as indicated in the figure. Experiments were done both with and without added Fe. Fe when added was supplied as ferrous sulphate solution prepared with a Fe to substrate mass ratio of 1:10. The concentration of beta-cyclodextrin when used was $1 \%$ (wt \%), which is well above its critical micelle concentration. The anolyte in the experiments were either deionized water or the oxidant itself. The catholyte in all experiments was DW. The electrodes were connected to a power supply in each case after assembling the apparatus and setting up the test. A constant applied voltage of 1.5 $\mathrm{V} / \mathrm{cm}$ or $2 \mathrm{~V} / \mathrm{cm}$ was used. $\mathrm{H}_{2} \mathrm{O}_{2}$ was used in different concentrations ranging from 5 to $30 \%$. All the chemicals were freshly prepared and the dilutions were made with DW. 
Kaolin Characterisation

orption studies
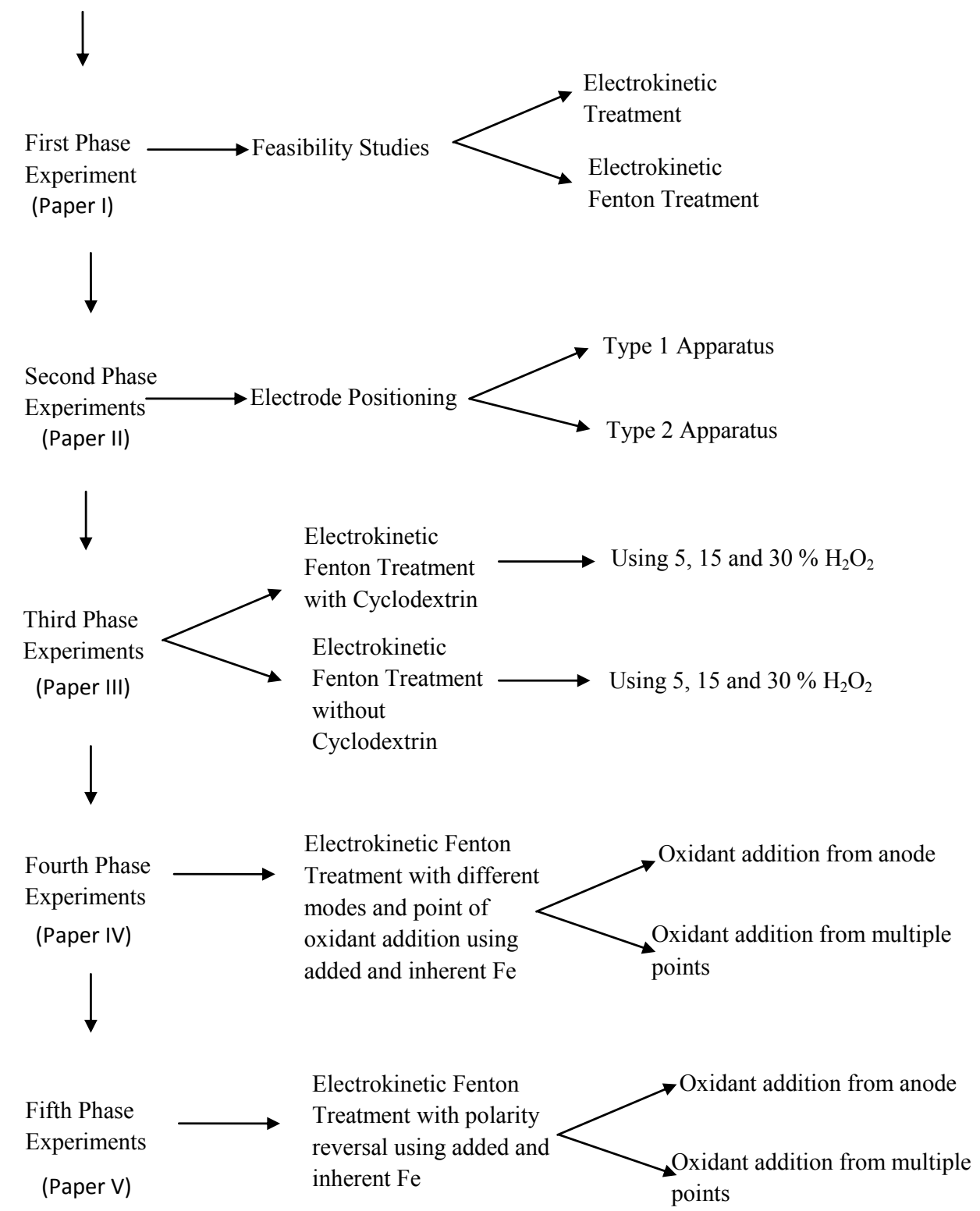

Fig: 3 Schematic representation of the experimental program 
Sorption studies - A series of batch adsorption tests were performed to determine the sorption capacity of HCB to kaolin.

First Phase - Three tests were carried out during the first phase, of which two were electrokinetic experiments to observe the suitability of $\beta$-cyclodextrin as a flushing solution for these processes. The third experiment was electrokinetic Fenton test using $\beta$-cyclodextrin as an enhancing agent (Paper I).

Second Phase - The influence of electrode positions in the system was compared by selecting two different kinds of apparatus. In Type 1 apparatus, the electrodes were contained in separate chambers. In Type 2 apparatus, the electrodes were directly immersed into the soil mass. $\beta$-cyclodextrin was used in both cases (Paper II).

Third Phase - Experiments were conducted in two series for fifteen consecutive days: First series experiments consisted of three tests with different concentrations of $\mathrm{H}_{2} \mathrm{O}_{2}$ in the absence of cyclodextrin. Test 1 with $30 \% \mathrm{H}_{2} \mathrm{O}_{2}$, Test 2 with $15 \% \mathrm{H}_{2} \mathrm{O}_{2}$, and Test 3 with $5 \%$ $\mathrm{H}_{2} \mathrm{O}_{2}$. Second series tests also consisted of three tests with the same different concentrations of $\mathrm{H}_{2} \mathrm{O}_{2}$, but in the presence of cyclodextrin. All the experiments were carried out in Type 2 apparatus without adding any Fe to the system. Inherent iron in Kaolin was expected to catalyze the $\mathrm{H}_{2} \mathrm{O}_{2}$ during the Fenton's oxidation (Paper III).

Fourth phase Experiments - A series of electrokinetic Fenton experiments have been carried out to investigate the effect of oxidant delivery and availability on contaminant removal and its subsequent impact on the treatment duration (Paper IV).The operating conditions of the experiments are shown in the Table: 5 
Table: 5 Operating conditions of fourth phase experiments

\begin{tabular}{|c|c|c|c|c|c|c|}
\hline $\begin{array}{l}\text { Experi } \\
\text { ment }\end{array}$ & $\begin{array}{l}\text { Voltage } \\
\text { (V/cm) }\end{array}$ & Anolyte & $\begin{array}{l}\text { Injection } \\
\text { well }\end{array}$ & Catholyte & Mode of oxidant delivery & $\begin{array}{l}\text { Duration } \\
\text { (Days) }\end{array}$ \\
\hline 1 & 1.5 & $\mathrm{H}_{2} \mathrm{O}_{2}$ & Nil & DW & from anode & 20 \\
\hline 2 & 1.5 & $\begin{array}{l}\mathrm{H}_{2} \mathrm{O}_{2} \\
+\mathrm{FeSO}_{4}\end{array}$ & Nil & DW & $\begin{array}{l}\text { Serial addition one after } \\
\text { the other from the anode }\end{array}$ & 20 \\
\hline 3 & 1.5 & $\begin{array}{l}\mathrm{H}_{2} \mathrm{O}_{2}+ \\
\mathrm{FeSO}_{4}\end{array}$ & Nil & DW & $\begin{array}{l}\mathrm{FeSO}_{4} \text { added as the } \\
\text { anolyte and then added } \\
\mathrm{H}_{2} \mathrm{O}_{2} \text { after five days to the } \\
\text { anode }\end{array}$ & 15 \\
\hline 4 & 1.5 & $\begin{array}{l}\mathrm{H}_{2} \mathrm{O}_{2} \\
+\mathrm{FeSO}_{4}\end{array}$ & $\begin{array}{l}\text { Two wells } \\
\text { at } \\
\text { distances } \\
4-6 \mathrm{~cm} \\
\text { from both } \\
\text { the walls }\end{array}$ & DW & $\begin{array}{l}\mathrm{FeSO}_{4} \text { added as the } \\
\text { anolyte and then added } \\
\mathrm{H}_{2} \mathrm{O}_{2} \text { after five days to the } \\
\text { anode and wells }\end{array}$ & 15 \\
\hline 5 & 2 & $\begin{array}{l}\mathrm{H}_{2} \mathrm{O}_{2} \\
+\mathrm{FeSO}_{4}\end{array}$ & $\begin{array}{l}\text { One well } \\
\text { at the } \\
\text { center of } \\
\text { the soil } \\
\text { mass }\end{array}$ & DW & $\begin{array}{l}\mathrm{FeSO}_{4} \text { added as the } \\
\text { anolyte and then added } \\
\mathrm{H}_{2} \mathrm{O}_{2} \text { after two days to the } \\
\text { anode and well. }\end{array}$ & 10 \\
\hline
\end{tabular}

Fifth Phase - A series of experiments were carried out to explore the possibilities of using polarity reversal as an enhancement during electrokinetic Fenton treatment of HCB contaminated soil (Paper V).

Details of the experiments are shown in the Table: 6 
Table: 6 Operating conditions of fifth phase experiments

\begin{tabular}{|c|c|c|c|c|c|c|c|}
\hline $\begin{array}{l}\text { Exper } \\
\text { iment }\end{array}$ & $\begin{array}{l}\text { Voltage } \\
\text { (V/cm) }\end{array}$ & Anolyte & Catholyte & $\begin{array}{l}\text { Mode of } \\
\text { oxidant } \\
\text { addition } \\
\end{array}$ & Injection well & $\begin{array}{l}\text { Duration } \\
\text { (days) }\end{array}$ & $\begin{array}{l}\text { Polarity } \\
\text { reversal }\end{array}$ \\
\hline 1 & 1.5 & $\mathrm{H}_{2} \mathrm{O}_{2}$ & $\overline{\mathrm{DW}}$ & $\begin{array}{l}\mathrm{H}_{2} \mathrm{O}_{2} \text { added } \\
\text { from the anode }\end{array}$ & nil & 10 & $\begin{array}{l}\text { After } 5 \\
\text { days }\end{array}$ \\
\hline 2 & 1.5 & DW & DW & $\begin{array}{l}\mathrm{H}_{2} \mathrm{O}_{2} \text { added to } \\
\text { the injection } \\
\text { well }\end{array}$ & $\begin{array}{l}\text { One in center, } \\
\text { cylindrical, } \\
2 \mathrm{~cm} \text { diameter }\end{array}$ & 10 & $\begin{array}{l}\text { After } 5 \\
\text { days }\end{array}$ \\
\hline 3 & 1.5 & $\mathrm{H}_{2} \mathrm{O}_{2}$ & DW & $\begin{array}{l}\mathrm{H}_{2} \mathrm{O}_{2} \text { added } \\
\text { from the anode }\end{array}$ & nil & 10 & nil \\
\hline 4 & 1.5 & $\begin{array}{l}\mathrm{FeSO}_{4}, \\
\mathrm{H}_{2} \mathrm{O}_{2}\end{array}$ & DW & $\begin{array}{l}\mathrm{FeSO}_{4} \text { added as } \\
\text { the anolyte and } \\
\text { then added } \\
\mathrm{H}_{2} \mathrm{O}_{2} \text { after two } \\
\text { days to the } \\
\text { anode }\end{array}$ & nil & 10 & $\begin{array}{l}\text { After } 5 \\
\text { days }\end{array}$ \\
\hline 5 & 1.5 & $\begin{array}{l}\mathrm{FeSO} 4 \\
\mathrm{H}_{2} \mathrm{O}_{2}\end{array}$ & DW & $\begin{array}{l}\mathrm{FeSO} 4 \text { added as } \\
\text { the anolyte and } \\
\text { then added } \\
\mathrm{H}_{2} \mathrm{O}_{2} \text { after two } \\
\text { days to the } \\
\text { anode and } \\
\text { injection well }\end{array}$ & $\begin{array}{l}\text { One in center, } \\
\text { cylindrical, } \\
2 \mathrm{~cm} \text { diameter. }\end{array}$ & 20 & $\begin{array}{l}\text { After } 10 \\
\text { days }\end{array}$ \\
\hline
\end{tabular}

\subsection{Chemical analyses}

pH and redox measurements

The $\mathrm{pH}$ and redox of the soil samples were measured using a $\mathrm{pH}$ meter and a redox meter (WTW 340i equipped with SenTix 61 and SenTix ORP sensors, pH 730 inoLab WTW series). The soil sample for the $\mathrm{pH}$ and redox measurements were made into a suspension of the sample in DW in the ratio $1: 25$ 


\section{Electroosmotic flow}

The electroosmotic flow was measured manually by measuring and balancing the additions made to the analyte and the volume removed from the catholyte. In few cases, the zeta potential of the soil samples was measured and the electroosmotic flow was calculated based on that. The zeta potential of the soil samples were measured by Zeta sizer Nano series (Malvern instrument), equipped with a microprocessor unit. A strong correlation existed between the values calculated using the zeta potential values and those measured manually.

\section{HCB Analysis}

HCB was extracted from the soil sample by ultrasonication based on a method adopted from Yuan et al. [35]. The extract so obtained was analyzed using a gas chromatograph coupled to an inert mass selective detector (Agilent 5975). The column used was HP-5 capillary column (30 x $0.32 \mathrm{~mm}$ ID) with a $0.25 \mu \mathrm{m}$ film thickness. Helium at constant flow rate $(25 \mathrm{~cm} / \mathrm{s})$ was used as carrier gas. The oven temperature was programmed from $40^{\circ} \mathrm{C}$ to $270^{\circ} \mathrm{C}$ at $10{ }^{\circ} \mathrm{C} / \mathrm{min}$. The injector temperature used was $250^{\circ} \mathrm{C}$ and the injection volume was $1 \mu \mathrm{L}$. Quantification was based on a linear curve made with four or five standard solutions of HCB. All the extractions and sample runs were done in duplicate to ensure the reliability of the measurements.

\section{Other}

Apart from the above analyses, the $\mathrm{H}_{2} \mathrm{O}_{2}$ concentrations in the soil samples were analyzed in some experiments using the permanganate method. The data obtained were used to ensure the presence of $\mathrm{H}_{2} \mathrm{O}_{2}$ in the soil sample and not directly used to interpret the results. 


\section{RESULTS AND DISCUSSION}

\subsection{Sorption studies}

The sorption data fitted to the following equation and seemed to follow a linear equation:

$\mathrm{Q}=1.3599 \mathrm{C}$

This is in good agreement with the results obtained by Schwarzenbach et al. [100] and Means et al. [101] who stated that the sorption of nonpolar organic compounds of low to intermediate lipophilicity by aquifer materials and the sorption of other PAHs on different sediment and soil substrates followed linear equilibrium isotherms.

\subsection{Feasibility Tests}

The preliminary feasibility tests included the experiments carried out to evaluate the suitability of electrokinetic and electrokinetic Fenton processes to treat HCB contaminated soil (Paper I). The results of the experiments showed that $\beta$-cyclodextrin could solubilise the sorbed $\mathrm{HCB}$ and transport them through the soil matrix. This result is in agreement with Yuan et al. [35] who demonstrated that HCB can be desorbed and mobilized by $\beta$-cyclodextrin. The electrokinetic Fenton test also resulted in an overall average removal of $64 \%$ HCB from the soil.

\subsection{Electrode positioning}

The influence of electrode positions in the system was compared by selecting two different kinds of apparatus, Type 1 and Type 2 (Paper II). $\beta$-cyclodextrin was used in both cases and hence, as the experiment proceeded, the sorbed HCB would have desorbed and the oxidation of HCB had occurred both in the sorbed and desorbed state. The electrode positions seemed to have drastically changed the soil $\mathrm{pH}$. The soil $\mathrm{pH}$ in Type 1 apparatus near anode and cathode was 
about 3 at the end of the experiment. In Type 2 apparatus, the soil $\mathrm{pH}$ near the anode dropped to 3 towards the end of the experiment and near the cathode the $\mathrm{pH}$ rose gradually and was 9.6 at the end of the experiment. This difference in the $\mathrm{pH}$ distribution had a significant effect on the contaminant removal (Fig. 4).

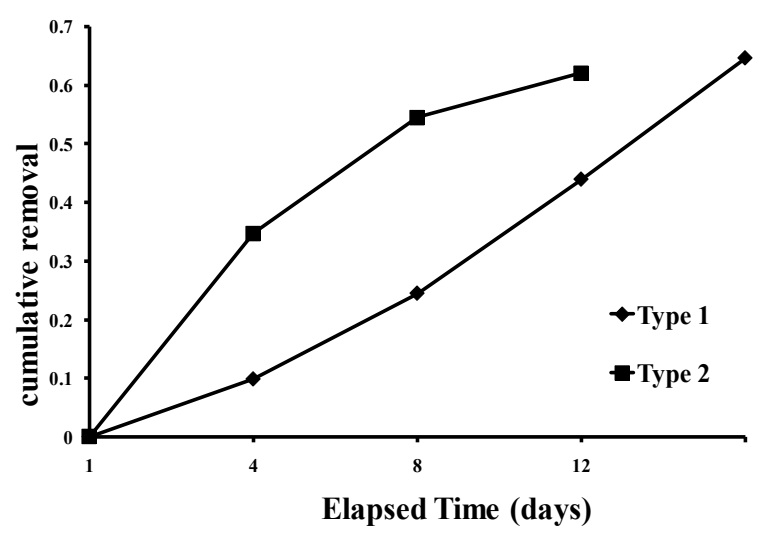

Fig: 4 Rate of contaminant removal. (Data from Paper II) 


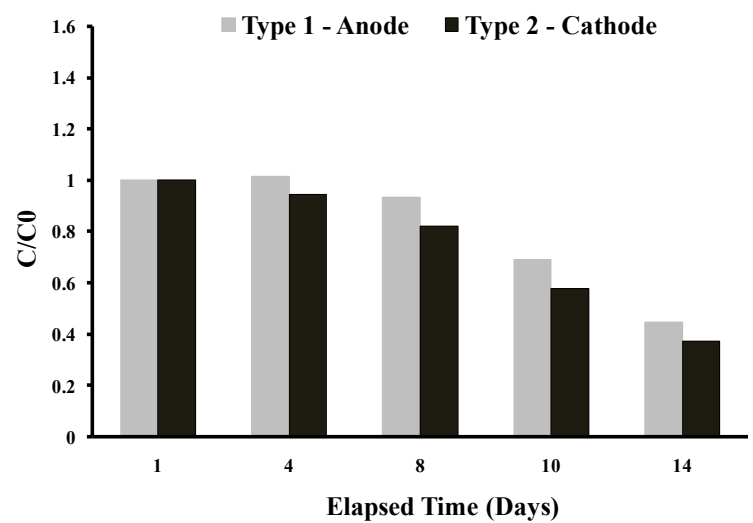

Fig: 5 HCB distribution along the anode and cathode region in Type 1 apparatus. (Data from Paper II)

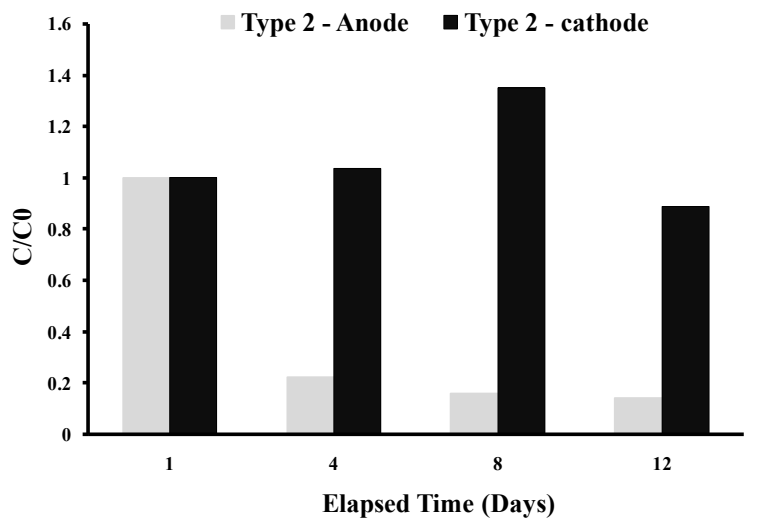

Fig: 6 HCB distribution along the anode and cathode region in Type 2 apparatus. (Data from Paper II) 
As evident from the Figure 4, the rate of contaminant removal was higher in Type 2 apparatus which was probably due to the higher electroosmotic flow rate incurred during the test. However, the contaminant distribution along the anode and cathode region (Fig:6) reveals that in Type 2 apparatus most of the removal had taken place from the region near the anode while the HCB near the cathode region had undergone minimal or no oxidation. This was because of the high $\mathrm{pH}$ developed in the cathode part which was not suitable for the Fenton's reaction to take place. An overall removal efficiency of $64 \%$ was observed "almost" uniformly across the soil during the electrokinetic Fenton Test in Type 1 apparatus which lasted for 14 days (Fig: 5). Though $86 \%$ of HCB was degraded from the anode region, the electrokinetic Fenton test in Type 2 apparatus resulted in an uneven contaminant removal across the soil due to the high $\mathrm{pH}$ developed at the cathode region. Thus, the performance of electrokinetic Fenton can be improved by using separate chambers for the electrolyte solutions, which make it possible to efficiently control the soil $\mathrm{pH}$ near the cathode. Moreover, the removal efficiency per unit of energy consumption for test in type 1 apparatus was found to be 2.46 times higher than that in type 2 apparatus.

\subsection{Electrokinetic Fenton Treatment with and without $\beta$-cyclodextrin}

Though the use of enhancing agents is highly beneficial, the fate of these agents and their mechanism of action need to be well understood and studied, especially when this technique aims at degrading the pollutants in the system itself. In this context, the study of degrading the contaminant in its sorbed state itself without desorbing it into the aqueous phase became relevant.

$\mathrm{H}_{2} \mathrm{O}_{2}$ in high concentrations ( $>2 \%$ ) is capable of degrading sorbed contaminants on the soil surface. Therefore, experiments were conducted to evaluate the performance of high 
concentration of $\mathrm{H}_{2} \mathrm{O}_{2}$ to oxidize the contaminants in the sorbed state in the presence and absence of cyclodextrin (Paper III).

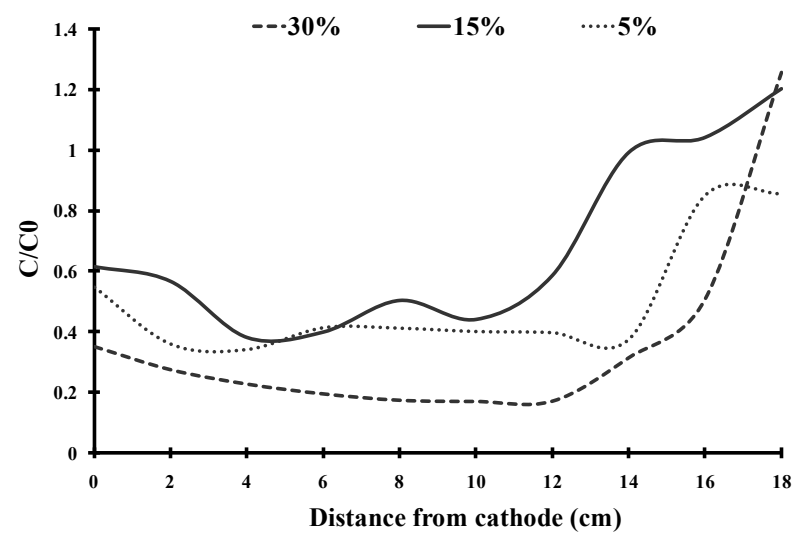

Fig: 7 Test 1 - without cyclodextrin, HCB distribution in the soil at the end of the experiment. (Data from Paper III)

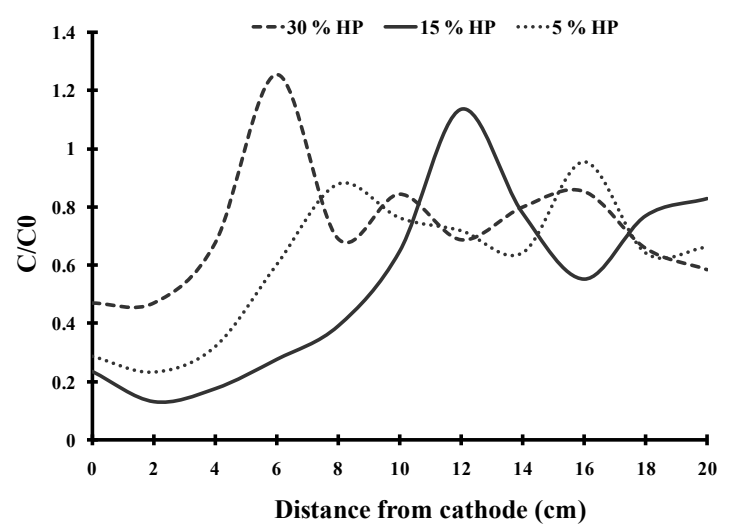

Fig: 8 Test 2 -with cyclodextrin, HCB distribution in the soil at the end of the experiment. (Data from Paper III) 
The results of the tests (Figs: 7 and 8) clearly showed that the sorbed contaminants were effectively oxidized by high concentration hydrogen peroxide catalyzed by inherent iron present in the soil. Therefore, during electrokinetic treatment hydrophobic compounds sorbed to the soil could be degraded without adding any enhancing agents. This is possible since, in this process the contaminants do not rely on their mobility or solubility in the pore water. However, the absence of cyclodextrin and soluble iron in the system resulted in an accumulation of the contaminant in the anode portion of the system. The treatment tests conducted in the presence of cyclodextrin as an enhancing agent led to a slower rate of oxidation when compared to the rapid oxidation of contaminants in the absence of cyclodextrin.

\subsection{Oxidant availability}

The rate of transport and availability of the oxidant are among the primary requirements for a successful soil treatment program using oxidation reactions. Therefore, the oxidant should be delivered to the soil in such a way so as to facilitate effective soil-oxidant interaction. In electrokinetic Fenton process, the oxidant is transported through the soil matrix by electroosmosis. During the course of its transport, the oxidant comes into contact with the soil and attacks the contaminant. Therefore the availability of oxidants in its active form is of paramount importance. Out of the different modes of oxidant addition tested, the one with stepwise addition of $\mathrm{Fe}$ and then after two days $\mathrm{H}_{2} \mathrm{O}_{2}$ showed better performance in terms of contaminant degradation (Paper IV). However, the addition of Fe as ferrous sulphate did not significantly improve the contaminant removal. Addition of oxidants through multiple injection wells resulted in increased rate of $\mathrm{HCB}$ oxidation, but the point of injection is a 
matter to be chosen since the stability of $\mathrm{H}_{2} \mathrm{O}_{2}$ decreases with increasing $\mathrm{pH}$. The oxidation reactions in these experiments did not show any $\mathrm{pH}$ dependence in the range 2.9 to 5 .

\subsection{Electrokinetic Fenton treatment with polarity reversal}

Treatment duration is another important criterion while considering a cost effective remediation process. The time required to bring the contaminant concentration to the desired concentration could be regarded as the treatment duration for remediation purposes. The treatment duration can be considerably shortened if the contaminant present throughout the soil section can be subjected to oxidation effectively by controlling and directing the flow of oxidant through the soil. This could be achieved by controlling the direction of flow of oxidant by reversing the electrode polarities. Such a polarity reversal would be beneficial since it can enhance the process by propagating the oxidant through the soil matrix in a better way and also result in a more uniform $\mathrm{pH}$ throughout the soil section, thus avoiding a large $\mathrm{pH}$ gradient in the final treated soil.

When the treatment tests run for 10 days were compared, the test which had undergone a polarity reversal resulted in a HCB removal of $33 \%$ and the one without the polarity reversal resulted in a $10 \%$ removal of $\mathrm{HCB}$ (Paper V). Therefore, the results of the experiments indicate that regulating and hence controlling the flow of $\mathrm{H}_{2} \mathrm{O}_{2}$ by reversing the electrode could bring about better contaminant degradation than expected with uni-directional flow of $\mathrm{H}_{2} \mathrm{O}_{2}$ which would take longer time for the entire soil section to come into contact with $\mathrm{H}_{2} \mathrm{O}_{2}$. However, extending the tests for a longer duration (20 days) did not show a corresponding increase in the HCB removal rate. 


\subsection{General}

Apart from the major results based on the HCB degradation during the treatment runs, there were some general observations which are noteworthy.

\section{$5.7 .1 \mathrm{pH}$}

The electrode chamber $\mathrm{pH}$ followed a general trend in all the experiments. The analyte $\mathrm{pH}$ dropped to 2 or less and the catholyte $\mathrm{pH}$ rose to 9.8 or more within the first two days of operation in all the cases. This is because, due to the applied electric field, electrolysis takes place and $\mathrm{H}+$ and $\mathrm{OH}-$ ions are generated at anode and cathode respectively which results in a low $\mathrm{pH}$ at the anode and high $\mathrm{pH}$ at the cathode.

These acidic and basic fronts which are developed at the anode and the cathode migrate slowly to the soil and thus change the $\mathrm{pH}$ of soil. The initial $\mathrm{pH}$ of the soil used was 5.2. In general, the final soil $\mathrm{pH}$ ranged between 2 near the anode region and 6 near the cathode region. In any case, the soil $\mathrm{pH}$ did not rise above 6 , except for the tests performed in Type 2 apparatus where the electrodes were directly immersed into the soil. This shows that the acidic front advanced faster than the basic front and neutralized the $\mathrm{OH}^{-}$ions migrating towards the anode area. Under applied voltage gradient, the $\mathrm{H}^{+}$ions formed at the anode move at a faster rate, nearly double that of the rate of $\mathrm{OH}^{-}$ions $[20,102]$ This holds true in most of the cases unless the soil has a very high buffering capacity which impedes the rate of movement of the acidic front.

However, the experiments with polarity reversal resulted in a more uniform $\mathrm{pH}$ towards the end of the experiment. This is due to the obvious reasons of changed electrode polarity and the corresponding formation of acidic and basic fronts from either sides of the soil. The 
addition of $\mathrm{H}_{2} \mathrm{O}_{2}$ to the soil as observed in the fourth phase experiments through injection wells might also cause the $\mathrm{pH}$ to rise in the soil section. Similarly the addition of Fe as ferrous sulphate was also seen to influence the soil $\mathrm{pH}$.

\subsubsection{Redox Potential}

The redox values across the soil section indicate that a strong oxidizing condition existed throughout the soil section in the experiments where the redoxes were measured. The redox potential is generally found to decrease from the anode section to the cathode section during a normal electrokinetic process.

The redox values showed a good correlation with the corresponding $\mathrm{pH}$ values except for the fifth phase experiments with polarity reversal. This is because, the generally found correlation between $\mathrm{pH}$ and redox cannot be expected in these cases, since due to the polarity reversal, the soil section was constantly under changing redox conditions. These redox values were used to depict the predominant form of Fe that existed in the soil.

In our experiments, the effect of Fe in the electrokinetic Fenton treatments were evaluated by a comparison of experiments carried out with and without Fe. Redox potential data were used as an indication of the speciation of $\mathrm{Fe}$ in soil. However, the fate and transportation of $\mathrm{Fe}$ in the soil is to be more precisely determined using elemental analysis in order to study the influence of Fe in such electrokinetic Fenton systems.

\subsubsection{Electroosmotic flow}


Electroosmotic flow plays an important role in electrokinetics especially when employed for the removal of organic compounds. In experiments where cyclodextrin was used, electroosmosis was the primary and the only pathway by which the desorbed HCB was transported through the soil matrix. In the experiments conducted during the later stage which aimed at the degradation of $\mathrm{HCB}$ in the sorbed state itself, the oxidant was transported through the soil via electroosmosis. Therefore, higher electroosmotic flow ensures better interaction between the soil-contaminant particles and the pore fluid.

However, for the oxidation of sorbed HCB to occur, other conditions like suitable $\mathrm{pH}$ and availability of $\mathrm{H}_{2} \mathrm{O}_{2}$ in its active form are to be met. Hence, as observed from the results of fifth phase experiments a higher electroosmotic flow alone does not ensure better $\mathrm{HCB}$ oxidation. A comparatively decreased flow was observed in experiments with polarity reversal after changing the electrode polarities. This is due to the sudden change in the $\mathrm{pH}$ dependent physio-chemical properties of the soil which in turn retarded the electroosmotic flow.

\subsection{Significance of the obtained results}

The initial experiments performed with $\beta$-cyclodextrin proved to be a feasible method for the electrokinetic flushing of HCB through the soil [Paper I and II]. Though the results by Yuan et al [35]supports this, other studies performed with cyclodextrin derivatives like HPCD for phenanthrene removal from soil gave mixed results especially when compared with other surfactants and cosolvents [37, 46, 49]. Moreover, our further studies on electrokinetic Fenton treatment using high concentrations of $\mathrm{H}_{2} \mathrm{O}_{2}$ showed promise and highest oxidation rates were observed with the highest concentration of $\mathrm{H}_{2} \mathrm{O}_{2}$ used [Paper III]. Therefore, 
enhancement agents were not used for our studies thereafter. Similar results of increasing oxidation rates with increasing $\mathrm{H}_{2} \mathrm{O}_{2}$ concentrations were obtained by Reddy and Kari for the electrokinetic treatment of phenanthrene spiked kaolin [83]. However, little attention has been given on the aspects regarding oxidant availability and oxidant delivery during electrokinetic Fenton treatment of soils. Our subsequent studies identified the importance of different oxidant delivery methodologies [Paper IV]. Another area which received little or no attention was the treatment duration of the process. By adopting a polarity reversal of the electrodes towards the end of the experiment, in our following studies, we tried to improve the $\mathrm{H}_{2} \mathrm{O}_{2}$ reachability in a shorter duration [Paper V]. However, further studies are still required to elaborately explain the physico-chemical changes that may occur during the polarity reversal of electrodes and assess their suitability for electrokinetic studies. 


\section{CONCLUSIONS}

Electrokinetic Fenton process using high concentration of $\mathrm{H}_{2} \mathrm{O}_{2}$ is an effective treatment method for the remediation of low permeable soil contaminated with hydrophobic organic contaminants. This thesis is a study conducted for the investigation of such a process by selecting HCB as the representative HOC and Kaolin as the model low permeable soil. The major findings observed during the study are summarized below:

- Though cyclodextrin was proved to be a good flushing solution for mobilizing HCB through the soil matrix during the electrokinetic treatment, addition of cyclodextrin is not necessary to desorb the contaminants when high concentration hydrogen peroxide is used. In such systems, the presence of cyclodextrin leads to a slower rate of oxidation when compared to the rapid oxidation of contaminants in the absence of cyclodextrin.

- HCB sorbed to low permeable soil can readily be oxidized using high concentration of HCB (concentrations tested in this study $>5 \%$ ) in electrokinetic Fenton treatments. However, these treatments are subject to success only if other pre-requisites for the degradation are also met. These pre-requisites include the suitable $\mathrm{pH}$ range in which the oxidation could occur and also the availability of oxidant in its active form.

- The point and mode of oxidant delivery is critical to the remediation process and influences the overall system performances. Out of the different modes of oxidant delivery tested, the serial addition of $\mathrm{H}_{2} \mathrm{O}_{2}$ two days after the addition of $\mathrm{Fe}$ as ferrous sulphate was found to aid the catalytic behavior of Fe. Though, oxidant addition through multiple 
locations results in increased availability of oxidant, positions near the cathode should be avoided, since the decomposition rate of $\mathrm{H}_{2} \mathrm{O}_{2}$ increases with increasing $\mathrm{pH}$ and also the oxidation reactions probably are $\mathrm{pH}$ dependent at higher $\mathrm{pH}$ values. However, $\mathrm{HCB}$ oxidation in these studies did not show any $\mathrm{pH}$ dependence in the range 2.9 to 5 .

- Polarity reversal is a good method to control and thus direct the electroosmotic flow in electrokinetic Fenton treatments. By reversing the electrode polarities it is also possible that the treatment duration of these processes can be considerably reduced by improving the reachability of the oxidant.

This study forms the basis for several further studies. Though, the experiments have been designed keeping in mind the practical applications of these processes, there are other parameters to be understood before plunging into large scale applications. The experiments have been conducted in artificially contaminated kaolin and might represent differently when real soils are subject to the treatment. However, model soils like kaolin are best suited for understanding the parameter influences in lab scale studies. This is because it is very difficult to model real soil and understand the effect of parameters on the treatment efficiencies. Future research should be directed towards the treatment of real contaminated soil. 


\section{REFERENCES}

1. Reddy K. R. \& Cameselle C., Chapter 1 Overview of electrochemical remediation technologies, In: Reddy K.R and Cameselle C. (Eds.), Electrochemical Remediation Technologies for Polluted Soils, Sediments and Groundwater, John Wiley \& Sons, Hoboken, New Jersey, USA, 2009, p. 3-28.

2. Acar Y. B., Gale R. J., Alshawabkeh A. N., Marks R. E., Puppal S., Bricka M., Parker R., Electrokinetic remediation: basics and technology status, Journal of Hazardous Materials 40 (1995) 117-137.

3. Maturi K., Reddy K. R., Simultaneous removal of organic compounds and heavy metals from soils by electrokinetic remediation with a modified cyclodextrin, Chemosphere 63 (2006)1022-1031.

4. Park S-W., Lee J-Y., Yang J-S., Kim K-J., Baek K.., Electrokinetic remediation of contaminated soil with waste-lubricant oils and zinc, Journal of Hazardous Materials 169 (2009) 1168-1172.

5. Virkutyte J., Sillanpää M., Latostenmaa P., Electrokinetic Soil Remediation - a critical overview, The Science of the Total Environment 289 (2002) 97-121.

6. Oonnittan A., Sillanpää M., Cameselle C., Reddy K. R., Chapter 29 Field applications of electrokinetic remediation of soils contaminated with heavy metals, In: Reddy K.R and Cameselle C. (Eds.), Electrochemical Remediation Technologies for Polluted Soils, Sediments And Groundwater, John Wiley \& Sons, Hoboken, New Jersey, USA, 2009, p. 609-624.

7. Hicks R. E. and Sebastian T., Electrorestoration of metal contaminated soils, Environmental Science and Technology 28 (1994) 2203-2210. 
8. Sah J. G., Chen J. Y., Study of the electrokinetic process on $\mathrm{Cd}$ and $\mathrm{Pb}$ spiked soils, Journal of Hazardous Materials 58 (1998) 301-315.

9. Shapiro A. P. and Probstein R. F., Removal of contaminants from saturated clay by electroosmosis, Environmental Science and Technology 27 (1993) 283-291.

10. Reddy K. R. and Shirani A. B., Electrokinetic Remediation of Metal Contaminated Glacial Tills, Geotechnical and Geological Engineering 15 (1997) 3-29.

11. Yu J.-W., Neretnieks I., Theoretical evaluation of a technique for electrokinetic decontamination of soils, Journal of Contaminant Hydrology 26 (1997) 291-299.

12. Zhongming L., Yu J.-W. , Neretnieks I., A new approach to electrokinetic remediation of soils polluted by heavy metals, Journal of Contaminant Hydrology 22 (1996) 241253.

13. Wong J. S. H., Hicks R. E., Probstein R. F., EDTA-enhanced electroremediation of metal-contaminated soils, Journal of Hazardous Materials 55 (1997) 61-79.

14. Mohamed A. M. O., Remediation of heavy metal contaminated soils via integrated electrochemical processes, Waste Management 16 (1996)741-747.

15. Reddy K.R., and Chinthamreddy S., Comparison of different extractants for removing heavy metals from contaminated clayey soils, Journal of Soil and Sediment Contamination 9(2000) 449-462.

16. Li T., Yuan S., Wan J., Lin L., Long H., Wu X., Lu X., Pilot-scale electrokinetic movement of $\mathrm{HCB}$ and $\mathrm{Zn}$ in real contaminated sediments enhanced with hydroxypropyl - $\beta$ - cyclodextrin, Chemosphere 76 (2009) 1226-1232.

17. Agnew K., Cundy A. B., Hopkinson L., Croudace I. W., Warwick P. E., Purdie P., Electrokinetic remediation of plutonium-contaminated nuclear site wastes: Results from a pilot-scale on-site trial, Journal of Hazardous Materials 186 (2011) 1405-1414. 
18. Kim G.-N., Shon D.-B., Park H.-M., Lee K.-W., Chung U.-S., Development of pilotscale electrokinetic remediation technology for uranium removal, Separation and Purification Technology 80 (2011) 67-72.

19. Yeung A. T., Milestone developments, myths, and future directions of electrokinetic remediation, Separation and Purification Technology 79 (2011) 124 -132.

20. Probstein R. F. and Hicks R. E., Removal of contaminants from soil by electric field, Science 260 (1993) 498-503.

21. Alshawabkeh A.N., Practical aspects of insitu electrokinetic extraction, Journal of Environmental Engineering 125 (1999) 27-35.

22. Wise D. L., Trantolo D. J., Cichon E. J, Inyang H. I., Stottmeister U., Remediation Engineering of Contaminated Soils, CRC, New York, USA, 1st edition, 2000.

23. Mahmoud A., Oliver J., Vaxelaire J., Hoadley A. F. A., Electrical field: A historical review of its application and contributions in wastewater sludge dewatering, Water Research 44 (2010) 2381-2407.

24. Acar Y. B., Alshawabkeh A. N., Principles of electrokinetic remediation, Environmental Science and Technology 27 (1993) 2638-2647.

25. Yeung A. T., Chapter 3 Geochemical processes affecting electrochemical remediation, In: Reddy K.R and Cameselle C. (Eds.), Electrochemical Remediation Technologies for Polluted Soils, Sediments and Groundwater, John Wiley \& Sons, Hoboken, New Jersey, USA, 2009, p. 65-94.

26. Renaud P. C. and Probstein R. F., Electroosmotic control of hazardous wastes, Physicochemical Hydrodynamics 9 (1987) 345-360. 
27. Shapiro A. P., Renaud P. C. and Probstein, R.F., Preliminary studies on the removal of chemical species from saturated porous media by electroosmosis, Physicochemical Hydrodynamics 11 (1989) 785-802.

28. Yuan, C. and Weng, C. H. Remediating ethylbenzene-contaminated clayey soil by a surfactant aided electrokinetic process, Chemosphere 57 (2004) 225-232.

29. Jiradecha C., Urgun- Demirtas M., Pagilla K., Enhanced electrokinetic dissolution of naphthalene and 2, 4-DNT from contaminated soils, Journal of Hazardous Materials $136(2005)$ 61-67.

30. Saichek R. E., Reddy K. R., Electrokinetically enhanced remediation of hydrophobic organic compounds in soils: A review, Critical Reviews in Environmental Science and Technology 35 (2005) 115-192.

31. Yang J-W. and Lee Y-J., Chapter 9 Electrokinetic removal of PAHs, In: Reddy K.R and Cameselle C. (Eds.), Electrochemical Remediation Technologies for Polluted Soils, Sediments and Groundwater, John Wiley \& Sons, Hoboken, New Jersey, USA, 2009, p. 197-217.

32. West C. C., Harwell J. H., Surfactants and subsurface remediation, Environmental Science and Technology 26 (1992) 2324-2330.

33. Jafvert C. T., Surfactants/Cosolvents, Technology evaluation report, Prepared for Ground-water Remediation Technologies Analysis Center, USA, 1996.

34. Fenyvesi E., Gruiz K., Verstichel S., De Wilde B., Leitgib L., Csabai K., Szaniszlo N., Biodegradation of cyclodextrin in soil, Chemosphere 60 (2005) 1001-1008.

35. Yuan S., Tian M., Lu X. . Electrokinetic movement of hexachlorobenzene in clayed soils enhanced by Tween 80 and $\beta$ - cyclodextrin, Journal of Hazardous Materials 137 (2006) 1218-1225. 
36. Gonzini O., Plaza A., Palma L. D., Lobo M. C., Electrokinetic remediation of gasoil contaminated soil enhanced by rhamnolipid, Journal of Applied Electrochemistry 40 (2020) 1239-1248.

37. Li T., Yuan S., Wan J., Lu X., Hydroxypropyl- $\beta$-cyclodextrin enhanced electrokinetics remediation of sediment contaminated with $\mathrm{HCB}$ and heavy metals, Journal of Hazardous Materials 176 (2010) 306-312.

38. Han H., Lee Y.-J., Kim S.-H., Yang J.-W., Electrokinetic remediation of soil contaminated with diesel oil using EDTA-cosolvent solutions, Separation Science and Technology 44 (2009) 2437-2454.

39. Chang J.-H., Qiang Z., Huang C.-P., Ellis A. V., Phenanthrene removal in unsaturated soils treated by electrokinetics with different surfactants- Triton X-100 and rhamnolipid, Colloids and Surfaces A: Physicochemical and engineering aspects 348 (2009) $157-163$.

40. Maturi K., Reddy K. R., Cameselle C., Surfactant-enhanced electrokinetic remediation of mixed contamination in low permeability soil, Separation Science and Technology 44 (2009) 2385-2409.

41. Maturi K., Khodadoust A. P., Reddy K. R., Comparison of extractants for removal of lead, zinc and phenanthrene from manufactured gas plant field soil, Practice Periodical of Hazardous, Toxic, and Radioactive Waste Management (2008) 230-238.

42. Maturi K., Reddy K. R., Cosolvent-enhanced desorption and transport of heavy metals and organic contaminants in soils during electrokinetic remediation, Water, Air and Soil Pollution 189 (2008) 199-211. 
43. Park J.-Y., Lee H.-H., Kim S.-J., Lee Y.-J., Yang J.-W., Surfactant -enhanced electrokinetics removal of phenanthrene from kaolinite, Journal of Hazardous Materials 140 (2007) 230-236.

44. Karagunduz A., Gezer A., Karasuloglu G., Surfactant enhanced electrokinetic remediation of DDT from soils, Science of the Total Environment 385 (2007) 1-11.

45. Reddy K. R., Ala P. R., Sharma S., Kumar S. N., Enhanced electrokinetic remediation of contaminated manufactured gas plant soil, Engineering Geology 85 (2006) 132146.

46. Khodadoust A., Reddy K. R., Narla O., Cyclodextrin-enhanced remediation of soils contaminated with 2, 4-dinitrotoluene, Journal of Environmental Engineering (2006) 1043-1050.

47. Khodadoust A., Reddy K. R., Maturi K., Effect of different extraction agents on metal and organic contaminant removal from a field soil, Journal of Hazardous Materials B117 (2005) 15-24.

48. Yang J.-W., Lee Y.-J., Park J.-Y., Kim S.-J., Lee J.-Y., Application of APG and Calfax 16L-35 on surfactant-enhanced electrokinetics removal of phenanthrene from kaolinite, Engineering Geology 77(2005) 243-251.

49. Khodadoust A., Reddy K. R., Maturi K., Removal of nickel and phenanthrene from kaolin soil using different extractants, Environmental Engineering Science 21 (2004) 691-704.

50. Saichek R. E., Reddy K. R., Evaluation of surfactants/cosolvents for desorption/solubilization of phenanthrene in clayey soils, International Journal of Environmental Studies 61 (2004) 587-604. 
51. Reddy K. R., Saichek R. E., Effect of soil type on electrokinetics removal of phenanthrene using surfactants and cosolvents, Journal of Environmental Engineering (2003) 336-346.

52. Li A., Cheung K. A., Reddy K. R., Cosolvent-enhanced electrokinetics remediation of soils contaminated with phenanthrene, Journal of Environmental Engineering (2000) $527-533$.

53. Isosaari P., Piskonen R., Ojala P., Voipio S., Eilola K., Lehmus E., Itävaara M. , Integration of electrokinetics and chemical oxidation for the remediation of creosotecontaminated clay Journal of Hazardous Materials 144 (2007) 538-548.

54. Thepsithar P., Roberts E. P. L., Removal of phenol from contaminated kaolin using electrokinetically enhanced in-situ chemical oxidation, Environmental Science and Technology 40 (2006) 6098-6103.

55. Pham T. D., Shrestha, R. A., Sillanpää M., Electrokinetic and ultrasonic treatment of kaolin contaminated by POPs, Separation Science and Technology 44 (2009) 24102420.

56. Yang G. C. C., Yeh C.-F., Enhanced nano-Fe3O4/S2O82- oxidation of trichloroethylene in a clayey soil by electrokinetics, Separation and Purification Technology 79 (2011) 264-271.

57. Fenton H. J. H., Oxidation of Tartaric acid in presence of iron, Journal of Chemical Society 65 (1894) 899-910.

58. Tyre, B. W. Watts R. J., Miller G. C., Treatment of four biorefractory contaminants in soils using catalyzed hydrogen peroxide, Journal of Environmental Quality 20 (1991) $832-838$. 
59. Watts R. J., Kong S., Dippre M., Barnes W. T., Oxidation of sorbed hexachlorobenzene in soils using catalyzed hydrogen peroxide, Journal of Hazardous Materials 39 (1994) 33-47.

60. Kong S-H., Watts R. J., Choi J-Ho, Treatment of petroleum-contaminated soils using iron mineral catalyzed hydrogen peroxide, Chemosphere 37 (1998) 1473-1482.

61. Jonsson S., Persson Y., Frankki S., van Bavel B-., Lundstedt S., Haglund P., Tysklind M., Degradation of polycyclic aromatic hydrocarbons (PAHs) in contaminated soils by Fenton's reagent: A multivariate evaluation of the importance of soil characteristics and PAH properties, Journal of Hazardous Materials 149 (2007) 86-96.

62. Quan H. N., Teel A. L., Watts R. J., Effect of contaminant hydrophobicity on hydrogen peroxide dosage requirements in the Fenton-like treatment of soils, Journal of Hazardous Materials B102 (2003) 277-289.

63. Kang N., Hua I., Enhanced chemical oxidation of aromatic hydrocarbons in soil systems, Chemosphere 61 (2005) 909-922.

64. Kakarla P. K. C., Watts R. J., Depth of Fenton-like oxidation in remediation of surface soil, Journal of Environmental Engineering (1997) 11-17.

65. Pignatello J. J., Baehr K., Ferric Complexes as Catalysts for Fenton degradation of 2, 4-D and metolachlor in soil, Journal of environmental quality 23 (1994) 365-370.

66. Pirkanniemi K., Metsärinne S., Sillanpää M., Degradation of EDTA and novel complexing agents in pulp and paper mill process and waste waters by Fenton's reagent, Journal of Hazardous Materials 147 (2007) 556-561.

67. Ravikumar J. X. and Gurol M. D., Chemical oxidation of chlorinated organics by hydrogen peroxide in the presence of sand, Environmental Science and Technology 28 (1994) 394-400. 
68. Watts R.J. and Stanton P.C., Mineralization of sorbed and NAPL-phase hexadecane by catalyzed hydrogen peroxide, Water Research. 33 (1999) 1405-1414.

69. Yang G. C. C, Long Y.-W., Removal and degradation of phenol in a saturated flow by in-situ electrokinetic remediation and Fenton-like process, Journal of Hazardous Materials B69 (1999) 259-271.

70. Yang G. C. C., Liu C.-Y., Remediation of TCE contaminated soils by in situ EKFenton process, Journal of Hazardous Materials B85 (2001) 317-331.

71. Neyens E., Baeyens J., A review of classic Fenton's peroxidation as an advanced oxidation technique, Journal of Hazardous Materials B98 (2003) 33-50.

72. Ferrarese E., Andreottola G., Oprea I. A., Remediation of PAH-contaminated sediments by chemical oxidation, Journal of Hazardous Materials 152 (2008) 128139.

73. Rivas F. J., Polycyclic aromatic hydrocarbons sorbed on soils: A short review of chemical oxidation based treatments, Journal of Hazardous Materials B138 (2006) 234-251.

74. Kawahara F. K., Davila B., Al-Abed S. R., Vesper S. J., Ireland J. C., Rock S., Polynuclear aromatic hydrocarbon (PAH) release from soil during treatment with Fenton's reagent, Chemosphere 31 (1995) 4131-4142.

75. Yap C. L., Gan S., Ng H. K., Fenton based remediation of polycyclic aromatic hydrocarbons - contaminated soils, Chemosphere 83 (2011) 1414-1430.

76. Sirguey C., de Souza e Silva P. T., Schwartz C., Simonnot M-O., Impact of chemical oxidation on soil quality, Chemosphere 72 (2008) 282-289. 
77. Luo Q., Zhang X., Wang H., Qian Y., The use of non-uniform electrokinetics to enhance in situ bioremediation of phenol-contaminated soil, Journal of hazardous materials B121 (2005) 187-194.

78. Luo Q., Zhang X., Wang H., Qian Y., Mobilization of phenol and dichlorophenol in unsaturated soils by non-uniform electrokinetics. Chemosphere (2005) 1289-98.

79. Park Ji-Y., Kim S-J, Lee Y-Jin, Baek K., Yang Ji-W., EK-Fenton process for removal of phenanthrene in a two-dimensional soil system, Engineering Geology 77 (2005) 217-224.

80. Kim S.-S., Kim J.-H., Han S.-J., Application of the electrokinetic Fenton process for the remediation of kaolinite contaminated with phenanthrene, Journal of Hazardous Materials B118 (2005) 121-131.

81. Kim J.-H., Han S.-J., Kim S.-S., Yang J.-W., Effect of soil chemical properties on the remediation of phenanthrene - contaminated soil by electrokinetic Fenton process, Chemosphere 63 (2006) 1667-1676.

82. Kim J. H., Kim S. S., Yang J. W., Role of stabilizers for treatment of clayey soil contaminated with phenanthrene through electrokinetic-Fenton process-Some experimental evidences, Electrochimica Acta 53 (2007) 1663-1670.

83. Reddy K. R., and Karri M. R., Effect of Oxidant Dosage on Integrated Electrochemical Remediation of Contaminant Mixtures in Soils, Journal of environmental science and health 43 (2008) 881-893.

84. Reddy K. R, and Chandhuri K.S., Fenton-like oxidation of PAHs in clayey soils using electrokinetics, Geotechnical and Geological Engineering 135 (2009) 1429-1439. 
85. Tsai T-T., Sah J., Kao C-M., Application of iron electrode corrosion enhanced electrokinetic Fenton oxidation to remediate diesel contaminated soils: A laboratory feasibility study, Journal of Hydrology 380 (2010) 4-13.

86. Alcántara T., Pazos M., Gouveia S., Cameselle C., Sanroman M. A., Remediation of phenanthrene from contaminated kaolinite by electroremediation-Fenton technology, Journal of Environmental Science and Health - Part A Toxic/Hazardous substances and environmental engineering 43 (2008) 901-906.

87. Breivik K., Alcock R., Li Y.-F., Bailey R. E., Fiedler H., Pacyna J. M., Primary sources of selected POPs: regional and global scale emission inventories, Environmental Pollution 128 (2004) 3-16.

88. UNEP, 2001. The Stockholm Convention on Persistent Organic Pollutants. United nations environmental programme. Internet:http://www.chem.unep.ch/sc/default.htm].

89. Bailey, R. E., Global hexachlorobenzene emissions. Chemosphere 43 (2001) 167182.

90. Barber J. L., Sweetman A. J., van Wijk D., Jones K. C., Hexachlorobenzene in the global environment: Emissions, levels, distribution, trends and processes, Science of the Total Environment 349 (2005) 1-44.

91. Meijer S. N., Ockenden W. A., Sweetman A., Breivik K., Grimalt J. O., Jones K. C., Global distribution and budget of PCBs \& $\mathrm{HCB}$ in background soil: Implications for sources and environmental processes, Environmental Science and Technology 37 (2003) 667-672.

92. Rantalainen A-L, Paasivirta J, Herve S. Uptake of chlorohydrocarbons from soil by lipid-containing semipermeable membrane devices (SPMDs), Chemosphere (1998) $1415-27$. 
93. Vrana B, Paschke A, Popp P, Schuurman G. Use of semi-permeable membranes: Determination of bioavailable organic waterborne, contaminants in the industrial region of Bitterfeld, Saxony- Anhalt, Germany. Environmental Science and Pollution Research 8 (2001) 27- 34

94. Schell L. M., Gallo M. V., DeCaprio A. P., Hubickid L., Denhama M., Ravenscrofta J., Thyroid function in relation to burden of PCBs, p, p-DDE, HCB, mirex and lead among Akwesasne Mohawk youth: a preliminary study, Environmental Toxicology and Pharmacology 18 (2004) 91-99.

95. Lelli S. M., Ceballosb N. R., Mazzetti M. B., Aldonatti C. A. , San Martı'n de Viale L. C. , Hexachlorobenzene as hormonal disruptor-studies about glucocorticoids: Their hepatic receptors, adrenal synthesis and plasma levels in relation to impaired gluconeogenesis, Biochemical pharmacology 73 (2007) 873-879.

96. Eggesb M., Stigum H., Longnecker M. P., Polder A., Aldrin M., Bassob O., Thomsene C., Utne Skaare J., Becher G., Magnus P., Levels of hexachlorobenzene (HCB) in breast milk in relation to birth weight in a Norwegian cohort, Environmental Research 109 (2009) 559-566.

97. Aylward L. L., Hays S. M., Gagne M., Nong A., Krishnan K., Biomonitoring equivalents for hexachlorobenzene, Regulatory Toxicology \& Pharmacology 58 (2010) 25-32.

98. Agency for Toxic Substances and Disease Registry (ATSDR), 2002. Toxicological Profile for Hexachlorobenzene. http:/www.atsdr.cdc.gov/ toxprofiles/tp90.html.

99. Rowell D. L., Soil Science: Methods and Applications, Longman Scientific \& Technical, Harlow, England, 1994. 
100. Schwarzenbach R. P., Westall J., Transport of nonpolar organic compounds from surface water to groundwater. Laboratory sorption studies, Environmental Science and Technology 15 (1981) 1360-1367.

101. Means J. C., Wood S. G., Hassett J. J., Banwart W. L., Sorption of polynuclear aromatic hydrocarbons by sediments and soils, Environmental Science and Technology 14 (1980) 1524-1528

102. Narasimhan B., Ranjan R., Electrokinetic barrier to prevent subsurface contaminant migration: theoretical model development and validation, Journal of Contaminant Hydrology 42 (2000) 1-17. 

PUBL. 1

Anshy Oonnittan, Reena Shrestha, Mika Sillanpää, Remediation of hexachlorobenzene in soil by enhanced electrokinetic Fenton process, Journal of environmental science and health Part A, Vol. 43, No.8 (2008), 894-900.

(C) Taylor and Francis group, LLC

Reprinted with the permission of Taylor and Francis group. 



\title{
Remediation of hexachlorobenzene in soil by enhanced electrokinetic Fenton process
}

\author{
ANSHY OONNITTAN, REENA A. SHRESTHA and MIKA SILLANPÄÄ \\ University of Kuopio, Laboratory of Applied Environmental Chemistry, Patteristonkatu, Mikkeli, Finland
}

The feasibility of enhanced electrokinetic Fenton process for the remediation of Hexachlorobenzene (HCB) in low permeability soil was investigated. Kaolin was artificially contaminated with HCB and treated by electrokinetic and electrokinetic Fenton processes $\beta$-Cyclodextrin was used to enhance the solubility of HCB in pore fluid. Three tests were carried out, of which two were electrokinetic experiments to observe the suitability of $\beta$-cyclodextrin as a flushing solution for these processes. The third experiment was the electrokinetic Fenton test using $\beta$-cyclodextrin as an enhancing agent. Results show that the removal efficiency depends on the choice of a suitable flushing solution and physical parameters like $\mathrm{pH}$, electric current and electro-osmotic flow.

Keywords: Soil remediation, electrokinetics, Fenton process, hexachlorobenzene, cyclodextrin.

\section{Introduction}

Persistent organic pollutants (POPs) are among the most dangerous of all the pollutants released into the environment every year. ${ }^{[1]}$ One of the major traits of POPs, the cause of which the international community is calling for global action, is their ability for long-range transport. They are transported to regions where they have never been produced or even used. Previously, POPs have been destroyed by combustion technologies that can create by-products such as dioxins and furans. ${ }^{[2]}$ Later, other technologies were developed and commercialized for the treatment of POPs. However, none of these proved to be successful in treating low permeability soil contaminated with POPs.

Several researchers were successful in applying electrokinetic technology for the remediation of organic compounds in soil. ${ }^{[3-8]}$ In electrokinetic remediation, organic compounds are transported through the soil matrix by the electric field-induced flow of pore fluids called electroosmosis. ${ }^{[9,10]}$ The negative charge at the surface of most soil particles causes an accumulation of positively charged cations near the surface. When an electric field is applied, the movement of these cations to the cathode causes the water molecules to move toward the cathode. Therefore, electro-osmosis is effective to generate a uniform fluid and

Address correspondence to Anshy Oonnittan, Laboratory of Applied Environmental Chemistry, Patteristonkatu 1, FIN-50101, Mikkeli, Finland; E-mail: plamthot@uku.fi mass transport when the soil surface is sufficiently negatively charged like as in clays. ${ }^{[1]}$ However, POPs have low aqueous solubility and thus during electrokinetic remediation it becomes difficult to drive them by electro-osmosis unless some surfactant or cosolvent that enhances their solubility in pore fluid is used. ${ }^{[7,11,12]}$ Enhanced electrokinetic remediation of PAHs and HCB in soil have already been studied by Saichek and Reddy ${ }^{[12]}$ and Yuan et al. ${ }^{[13]}$ The results from these studies show that significant contaminant movement occurred by enhanced electrokinetic treatment. But, these processes transport the contaminants from the soil to the electrode well, thus generating a secondary waste stream which requires further treatment. Thus, it becomes necessary to develop a process where the contaminants are degraded in the system itself without producing a secondary waste stream. Fenton's oxidation is an effective mechanism for the mineralization of toxic organic compounds. The Fenton system consists of ferrous catalysed hydrogen peroxide in acidic conditions. During the Fenton reaction, hydrogen peroxide is catalysed by ferrous ions resulting in the generation of hydroxyl radicals (Equation 1). The reaction is propagated by the regeneration of ferrous ions as shown in Equation 2.

$$
\begin{aligned}
& \mathrm{H}_{2} \mathrm{O}_{2}+\mathrm{Fe}^{2+} \rightarrow \mathrm{OH}^{*}+\mathrm{OH}^{-}+\mathrm{Fe}^{3+} \\
& \mathrm{H}_{2} \mathrm{O}_{2}+\mathrm{Fe}^{3+} \rightarrow \mathrm{HO}_{2}^{*}+\mathrm{H}^{*}+\mathrm{Fe}^{2+}
\end{aligned}
$$

Various competing reactions (Equations 3 to 5) including the production of perhydroxyl radical are also involved in 
Fenton's system

$$
\begin{aligned}
\mathrm{OH}^{*}+\mathrm{Fe}^{2+} & \rightarrow \mathrm{OH}^{-}+\mathrm{Fe}^{3+} \\
\mathrm{HO}_{2}^{*}+\mathrm{Fe}^{3+} & \rightarrow \mathrm{O}_{2}+\mathrm{H}^{+}+\mathrm{Fe}^{2+} \\
\mathrm{H}_{2} \mathrm{O}_{2}+\mathrm{OH}^{*} & \rightarrow \mathrm{H}_{2} \mathrm{O}+\mathrm{HO}_{2}^{*}
\end{aligned}
$$

where $\mathrm{OH}^{*}=$ hydroxyl radical and $\mathrm{HO}_{2}^{*}=$ perhydroxyl radical.

In the presence of organic substrate the reactions include:

$$
\begin{aligned}
\mathrm{RH}+\mathrm{OH}^{*} & \rightarrow \mathrm{R}^{*}+\mathrm{H}_{2} \mathrm{O}+\mathrm{HO}_{2}^{*} \\
\mathrm{R}^{*}+\mathrm{Fe}^{3+} & \rightarrow \mathrm{Fe}^{2+}+\text { products }
\end{aligned}
$$

where $\mathrm{R}^{*}=$ organic radicals

Fenton's reaction was applied for soil remediation and it was found that an optimum $\mathrm{pH}$ of 2 to 3 is required for the process. ${ }^{[14]}$ However, when applied alone, Fenton's process failed to treat low permeability soil. Also, hydroxyl radicals generated by Fenton's reaction have limited capability to oxidize the contaminants sorbed to the soil. ${ }^{[13]}$ But Fenton's process, when integrated with electrokinetics, was found to be efficient in destroying the organic wastes sorbed to soil. ${ }^{[15-17]}$ Results of these electrokinetic Fenton studies on compounds such as phenanthrene showed that removal of contaminants sorbed to soil surface was possible only when treated for considerably longer periods and the removal efficiency increased with increased applied voltage. Isosaari et al. ${ }^{[18]}$ reported that the research on electrokinetic removal of PAHs from soil resulted in a very low removal and that combination of electrokinetics with Fenton's process did not improve the removal efficiency of the process.

The effectiveness of electrokinetic Fenton process in treating low permeability contaminated soil depends largely on the hydrophobic nature of the contaminants. Therefore, the role of an enhancing agent to solubilise these hydrophobic compounds in the pore fluid seems to be very significant in the success of these remediation techniques.

In this study, the effectiveness of enhanced Electrokinetic Fenton process in treating low permeability soil contaminated with POPs was tested by selecting HCB as the model compound. Enhanced electrokinetic experiments were first carried out to ensure the suitability of $\beta$-cyclodextrin as a good flushing solution to increase the solubility of HCB in the pore fluid and thus enhancing its mobility through the soil section. This was followed by a third experiment in which HCB-contaminated soil was treated by enhanced electrokinetic Fenton process. Physical parameters like $\mathrm{pH}$, electric current and electro-osmotic flow were measured and their influence on removal efficiency was also studied.

\section{Materials and methods}

\section{Soil characterization and chemicals}

Kaolin (VWR International (FIN)) was used as the model clay in all the experiments. The appearance was greyish powder and some preliminary analysis was done to deter-
Table 1. Kaolin characteristics.

\begin{tabular}{lc}
\hline Properties & Values \\
\hline Mineralogy & \\
$\quad$ Kaolin & $100 \%$ \\
Paricle size distribution & \\
$\quad$ Gravel $\%$ & 0 \\
Sand $\%$ & 7 \\
Silt $\%$ & 17 \\
Clay $\%$ & 76 \\
Specific gravity & 0.508 \\
Organic matter $\%$ & Near 0 \\
Calcium carbonate content $\%$ & 5.5 \\
pH & 5.2 \\
Electrical conductivity $(\mu \mathrm{S})$ & 189.2 \\
Cation exchange capacity $(\mathrm{m} \mathrm{mol} / 100 \mathrm{~g})$ & 3 \\
\hline
\end{tabular}

mine the physical and chemical characteristics of soil. ${ }^{[19]}$ The Kaolin characteristics are listed in Table 1. HCB was used as the representative POP in this study. HCB is a white crystalline solid that is practically insoluble in water. Physical and chemical properties of HCB are shown in Table 2. ${ }^{20]}$

From J. T. Baker we obtained 30\% hydrogen peroxide and ferrous sulphate (99\% Ferrous sulphate heptahydrate) was supplied by Fluka. All other chemicals were purchased from VWR International. Deionized water was used for all dilutions.

\section{Experimental setup}

Experiments were carried out in an electrokinetic reactor which consisted of three parts: two electrode chambers with a soil chamber in between. Figure 1 shows the apparatus used. The cell was made of glass and the dimensions of the electrode chambers were $12 \times 20 \times 20 \mathrm{~cm}$ and that of the soil chamber was $13 \times 20 \times 20 \mathrm{~cm}$. Inert electrodes made of titanium and coated with platinum were used for all the experiments. A weighed quantity of contaminated soil was uniformly stacked into the soil chamber and the anode and cathode chambers were then filled with respective solutions. The chambers were closed by a removable lid with openings for inserting the electrodes that also served as gas vents. The electrodes were then connected to the power

Table 2. Physical and chemical properties of HCB. ${ }^{[20]}$

\begin{tabular}{ll}
\hline Property & Value \\
\hline Molecular mass, g & 284.78 \\
Melting point, ${ }^{\circ} \mathrm{C}$ & 231 \\
Boiling point, ${ }^{\circ} \mathrm{C}$ & 325 \\
Vapour pressure $\mathrm{mm} \mathrm{Hg}$ at $20^{\circ} \mathrm{C}$ & $1.09 \times 10^{-5}$ \\
Water solubility $\mathrm{mg} / \mathrm{L}$ at $20^{\circ} \mathrm{C}$ & 0.005815 \\
Log octanol $/$ water partition coefficient $^{\circ} \mathrm{Den}^{3}$ & 5.73 \\
Density at $23^{\circ} \mathrm{C} \mathrm{g} / \mathrm{cm}^{3}$ & 2.044 \\
Flash point, ${ }^{\circ} \mathrm{C}$ & 242 \\
\hline
\end{tabular}




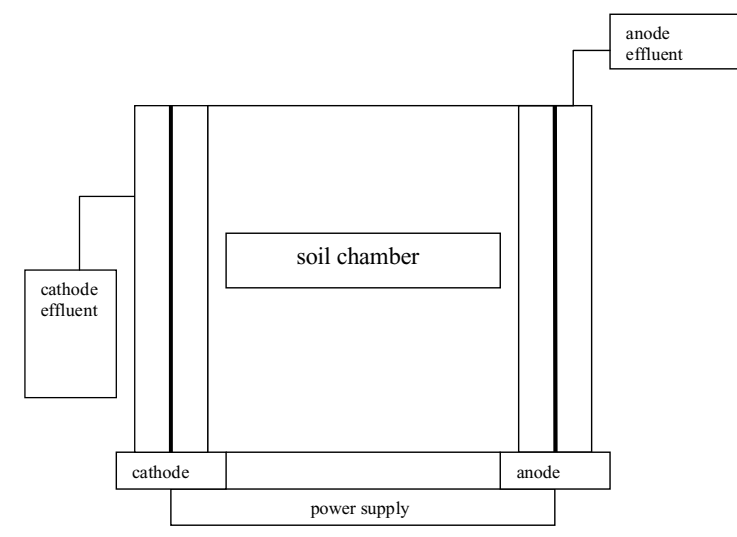

Fig. 1. Electrokinetic apparatus.

supply. The same electrokinetic apparatus was used for all the experiments.

\section{Sampling and chemical analyses}

Soil samples were taken periodically and analysed for HCB. Soil $\mathrm{pH}$, zeta potential and current were monitored continuously. A maximum of approximately $2 \mathrm{~g}$ of soil samples were taken without disturbing the system. Soil samples along the anode and cathode portions for all analyses and measurements were taken from a distance of about $2 \mathrm{~cm}$ from the walls of the chamber. Extraction of HCB from soil was done by ultrasonication based on a method by Yuan et al. ${ }^{[13]}$ The extract obtained was then analysed by gas chromatography (Agilent 5975) following USEPA method $8270 \mathrm{C} .{ }^{[21]}$ The average electro-osmotic flow was quantified using the Helmholtz-Smoluchowski equation as described by Sharma and Reddy. ${ }^{[22]} \mathrm{pH}$ was measured using $\mathrm{pH} 730$ inoLab WTW series, and the zeta potential who measured by the Zeta sizer Nano series (Malvern instrument).

\section{Operating procedure}

Tests 1 and 2 were electrokinetic experiments conducted to evaluate the suitability of $\beta$-cyclodextrin for the process and the distribution of HCB in the soil with elapsed time.
Test 3 was an electrokinetic Fenton process, where Fenton's reagent was supplied to the soil from the anode chamber. The anode chamber was filled with $1.5 \mathrm{~L}, 85 \mathrm{mg} / \mathrm{L}$ ferrous sulphate solution so that $\mathrm{Fe}$ : substrate ratio is $1: 10(\mathrm{wt} \%)$ and $1 \%(\mathrm{wt} \%) \beta$-cyclodextrin. The initial concentration of $\mathrm{HCB}$ in soil $\left(\mathrm{C}_{0}\right)$ after contamination was $45.9 \mathrm{mg} / \mathrm{kg}$ for Tests 1 and 2 and $376.4 \mathrm{mg} / \mathrm{kg}$ for Test 3 . After 48 hours when current developed, $15 \%$ hydrogen peroxide was supplied from the anode chamber. Table 3 shows the testing program for tests 1,2 and 3.

\section{Results and discussion}

\section{Soil pH}

When an electric field is applied, electrolysis takes place and $\mathrm{H}^{+}$and $\mathrm{OH}^{-}$ions are generated at the anode and cathode, respectively. This results in a low $\mathrm{pH}$ at the anode and a high $\mathrm{pH}$ at the cathode ${ }^{[7]}$ Figure 2 shows the soil $\mathrm{pH}$ profiles for tests 1, 2 and 3. A general trend of low $\mathrm{pH}$ at the anode and high $\mathrm{pH}$ at the cathode was found in all the tests. The initial $\mathrm{pH}$ of the contaminated soil was 5.2. During the period of test, the soil $\mathrm{pH}$ at the anode and at the cathode decreased. This may be because the acid front generated at the anode advanced through the soil specimen and thus lowered the $\mathrm{pH}$. This happens because the ionic mobility of $\mathrm{H}^{+}$is 1.75 times greater than that of $\mathrm{OH}^{-}$ion. ${ }^{[23]}$ The $\mathrm{pH}$ of soil in test 2 when $\beta$-cyclodextrin was used were more acidic than in test 1 . This could be attributed to the still higher ionic mobility which occurred due to the use of $\beta$-cyclodextrin. Kaya and Yukselen ${ }^{[24]}$ reported that the $\mathrm{pHs}$ of soils like kaolinite, montmorillonite and quartz powder are slightlyto-moderately acidic in the presence of surfactants.

Soil $\mathrm{pH}$ along anode as well as cathode for test 3 were observed to be more acidic than in test 2 where $\beta$-cyclodextrin was used. The soil $\mathrm{pH}$ along anode decreased to 2 and along the cathode decreased to 3 after 6 to 7 days of operation. This is because of the use of ferrous sulphate in test 3 , which was supplied from the anode chamber.

\section{Current}

The current developed during tests 1,2 and 3 is shown in Figure 3. A maximum of $30 \mathrm{~mA}$ current was observed

Table 3. Testing program.

\begin{tabular}{lcclccc}
\hline Test & Soil & Contaminant & Anodic solution & Cathodic solution & Voltage (volts) & Total duration (hrs) \\
\hline 1 & Kaolin & HCB & $0.01 \mathrm{M} \mathrm{KC1}$ & Deionized water & 15 & 144 \\
2 & Kaolin & HCB & $1 \%$ Cyclodextrin solution & Deionized water & 15 & 144 \\
3 & Kaolin & HCB & Ferrous sulphate, & Deionized water & 30 & 336 \\
& & $1 \%$ cyclodextrin and & & \\
& & & & & \\
& & & & & \\
& & & & & \\
\end{tabular}




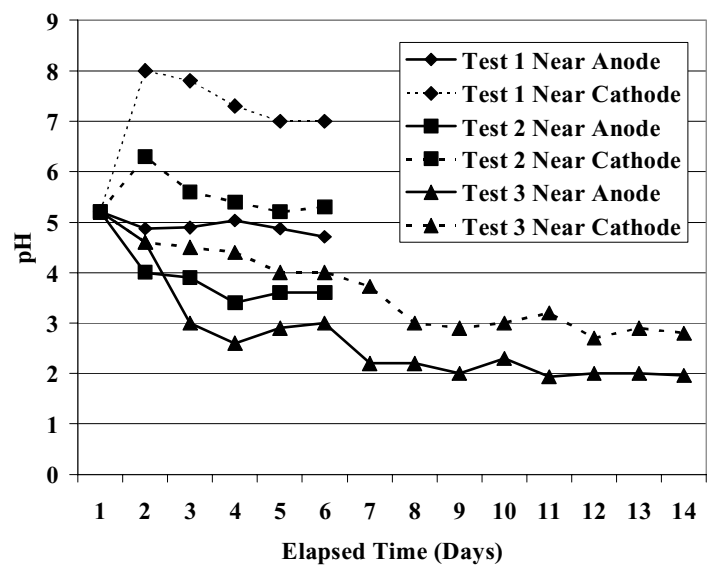

Fig. 2. Soil pH near anode and cathode for tests 1, 2 and 3.

during the start of test 1 . During the test period, the current decreased to $10 \mathrm{~mA}$ and remained constant. The high current developed during the start of the test 1 where $0.01 \mathrm{M}$ $\mathrm{KCl}$ was used is due to the high ionic strength of the electrolyte solution. The gradual decrease in the current could be attributed to the depletion of ions in the system.

During test 2, current increased to $10 \mathrm{~mA}$ after 1 day and then decreased and became zero towards the end of the experiment. Initially, there were no conducting ions in the system and then the soluble ion minerals in the soil might have contributed the increase in current. After 1 day of operation, current in test 3 was increased to $10 \mathrm{~mA}$ and then remained constant for the entire period of test. During the test, Fenton's reagent was supplied from the anode chamber and thus the presence of Fentons reagent in the system might have maintained the current constant during the test period.

\section{Electro-osmotic flow}

The electro-osmotic flow was found to be higher for test 2 when compared to test 1 (Fig. 4). Test 1 which showed higher current and $\mathrm{pH}$ along the soil cross-section should give higher electro-osmotic flow, because, as the $\mathrm{pH}$ decreases, the soil surface becomes more positive and thereby zeta potential becomes more positive. The higher flow in test 2 , therefore, could be because of the use of $\beta$-cyclodextrin, which made kaolin more permeable. ${ }^{[12]}$ Test 3 gave a maximum flow of $32 \mathrm{ml}$ by 14 days of operation. The reason for low electro-osmotic flow even though the applied voltage is higher in test 3 could be the highly acidic soil $\mathrm{pH}$ that developed during the test.

\section{Distribution of contaminant in soil}

Figures 5, 6 and 7 show the fraction (mass concentration divided by initial mass concentration) of contaminant across the anode and cathode portion of the soil with elapsed time. In test 1 where $0.01 \mathrm{M} \mathrm{KCl}$ was used, an uneven distribution of contaminant particles is observed (Fig. 5). The contaminant particles seemed to be mobilized and accumulated unevenly. The HCB concentration on the final day was nearly 40 to $50 \%$ above the initial concentration. This anomalous behaviour clearly indicates that the movement was not because of electro-osmotic flow or under the influence of an electric field. This is because the aqueous solubility of $\mathrm{HCB}$ is very low in the range of $5 \mu \mathrm{g} / \mathrm{L}$ at $25^{\circ} \mathrm{C}$. Since there was no solubilizing agent in the system, the movement and uneven distribution of the contaminant particles might have occurred by washing of the loosely bound or weekly sorbed

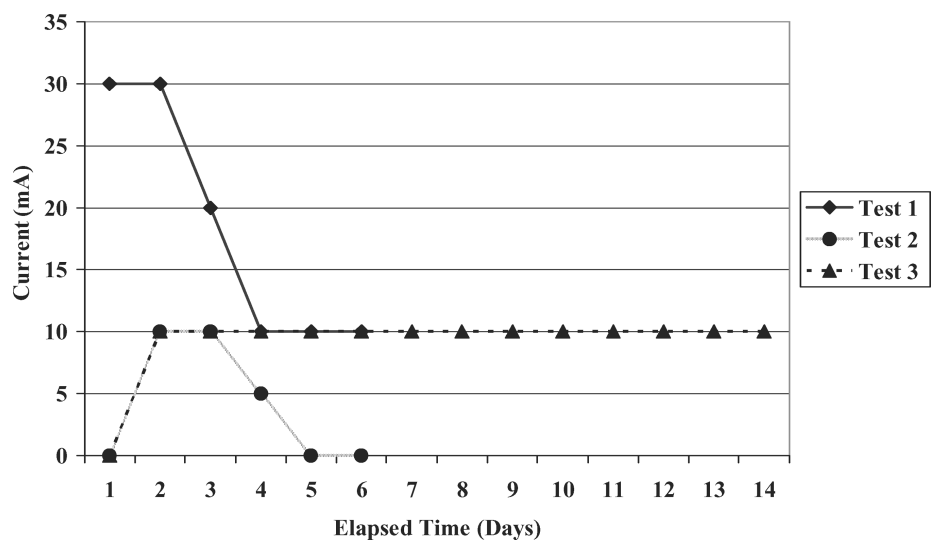

Fig. 3. Current (mA) during tests 1, 2 and 3. 


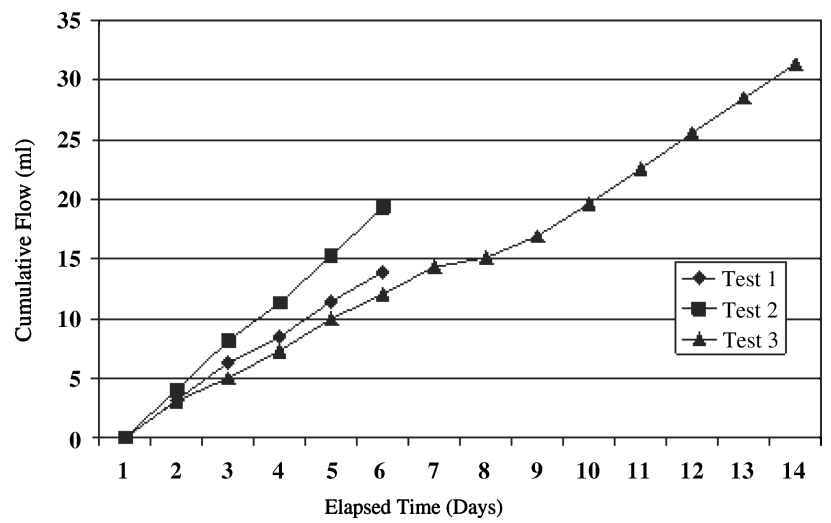

Fig. 4. Cumulative electro-osmotic flow during test 1, 2 and 3.

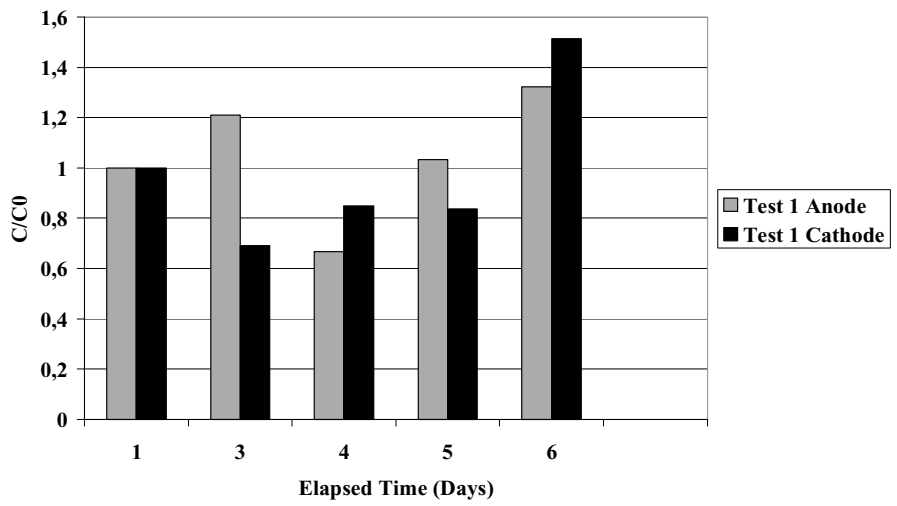

Fig. 5. Distribution of HCB in soil with elapsed time during test 1.

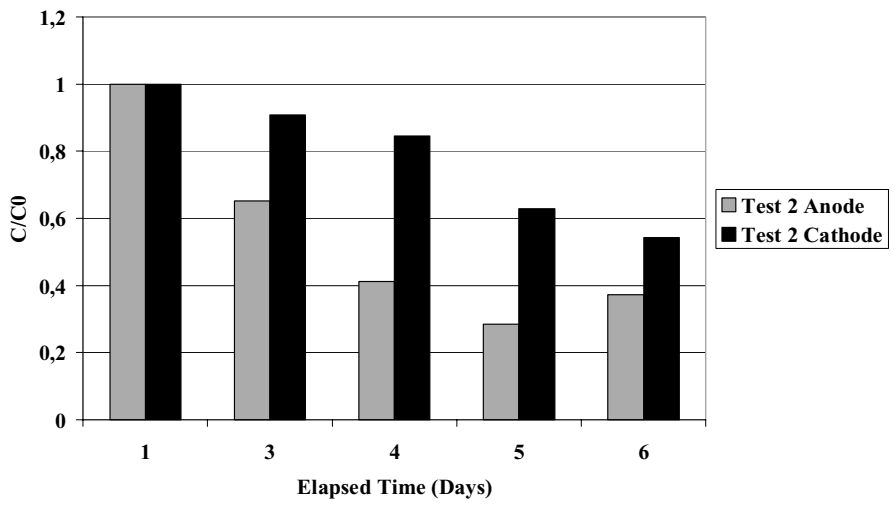

Fig. 6. Distribution of HCB in soil with elapsed time during test 2. 


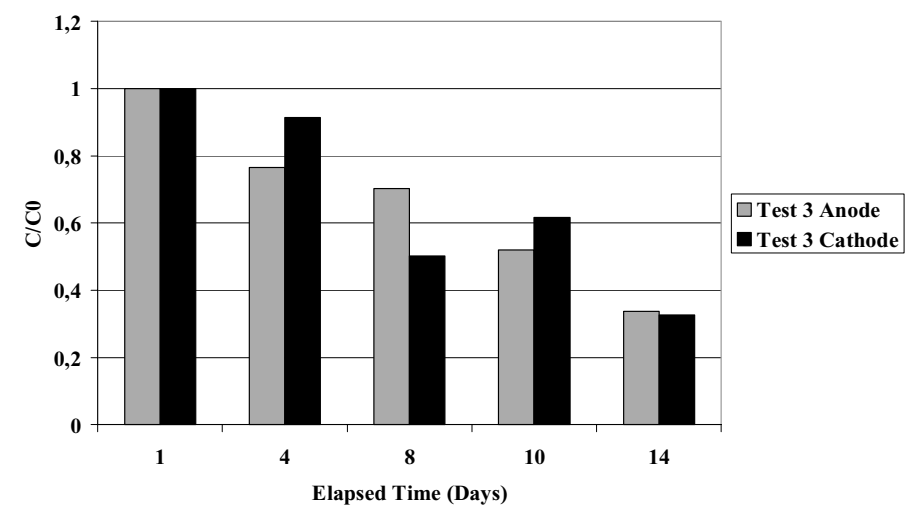

Fig. 7. Distribution of HCB in soil with elapsed time during test 3.

particles by the bulk movement of water in the system. Saichek and Reddy reported that the low organic content of kaolin could be a reason for the weak sorption of organic compounds to kaolin. ${ }^{[12]}$ This shows that the insolubility of HCB in the pore fluid has resulted in its non-uniform movement in soil.

Test 2 where $\beta$-cyclodextrin was used gave a more uniform distribution of HCB with elapsed time (Fig. 6). It resulted in a significant contaminant movement through the soil section. There was a stepwise reduction in the contaminant concentration along the anode and cathode portions of the soil. Then, $63 \%$ of contaminant was removed from the anode portion and $46 \%$ from the cathode portion which gave an overall removal of 54\% during the test. This is because of the use of $\beta$-cyclodextrin which solubilised the HCB sorbed to the soil and enhanced its mobility through the soil section. Also, the relatively high electro-osmotic flow rate in test 2 contributed to the increased removal of contaminant from the soil and the relative accumulation near the cathode. Thus, the use of $\beta$-cyclodextrin proved to be effective in bringing about a better HCB removal from soil. Work done by Yuan et al. ${ }^{[13]}$ also showed a higher removal of HCB from soil with $\beta$-cyclodextrin compared to Tween 80

Test 3 was conducted based on the results obtained from tests 1 and 2 . Results from test 2 clearly demonstrated the suitability of $\beta$-cyclodextrin as a flushing solution for electrokinetic removal of $\mathrm{HCB}$ from kaolin. But, the movement of contaminants from the soil generated a secondary waste stream that required further treatment. Test 3, where Fenton's reagent was used aimed at decomposing the contaminants in the system itself. Figure 7 shows the distribution of $\mathrm{HCB}$ with elapsed time during test 3 . Though there was a uniform reduction in the contaminant concentration, the reduction was gradual and took longer time than in test 2 . This happened because of the lower electro-osmotic flow in test 3. The presence of Fenton's reagent in the soil seemed to reduce the $\mathrm{pH}$ of the soil system, which influenced the electro-osmotic flow. $66 \%$ of HCB present initially was removed from the anode portion and $67 \%$ from the cathode portion which resulted in an overall removal of $64 \%$ of $\mathrm{HCB}$ from the soil. A slightly higher removal was observed along the cathode portion. This could be because of the comparatively higher electro-osmotic flow which developed at the cathode portion due to the relatively higher $\mathrm{pH}$ in that region which resulted in better soil-solution contaminant interaction than in the portion near anode.

\section{Conclusions}

Major conclusions drawn from the enhanced electrokinetic and electrokinetic Fenton experiments carried out are:

$\beta$-Cyclodextrin was proved to be a good flushing solution for the electrokinetic and electrokinetic Fenton treatment of low permeability soil contaminated with HCB. The choice of a good flushing solution is important to enhance the mobility of contaminant through the soil and thus bringing about higher removal efficiency within shorter time period.

HCB was effectively removed from soil by enhanced electrokinetic Fenton treatment. An overall removal of $64 \%$ was observed in the enhanced electrokinetic Fenton treatment of soil which lasted for 14 days. However, the presence of Fenton's reagent in the system affected the rate of removal of contaminants from the system.

\section{Acknowledgment}

The authors would like to thank TEKES for financially assisting the project.

\section{References}

[1] Toxics Link Factsheet. Fighting the menace of persistent organic pollutants. Number 18, Oct 2003. 
[2] USEPA. EPA-542-R-05-006 Reference Guide to Non-Combustion Technologies for Remediation of Persistent Organic Pollutants in Stockpiles and Soil. USEPA, Washington, D.C., 2005. Available at http://www.epa.gov/tio/download/remed/542r05006/final_pops_ report_web.pdf

[3] Chang, J.-H.; Qiang, Z.; Huang, C.P. Remediation and simulation of selected chlorinated organic solvents in unsaturated soil by a specific enhanced electrokinetics. Coll. Surf. A: Physicochem. Eng. Aspects. 2006, 287, 86-93.

[4] Luo, Q.; Zhang, X.; Wang, H.; Qian, Y. Mobilization of phenol and dichlorophenol in unsaturated soils by non uniform electrokinetics. Chemosphere 2005, 59(9), 1289-1298.

[5] Ribeiro, A.B ; Rodriguez-Maroto, J.M ; Mateus, E.P.; Gomes, H. Removal of organic contaminants from soils by an electrokinetic process: the case of atrazine. Experimental and modeling. Chemosphere 2005, 59(9), 1229-1239.

[6] Jiradecha, C.; Urgun-Demirtas, M.; Pagilla. K. Enhanced electrokinetic dissolution of naphthalene and 2,4-DNT from contaminated soils. J.H. Mater. 2005, 136(1), 61-67.

[7] Maturi, K.; Reddy, K.R. Simultaneous removal of organic compounds and heavy metals from soils by electrokinetic remediation with a modified cyclodextrin. Chemosphere 2006, 63(6), 10221031.

[8] Yuan, C.; Weng, C.H. Remediating ethylbenzene-contaminated clayey soil by a surfactant aided electrokinetic process. Chemosphere 2004, 57(3), 227-232.

[9] Acar, Y.B.; Gale, R.J.; Alshawabkeh, A.N.; Marks, R.E.; Puppal, S.; Bricka, M.; Parker, R. Electrokinetic remediation: Basics and technology status. J. hazard. Mater. 1995, 40(2), 117137.

[10] Alshawabkeh, A.N.; Yeung, A.T. Practical aspects of insitu electrokinetic extraction. J. Environ. Eng. 1999, 125(1), 27-35.

[11] Lens, P.; Grotenhuis, T.; Makina, G.; Tabak, H. Soil and sediment remediation. IWA Publishing, London, UK, 2005.

[12] Saichek, R.E.; Reddy, K.R. Effects of system variables on surfactant enhanced electrokinetic removal of polycyclic aromatic hy- drocarbons from clayey soils. Environ. Technol. 2002, 24, 503515 .

[13] Yuan, S.; Tian, M.; Lu, X. Electrokinetic movement of hexachlorobenzene in clayed soils enhanced by Tween 80 and $\beta$ cyclodextrin. J. Hazard. Mater. 2006, 137(2), 1218-1225.

[14] Watts, R.J.; Kong, S.; Dippre, M.; Barnes, W.T. Oxidation of sorbed hexachlorobenzene in soils using catalyzed hydrogen peroxide. J. Hazard. Mater. 1994, 39(1), 33-47.

[15] Yang, C.C.; Liu, C.-Y. Remediation of TCE contaminated soils by in situ EK- Fenton process. J. Hazardous Materials. 2001, 85(3), 317-331

[16] Park, J.-Y.; Kim, S.-J.; Lee, Y.-J.; Baek, K.; Yang, J.-W. EK-Fenton process for removal of phenanthrene in a two-dimensional soil system. Eng. Geol. 2005, 77(3-4), 217-224.

[17] Kim, J.-H.; Han, S.-J.; Kim, S-S.; Yang, J-W. Effect of soil properties on the remediation of phenanthrene-contaminated soil by electrokinetic-Fenton process. Chemosphere 2006, 63(10), 16671676.

[18] Isosaari, P.; Piskonen, R.; Ojala, P; Voipio, S.; Eilola, K.; Lehmus, E.; Itävaara, M. Integration of electrokinetics and chemical oxidation for the remediation of creosote-contaminated clay. J. Hazard. Mater. 2007, 144(1-2), 538-548.

[19] Rowell, D.L. Soil Science: Methods and Applications, Longman Scientific \& Technical, London, England, 1994.

[20] ASTDR. Department of Health and Human Services. Toxicological profile for hexachlorobenzene, Atlanta, GA, 2002, CAS: 118-74-1.

[21] USEPA, Test Methods for Evaluating Solid Wastes, SW 846, 3rd edition. Office of Soil Waste, Washington, DC.

[22] Sharma, H.D.; Reddy, K.R. Geoenvironmental Engineering. John Wiley \& Sons, Inc. New York, 2004

[23] Narasimhan, B.; Ranjan, R. Electrokinetic barrier to prevent subsurface contaminant migration: theoretical model development and validation. J. Contam. Hydrol. 2000, 42(1), 1-17.

[24] Kaya, A.; Yukselen, Y. Zeta potential of soils with surfactants and its relevance to electrokinetic remediation. J. Hazard. Mater. 2005, 120(1-3), 119-126. 

PUBL. 2

Anshy Oonnittan, Reena Shrestha, Mika Sillanpää. Removal of hexachlorobenzene from soil by electrokinetically enhanced chemical oxidation. Journal of hazardous materials 162, (2009) 989-993

(C) 2008 Elsevier B.V. All rights reserved.

Reprinted with the permission of Elsevier. 



\title{
Removal of hexachlorobenzene from soil by electrokinetically enhanced chemical oxidation
}

\author{
Anshy Oonnittan*, Reena A. Shrestha, Mika Sillanpää \\ Laboratory of Applied Environmental Chemistry, Department of Environmental Sciences, University of Kuopio, \\ Patteristonkatu 1, FIN-50101 Mikkeli, Finland
}

\section{A R T I C L E I N F O}

\section{Article history:}

Received 19 September 2007

Received in revised form 26 May 2008

Accepted 27 May 2008

Available online $\mathrm{xxx}$

\section{Keywords:}

Soil remediation

Electrokinetic

Fenton

Hexachlorobenzene

Cyclodextrin

\begin{abstract}
A B S T R A C T
This study investigates the feasibility of enhanced electrokinetic Fenton process for the remediation of hexachlorobenzene (HCB) in low permeable soil. Laboratory scale experiments were carried out in two different type of experimental setup to evaluate the influence of electrode positions in the system. Kaolin was artificially contaminated with HCB and treated by electrokinetic Fenton process. $\beta$-Cyclodextrin was used to enhance the solubility of HCB in pore fluid. Results show that the position of electrodes in the system and the way in which Fenton's reagent was added to the system has a significant influence on the
\end{abstract} treatment efficiency.

(c) 2008 Elsevier B.V. All rights reserved.

\section{Introduction}

The global nature of persistent organic pollutants (POPs) contamination has created a growing concern over the chronic toxicity and their impacts on human health and environment. One of the properties of POPs that make them difficult to treat is their low aqueous solubility. Though various conventional physical, chemical and biological techniques are available for the treatment of contaminated sites, they have proved unsuccessful to remediate soils of low permeability contaminated with compounds of low water solubility like POPs.

Recent research has shown that electrokinetic remediation is one of the promising technologies for the remediation of low permeable soil. In this process, separation of contaminants is brought about by the application of electric field between two electrodes inserted in the contaminated mass. Application of electric field initiates certain transport mechanisms such as electromigration, electro-osmosis and electrophoresis in the soil that involve the movement of ions, pore fluid and charged particles, respectively in the medium [1-5]. When treating soil contaminated with POPs, the influence of electromigration and electrophoresis can be neglected because of the non-polar nature of POPs. Therefore electro-osmosis is the major mechanism by which POPs are

* Corresponding author. Tel.: +358 445567480; fax: +358 153556513 E-mail address: anshy_o@yahoo.com (A. Oonnittan). transported through the soil matrix during their treatment. The hydrophobic nature of POPs makes them difficult to be removed from soil. The contaminants sorbed to the soil particles can be moved by electro-osmosis only if they are soluble in the pore fluid. Thus the use of a surfactant or cosolvent to enhance the process is necessary for increasing the solubility and enhancing the mobility of these contaminants in the pore fluid [1]. But, this causes only the movement of contaminants from one point of the soil section to another and the waste stream collected from the electrode chambers of the electrokinetic system requires further treatment.

Among various treatment methods, oxidation by Fenton's reagent was found to be very effective for highly biorefractory contaminants [6]. The primary reactions in the Fenton's process are

$\mathrm{H}_{2} \mathrm{O}_{2}+\mathrm{Fe}^{2+} \rightarrow \mathrm{OH}^{\bullet}+\mathrm{OH}^{-}+\mathrm{Fe}^{3+}$

$\mathrm{H}_{2} \mathrm{O}_{2}+\mathrm{Fe}^{3+} \rightarrow \mathrm{HO}_{2} \cdot+\mathrm{H}^{\bullet}+\mathrm{Fe}^{2+}$

$\mathrm{OH}^{\bullet}+\mathrm{Fe}^{2+} \rightarrow \mathrm{OH}^{-}+\mathrm{Fe}^{3+}$

$\mathrm{HO}_{2} \cdot+\mathrm{Fe}^{3+} \rightarrow \mathrm{O}_{2}+\mathrm{H}^{+}+\mathrm{Fe}^{2+}$

$\mathrm{H}_{2} \mathrm{O}_{2}+\mathrm{OH}^{\bullet} \rightarrow \mathrm{H}_{2} \mathrm{O}+\mathrm{HO}_{2} \cdot$

where $\mathrm{OH}^{\bullet}$ is the hydroxyl radical and $\mathrm{HO}_{2}{ }^{\bullet}$ is the perhydroxyl radical.

In the presence of organic substrate the reactions include:

$\mathrm{RH}+\mathrm{OH}^{\bullet} \rightarrow \mathrm{R}^{\bullet}+\mathrm{H}_{2} \mathrm{O}+\mathrm{HO}_{2}^{\bullet}$

0304-3894/\$ - see front matter ( 2008 Elsevier B.V. All rights reserved. doi:10.1016/j.jhazmat.2008.05.132

Please cite this article in press as: A. Oonnittan, et al., Removal of hexachlorobenzene from soil by electrokinetically enhanced chemical oxidation, J. Hazard. Mater. (2008), doi:10.1016/j.jhazmat.2008.05.132 


\section{G Model}

HAZMAT-8394; No. of Pages 5

Table 1

Kaolin characteristics

\begin{tabular}{lc}
\hline Properties & Values \\
\hline Mineralogy & \\
$\quad$ Kaolin & $100 \%$ \\
Particle size distribution & \\
$\quad$ Gravel (\%) & 0 \\
Sand (\%) & 7 \\
Silt (\%) & 17 \\
Clay (\%) & 76 \\
Specific gravity & 0.508 \\
Carbonate content $(\%)$ & 5.5 \\
pH & 5.2 \\
Electrical conductivity $(\mu S)$ & 189.2 \\
Cation exchange capacity $(\mathrm{mmol} / 100 \mathrm{~g})$ & 3 \\
\hline
\end{tabular}

$\mathrm{R}^{\bullet}+\mathrm{Fe}^{3+} \rightarrow \mathrm{Fe}^{2+}+$ products

where $\mathbf{R}^{\bullet}$ is the organic radical.

Thus Fenton's oxidation is an effective mechanism for the decomposition of toxic organic compounds. However, when applied alone, Fenton's process fails to treat low permeable soil. Also, hydroxyl radicals generated by Fenton's reaction have limited capability to oxidize the contaminants sorbed to the soil [7]. This drawback can be overcome by integrating enhanced electrokinetics with Fenton's process. In Electrokinetic Fenton process, hydrogen peroxide passes through low permeable soil from anode to cathode by electro-osmosis and produces hydroxyl radicals in the presence of iron in soil. Finally hydroxyl radicals oxidize or decompose organic wastes. Some researchers have successfully integrated electrokinetics with Fenton's process to treat various organic compounds [8-11]. But little research has been done on electrokinetic Fenton process enhanced by surfactants or cosolvents for the treatment of low permeable soil contaminated with POPs.

Therefore, in this study, the performance of enhanced electrokinetic Fenton process for the treatment of low permeable contaminated soil is investigated by selecting HCB as the model compound. Though HCB is no longer manufactured commercially, it is still being produced as a byproduct during the manufacture of other chlorinated solvents. Kaolin was artificially contaminated with HCB and laboratory scale electrokinetic Fenton experiments were carried out in two different types of experimental setup. $\beta$ Cyclodextrin was used for the enhancement of HCB mobility in the soil system. The influence of electrode position in electrokinetic Fenton system is also analyzed by selecting two different apparatus for conducting the experiments.

\section{Materials and methods}

The model soil selected for the study was Kaolin. Laboratory grade Kaolin was obtained from VWR International (Finland).

A preliminary analysis of soil was done based on the methods prescribed by soil science methods and applications [12] physical and chemical properties of kaolin are shown in Table 1.

$\mathrm{HCB}$ was selected as the representative POP in this study and was purchased from VWR International (Finland). HCB is practically insoluble in water $\left(0.0062 \mathrm{mg} / \mathrm{L}\right.$ at $\left.25^{\circ} \mathrm{C}\right)$ and has a log octanol partition coefficient of 5.73 [13].

Thirty percentage hydrogen peroxide was supplied by J.T. Baker and ferrous sulphate ( $99 \%$ ferrous sulphate heptahydrate) from Fluka.

Test specimen was prepared by artificially contaminating kaolin by the following method: weighed quantity of kaolin was first homogeneously mixed with HCB-hexane solution. Then the wet

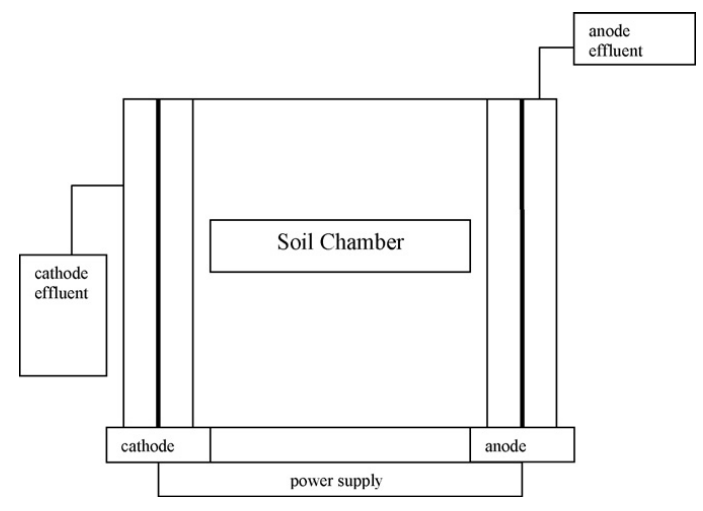

Fig. 1. Schematic diagram of electrokinetic apparatus used.

mass was left open in the fume hood till all the hexane evaporated and a totally dry soil mass was obtained.

\subsection{Electrokinetic Fenton reactor}

The electrokinetic apparatus used for test 1 is shown in Fig. 1. The apparatus was made of glass and consisted of three parts: two electrode chambers and a soil chamber in between. The dimensions of electrode chamber were $12 \mathrm{~cm} \times 20 \mathrm{~cm} \times 20 \mathrm{~cm}$ and that of soil chamber were $13 \mathrm{~cm} \times 20 \mathrm{~cm} \times 20 \mathrm{~cm}$. Inert electrodes made of titanium and coated with platinum were used for all experiments. Filter cloths were inserted on either sides of soil chamber to prevent soil from getting mixed with anode and cathode solutions. The chambers were closed using a removable lid with openings to insert electrodes which also served as gas vents.

Contaminated soil was uniformly stacked into the soil chamber and the electrode chambers were filled with respective solutions. Then the electrodes were inserted into the chambers and connected to the power supply.

Test 2 was carried out in an open pan with no separate chambers for electrodes. The dimensions of the cell were $28 \mathrm{~cm} \times 22 \mathrm{~cm} \times 10 \mathrm{~cm}$. Both the apparatus were designed by keeping in mind the practical implementations of the process in field.

\subsection{Operating conditions}

For test 1 , the contaminated soil was directly stacked into the soil chamber of the electrokinetic apparatus. The anode chamber was filled with $1.5 \mathrm{~L}$ ferrous sulphate solution so that Fe:substrate ratio is $1: 10$ and $1 \%$ (by weight) $\beta$-cyclodextrin. The cathode chamber was filled with deionized water. Electrodes were then inserted into the respective chambers and connected to the power supply. After $48 \mathrm{~h}$ when current developed, $15 \%$ hydrogen peroxide was supplied from the anode chamber.

For test 2, before stacking into the apparatus, the contaminated soil was soaked with ferrous sulphate solution, so that Fe:substrate ratio is $1: 10$, and $1 \%$ (by weight) $\beta$-cyclodextrin. The electrodes were then directly immersed into the soil and connected to the power supply.

A constant voltage of $30 \mathrm{~V}$ was applied during the entire period of both the tests. Moisture content of the soil in test 2 was maintained at around $35 \%$ by adding deionized water. Fifteen percentage hydrogen peroxide was periodically added from the anode part for both the tests. Blank tests were also run in order to estimate the contaminant loss by evaporation. 


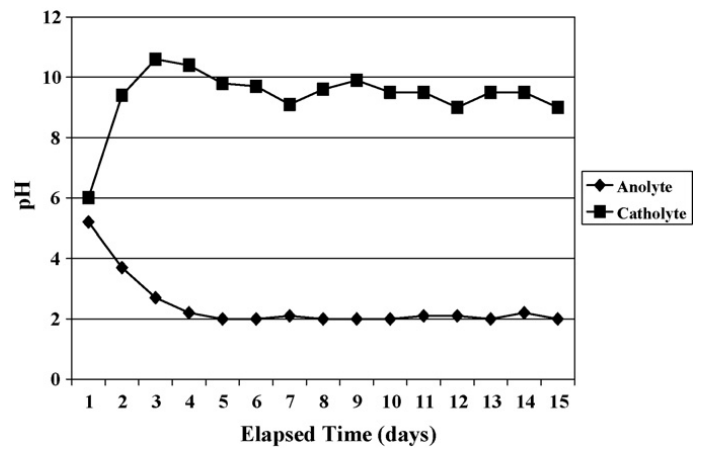

Fig. 2. Electrolyte $\mathrm{pH}$ : $\mathrm{pH}$ profile of anolyte and catholyte for test 1.

\subsection{Chemical analyses}

Soil samples were taken periodically and analyzed for HCB. pH and zeta potential of soil samples were monitored continuously. $\mathrm{pH}$ was measured by using a $\mathrm{pH}$ meter ( $\mathrm{pH} 730$ inoLab WTW series). The zeta potential of the soil samples were measured by Zeta sizer Nano-series (Malvern instrument), equipped with a microprocessor unit. A maximum of approximately $2 \mathrm{~g}$ of soil samples were taken without disturbing the system. Samples along the anode and cathode portions were taken from a distance of about $2 \mathrm{~cm}$ from the walls of the chamber.

HCB was extracted from the soil sample by ultrasonication based on a method adopted from Yuan et al. [14]. The extract so obtained was analyzed using a gas chromatograph coupled to an inert mass selective detector (Agilent 5975). The column used was HP-5 capillary column $(30 \mathrm{~mm} \times 0.32 \mathrm{~mm}$ ID) with a $0.25-\mu \mathrm{m}$ film thickness. Helium at constant flow rate $(25 \mathrm{~cm} / \mathrm{s})$ was used as carrier gas. The oven temperature was programmed from 40 to $270^{\circ} \mathrm{C}$ at $10^{\circ} \mathrm{C} / \mathrm{min}$. The injector temperature used was $250^{\circ} \mathrm{C}$ and the injection volume was $1 \mu \mathrm{L}$. All the analyses were done in duplicate soil samples.

\section{Results and discussions}

\subsection{Electrolyte and soil $\mathrm{pH}$}

The initial pH of anolyte was 5.2 and catholyte was 6 . After 3 days of operation, the anolyte $\mathrm{pH}$ decreased to 2 and remained almost constant for the rest of the days (Fig. 2). The catholyte $\mathrm{pH}$ increased to 10.6 after 2 days of operation and then remained constant in the range 9-9.8 for the entire period of the test. This shows the general trend of $\mathrm{pH}$ distribution during electrolysis. This is because, due to the applied electric field, electrolysis takes place and $\mathrm{H}^{+}$and $\mathrm{OH}^{-}$ions are generated at anode and cathode, respectively which results in a low $\mathrm{pH}$ at the anode and high $\mathrm{pH}$ at the cathode [15]. The reactions taking place at the electrodes are

$2 \mathrm{H}_{2} \mathrm{O}-4 \mathrm{e}^{-}=\mathrm{O}_{2}+4 \mathrm{H}^{+}$(anode)

$2 \mathrm{H}_{2} \mathrm{O}+2 \mathrm{e}^{-}=\mathrm{H}_{2}+2 \mathrm{OH}^{-}$(cathode)

The acidic and basic fronts developed near anode and cathode migrate slowly to the soil and thus change the $\mathrm{pH}$ of soil.

The soil $\mathrm{pH}$ with elapsed time for test 1 and test 2 is shown in Fig. 3. During test 1 , the soil $\mathrm{pH}$ at the anode and at the cathode decreased. The ionic mobility of $\mathrm{H}^{+}$is 1.75 times greater than that of $\mathrm{OH}^{-}$ion [16]. Therefore, the acid front generated at the anode advanced through the soil specimen and thus lowered the $\mathrm{pH}$. This

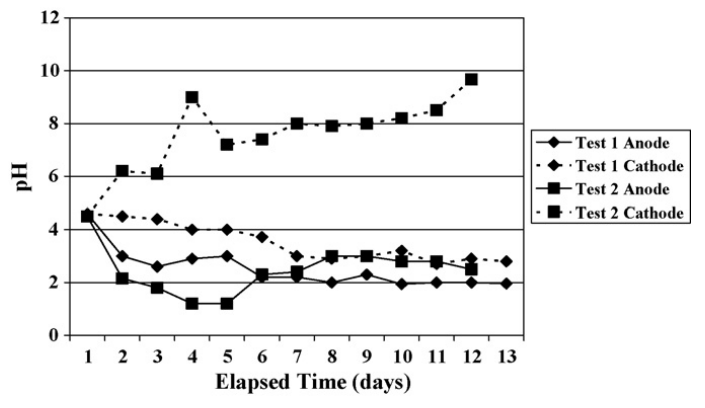

Fig. 3. Soil pH: pH profile of soil for tests 1 and 2.

decrease in the soil $\mathrm{pH}$ in the cathode part was not observed in test 2 . The soil $\mathrm{pH}$ near cathode in test 2 gradually increased and was 9.6 at the end of the test. This is because, in test 2, electrodes were directly immersed into the soil and therefore the alkaline front was developed in the soil itself. Also the precipitation of stable ferrous or ferric hydroxide from ferrous or ferric ions at higher $\mathrm{pH}$ which existed near cathode contributed to the increase in soil $\mathrm{pH}$ near cathode.

$\mathrm{Fe}^{2+}+\mathrm{OH}^{-}=\mathrm{Fe}(\mathrm{OH})_{2}$

$\mathrm{Fe}^{3+}+\mathrm{OH}^{-}=\mathrm{Fe}(\mathrm{OH})_{3}$

\subsection{Current}

The current developed with elapsed time in test 1 and test 2 for a constant applied voltage of $30 \mathrm{~V}$ is shown in Fig. 4. In test 1, current was initially $0 \mathrm{~mA}$ and after 2 days of operation reached a maximum value of $10 \mathrm{~mA}$ which then stabilized and remained constant for the entire period of test. The delay in developing the current might have occurred due to the time taken by ions to migrate into the soil from the electrode chambers. The Fenton's reagent was supplied from the anode chamber and as it reached the soil, the ionic strength of the pore water increased and thus caused current to increase. After a while, with elapsed time, a steady state would have reached which stabilized the current. Whereas in test 2 , at the beginning, current was higher than in test 1 and after 2 days of operation it decreased and then remained nearly constant for the entire period of test. Since the soil in test 2 was soaked in ferrous sulphate before the start of the experiment, initially ferrous ions in solution increased the electrolyte concentration in pore solution. Then the fluctuation

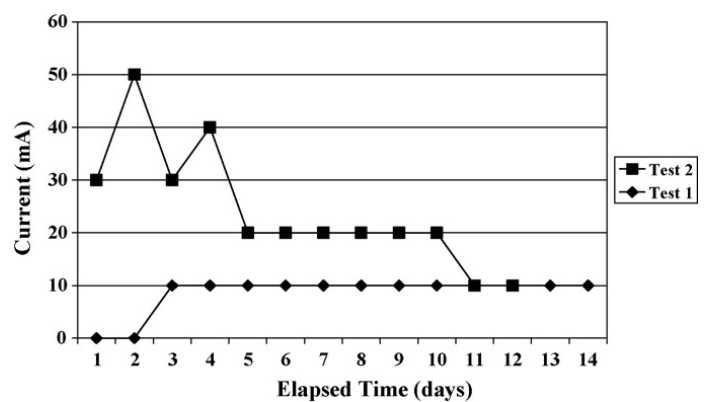

Fig. 4. Current: electric current developed with elapsed time during tests 1 and 2.

Please cite this article in press as: A. Oonnittan, et al., Removal of hexachlorobenzene from soil by electrokinetically enhanced chemical oxidation, J. Hazard. Mater. (2008), doi:10.1016/j.jhazmat.2008.05.132 


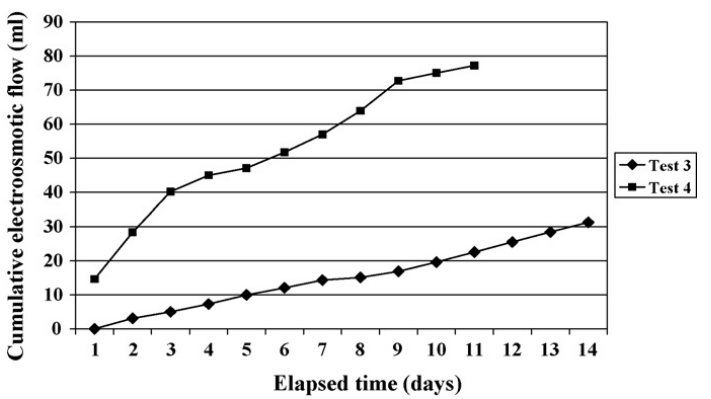

Fig. 5. Electro-osmotic flow: average electro-osmotic flow with elapsed time for tests 1 and 2.

and gradual decrease in current might have occurred due to the generation of $\mathrm{H}^{+}$and $\mathrm{OH}^{-}$ions and the subsequent precipitation of ions in the solution and migration of these ions to the electrodes [17].

\subsection{Electro-osmotic flow}

Contaminant transport is greatly influenced by electro-osmotic flow as increased electro-osmotic flow means better interaction between the soil-contaminant particles and the pore fluid.

Results show that the cumulative average electro-osmotic flow was maximum in test 2 when compared to test 1 (Fig. 5). Electroosmotic flow for all the tests was in the same direction from anode to cathode. Results indicate that electro-osmotic flow had a significant effect on the way in which Fenton's reagent was added to the system. Higher flow in test 2 could be attributed to the higher current developed during the test. A difference in current occurs due to the physico-chemical processes such as electromigration of ionic species and electrolysis reactions which could affect the surface charges of soil and hence the electro-osmotic flow [18]. Studies by Hamed and Bhadra [19] showed that increased current leads to higher electro-osmotic flow which results in decreased processing time.

\subsection{Contaminant removal}

Fig. 6 shows the cumulative contaminant removal during tests 1 and 2. An overall removal efficiency of $64 \%$ was observed for test 1 which lasted for 14 days. The overall removal efficiency for test 2 which lasted for 12 days was $62 \%$. The rate of contaminant removal was higher in test 2 when compared to test

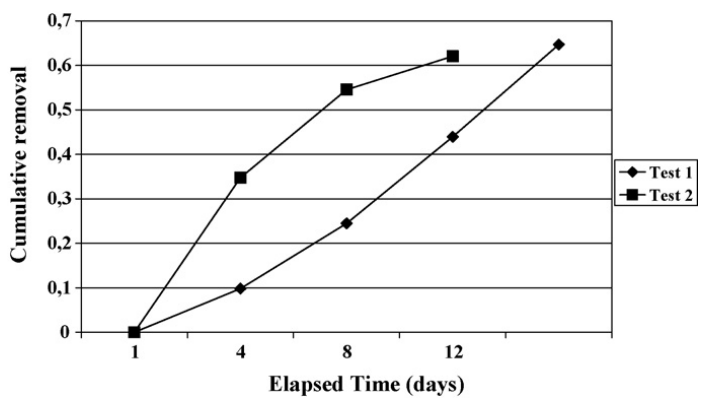

Fig. 6. Contaminant removal: cumulative rate of contaminant removal for tests 1 and 2 .

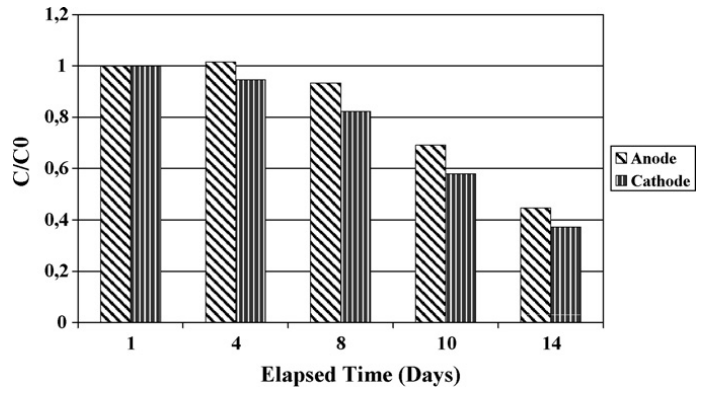

Fig. 7. Contaminant distribution: distribution of HCB in soil with elapsed time during test 1 .

1. This is because of higher electro-osmotic flow that developed in test 2. The increased electro-osmotic flow resulted in better interaction between the soil contaminant particles and the pore fluid which caused faster desorption of $\mathrm{HCB}$ from the soil. There was a steady increase in the removal rate with time, which indicates that further removal is possible with time.

The final average concentration of HCB in soil for both tests is nearly the same. But the degradation of HCB depends also on its position. Figs. 7 and 8 show the distribution of HCB in soil along the anode and cathode portions of soil for test 1 and test 2 , respectively (mass concentration, $C$ divided by initial mass concentration, $C_{0}$ ). Though there was a significant reduction in the contaminant concentration, from the figure it is evident that in test 1, removal was slower in the anode part. $66 \%$ of HCB present initially was removed from the anode portion and $67 \%$ from the cathode portion. A higher removal was observed along the cathode portion. This could be because of the comparatively higher electro-osmotic flow which developed at the cathode portion due to the relatively higher $\mathrm{pH}$ in that region which resulted in better soil-solution contaminant interaction than in the portion near anode.

But in test 2, HCB which accumulated in the cathode part did not undergo significant degradation. This was because of the high $\mathrm{pH}$ developed in the cathode part which was not suitable for the Fenton's reaction to take place. The final concentration of HCB in the anode part in test 2 was 0.141 , which shows that there was $86 \%$ removal in the anode part. This indicates that higher contaminant removal is possible in test 2 if $\mathrm{pH}$ at the cathode could be controlled.

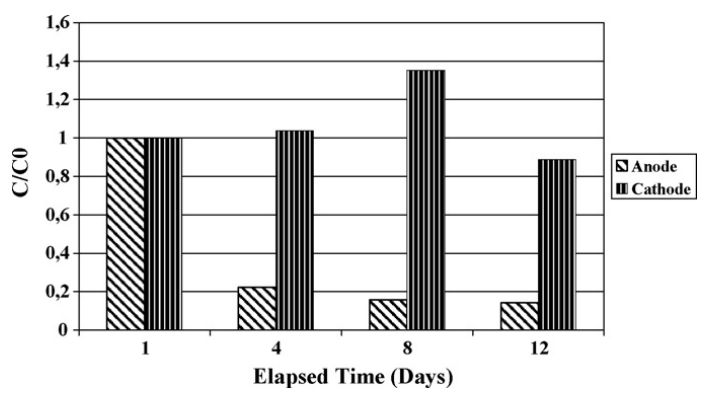

Fig. 8. Contaminant distribution: distribution of HCB in soil with elapsed time during test 2 . 
Table 2

Energy consumption

\begin{tabular}{lllll}
\hline Test & Voltage $(\mathrm{V})$ & Energy consumption $(\mathrm{kWh})$ & Removal efficiency $(\%)$ & Removal efficiency per energy consumption \\
\hline 1 & 30 & 0.0936 & 64 & 683.76 \\
2 & 30 & 0.2232 & 62 & 277.77 \\
\hline
\end{tabular}

\subsection{Energy consumption}

The energy consumption for the tests was calculated [20] and is presented in Table 2. During test 1 which lasted for 14 days, the energy consumed was $0.0936 \mathrm{kWh}$ and that for test 2 which lasted for 12 days was $0.2232 \mathrm{kWh}$. The removal efficiency per energy consumption for test 1 was found to be 2.46 times higher than that in test 2 . The relatively higher energy consumption in test 2 has occurred because of the high current developed during the test. Energy consumption is considered to be one of the major factors for a reasonable choice of remediation methods.

\section{Conclusions}

From the studies carried out, the following can be concluded:

- Enhanced electrokinetic process is a feasible method for treating low permeable soil contaminated with HCB.

- $\beta$-Cyclodextrin was observed to be effective in enhancing the mobility of HCB in the system.

- An overall removal efficiency of $64 \%$ was observed "almost" uniformly across the soil during the electrokinetic Fenton test 1 (electrodes in chamber) which lasted for 14 days.

- An overall removal efficiency of $62 \%$ was observed during electrokinetic Fenton test 2 (electrodes in soil) which lasted for 12 days. But the removal was uneven across the soil due to the high $\mathrm{pH}$ developed at the cathode region. The performance of electrokinetic Fenton test 2 (electrodes in soil) could be improved if the $\mathrm{pH}$ level can be controlled at the cathode region.

\section{Acknowledgements}

The authors would like to thank TEKES and Academy of Finland for financially assisting the project.

\section{References}

[1] R.E. Saicheck, K.R. Reddy, Electrokinetically enhanced remediation of hydrophobic organic compounds in soils: a review, Crit. Rev. Environ. Sci. Technol. 35 (2005) 115-192.
[2] Y.B. Acar, A.N. Alshawabkeh, Principles of electrokinetic remediation, Environ. Sci. Technol. 27 (1993) 2638-2647.

[3] J.-H. Chang, Z Diang, C.-P. Huang Remediation and simulation of selected chlorinated organic solvents in unsaturated soil by a specific enhanced electrokinetics, Colloid Surf. A 287 (2006) 86-93.
tros.

[4] Y.B. Acar, R.J. Gale, A.N. Alshawabkeh, R.E. Marks, S. Puppal, M. Bricka, R. Parker Electrokinetic remediation: basics and technology status, J. Hazard. Mater. 40 (1995) $117-137$.

[5] A.N. Alshawabkeh, Practical aspects of in situ electrokinetic extraction, J. Environ. Eng. 125 (1999) 27-35.

[6] B.W. Tyre, R.J. Watts, G.C. Miller, Treatment of four biorefractory contaminant in soils using catalyzed hydrogen peroxide, J. Environ. Qual. 20 (1991) 832 838.

[7] R.J. Watts, S. Kong, M. Dippre, W.T. Barnes, Oxidation of sorbed hexachlorobenzene in soils using catalysed hydrogen peroxide, J. Hazard. Mater. 39 (1994) $33-47$

[8] S.-S. Kim, J.-H. Kim, S.-J. Han, Application of the electrokinetic Fenton process for the remediation of kaolinite contaminated with phenanthrene, J. Hazard. Mater. B 118 (2005) 121-131.

[9] G.C.C. Yang, Y.-W. Long, Removal and degradation of phenol in a saturated flow by in situ electrokinetic remediation and Fenton-like process, J. Hazard. Mater. B 69 (1999) 259-271.

[10] G.C.C. Yang, C.-Y. Liu, Remediation of TCE contaminated soils by in situ EKFenton process, J. Hazard. Mater. B 85 (2001) 317-331.

[11] J.-H. Kim, S.-J. Han, S.-S. Kim, J.-W. Yang, Effect of soil chemical properties on the remediation of phenanthrene-contaminated soil by electrokinetic Fenton process, Chemosphere 63 (2006) 1667-1676.

[12] L. David, Rowell, Soil Science: Methods and Applications, Longman Scientific \& Technical, Harlow, England, 1994.

[13] ATSDR, Department of health and human services, http://www.atsdr.cdc.gov/toxprofiles.

[14] S. Yuan, M. Tian, X. Lu, Electrokinetic movement of hexachlorobenzene in clayed soils enhanced by Tween 80 and $\beta$-cyclodextrin, J. Hazard. Mater. 137 (2006) $1218-1225$

[15] K. Maturi, K.R. Reddy, Simultaneous removal of organic compounds and heavy metals from soils by electrokinetic remediation with a modified cyclodextrin Chemosphere 63 (2006) 1022-1031.

[16] B. Narasimhan, R. Ranjan, Electrokinetic barrier to prevent subsurface contaminant migration: theoretical model development and validation, J. Contam.

[17] R.E. Saichek, K.R. Reddy, Surfactant-enhanced electrokinetic remediation of polycyclic aromatic hydrocarbons in heterogeneous subsurface environments, Environ. Eng. Sci. 4 (2005) 327-339.

[18] K.R. Reddy, P.R. Ala, S. Sharma, N.S. Kumar, Enhanced electrokinetic remediation of contaminated manufactured gas plant soil, Eng. Geol. 85 (2006) 132-

[19] J.T. Hamed, A. Bhadra, Influence of current density and pH on electrokinetics, J. Hazard. Mater. 55 (1997) 279-294.

[20] J.-Y. Park S-J. Kim Y.J Lee K Baek J-W. Yang EK-Fenton process for removal ( 

PUBL. 3

Anshy Oonnittan, Reena Shrestha, Mika Sillanpää, Effect of Cyclodextrin on the Remediation of Hexachlorobenzene in Soil by Electrokinetic Fenton Process, Separation and purification technology 64 (2009) 314-320.

(C) 2008 Elsevier B.V. All rights reserved.

Reprinted with the permission of Elsevier. 



\title{
Effect of cyclodextrin on the remediation of hexachlorobenzene in soil by electrokinetic Fenton process
}

\author{
Anshy Oonnittan*, Reena A. Shrestha, Mika Sillanpää \\ University of Kuopio, Laboratory of Applied Environmental Chemistry, Patteristonkatu 1, FIN-50101 Mikkeli, Finland
}

\section{A R T I C L E I N F O}

Article history:

Received 13 May 2008

Received in revised form 1 October 2008

Accepted 4 October 2008

Keywords:

Electrokinetics

lectrokinetic Fenton

Cyclodextrin

Hydrogen peroxide

Hexachlorobenzene

\section{Introduction}

The main advantage of using electrokinetics in soil remediation is that it can be applied to fine grained soil. Electrokinetics is now being widely studied for its potential for remediating low permeable soil. As the pore size of soil decreases, its hydraulic permeability decreases and hence other remediation techniques which solely depend on the soil permeability for efficient contact between the contaminant and the reacting media are not suitable for low permeable soils like clay. Values of hydraulic conductivities of sand and clay are $1 \times 10^{-4}$ and $1 \times 10^{-8} \mathrm{~m} / \mathrm{s}$, respectively, whereas, the electrical conductivities of these soil lie within an order of magnitude [1]. Therefore electrokinetics can be applied to heterogeneous layer of soils also.

The mechanism of electrokinetic remediation for the treatment of soil contaminated with organic compounds is that the contaminants sorbed to the soil particles dissolve in the pore fluid and are transported towards the cathode by electroosmosis. The contaminants are thus removed from the soil and accumulated in the cathode chamber. These contaminants collected in the cathode chamber requires further treatment. This sequential treatment of contaminated soil would be more efficient if the contaminants

* Corresponding author. Tel.: +358 445567480; fax: +358 153556513

E-mail addresses: plamthot@uku.fi, anshy_o@yahoo.com (A. Oonnittan).

1383-5866/\$ - see front matter @ 2008 Elsevier B.V. All rights reserved. doi:10.1016/j.seppur.2008.10.021 are removed and at the same time destroyed in the soil without generating a waste stream. This could be achieved by integrating electrokinetics with a suitable chemical oxidation process. Electrokinetics and chemical oxidation when used concurrently simplifies the process and destroys the contaminants in the soil itself. However, during the treatment of organic compounds, the solubility of the compound in the pore water is pivotal for the process to be feasible. Therefore, when treating hydrophobic organic compounds (HOCs) characterized by high $\log K_{\mathrm{OW}}$, suitable enhancing agents which increase their solubility in the pore water should be used.

Cyclodextrins, formed by the degradation of starch by bacteria, are linear chain glucose molecules with their ends joined to form a cyclic structure. They form inclusion complexes with hydrophobic organic compounds by partitioning them to the center of their ring, thus significantly enhancing the aqueous solubility of organic compounds [2]. Major advantages of using cyclodextrins as enhancing agents are their low toxicity and higher degradability [3]. Moreover, cyclodextrins have been proved effective for the mobilization of PAHs and other HOCs in contaminated soil $[4,5]$.

Hydrogen peroxide is a moderately powerful oxidizing agent capable of oxidizing organic contaminants.

Due to the low rates of reaction, oxidation by $\mathrm{H}_{2} \mathrm{O}_{2}$ is not effective for certain refractory contaminants [6].

Catalyzed $\mathrm{H}_{2} \mathrm{O}_{2}$ systems are now being increasingly used and considered as a powerful oxidising agent. This is because of the 
ability of such systems to produce hydroxyl radicals which react with most organic compounds at diffusion controlled rate of $1 \times 10^{10} \mathrm{M}^{-1} \mathrm{~s}^{-1}$ [7]. Commonly used catalysts are transition metals typically iron due to its availability and abundance. The applicability of iron catalyzed $\mathrm{H}_{2} \mathrm{O}_{2}$ as an oxidizing agent was first reported by Fenton [8]. Later on, several works documented the use of iron catalyzed $\mathrm{H}_{2} \mathrm{O}_{2}$ system (Fenton's process) for the oxidation of several organic compounds including recalcitrant contaminants [9-15]. The use of Fenton's process is favored also due to the fact that the reaction products are rather environmentally benign.

The applicability of Fenton's oxidation to fine grained soil by integrating the process with electrokinetics was studied and successfully tested by several researchers [16-20].

The mechanism of hydroxyl radical generation by Fenton's process is shown in Eq. (1).

$$
\mathrm{H}_{2} \mathrm{O}_{2}+\mathrm{Fe}^{2+} \rightarrow \mathrm{OH} *+\mathrm{OH}^{-}+\mathrm{Fe}^{3+}
$$

In the presence of organic substrate the reactions include:

$\mathrm{RH}+\mathrm{OH} * \rightarrow \mathrm{R} *+\mathrm{H}_{2} \mathrm{O}+\mathrm{HO}_{2}$

The hydroxyl radicals are generated in aqueous solutions [6] and are capable of oxidizing the contaminants in aqueous solution. Therefore, during the treatment of sorbed contaminants, the use of enhancing agents bring the contaminants to the desorbed phase and thus make them available for oxidation.

However, it was documented that oxidation of sorbed contaminants in the subsurface can be promoted by using high concentration $\mathrm{H}_{2} \mathrm{O}_{2}(>2 \%)$ [21].

This is because, the use of high concentrations of $\mathrm{H}_{2} \mathrm{O}_{2}$ favors the generation of highly reactive species other than hydroxyl radical like hydroperoxide radicals $\left(\mathrm{HO}_{2}^{*}\right)$, superoxide anions $\left(\mathrm{O}_{2}^{*}{ }^{-}\right)$and hydroperoxide anions $\left(\mathrm{HO}^{*}{ }_{2}^{-}\right)$which are capable of degrading even the most recalcitrant compounds in the sorbed form [22].

$$
\begin{aligned}
& \mathrm{H}_{2} \mathrm{O}_{2}+\mathrm{OH} * \rightarrow \mathrm{H}_{2} \mathrm{O}+\mathrm{HO} *_{2} \\
& \mathrm{HO} *_{2} \rightarrow \mathrm{O} *_{2}+\mathrm{H}^{+} \\
& \mathrm{HO}_{2}+\mathrm{Fe}^{2+} \rightarrow \mathrm{HO}_{2} *^{-}+\mathrm{Fe}^{3+}
\end{aligned}
$$

These studies reveal that sorbed hydrophobic contaminants can be treated without any enhancing agents if high concentration $\mathrm{H}_{2} \mathrm{O}_{2}$ is used. These findings throw light on effective treatment of low permeability soil contaminated with HOCs. Though the use of enhancing agents are highly beneficial, the fate of these agents and their mechanism of action need to be well understood and studied, especially when this technique aims at degrading the pollutants in the system itself.

This study investigates the efficiency of high concentration $\mathrm{H}_{2} \mathrm{O}_{2}$ in remediating soil contaminated with a hydrophobic organic compound by electrokinetic Fenton process. The representative HOC in this study is HCB. Though the commercial manufacture of HCB is banned in most of the countries, it is still being produced as a byproduct in the waste stream during the manufacture of perchloroethylene, carbon tetrachloride, trichloroethylene and other chlorinated hydrocarbons. Moreover, the estimated half life of HCB in soil is around 4 years. Laboratory scale experiments were performed for treating HCB contaminated soil by electrokinetic Fenton process with different concentrations of $\mathrm{H}_{2} \mathrm{O}_{2}$ (5\%, 15\% and 30\%). The effect of an enhancing agent in these system were also studied by conducting the same series of experiments in the presence of an enhancing agent. Cyclodextrin was used as the enhancing agent in this study.
Table 1

Kaolin characteristics.

\begin{tabular}{lc}
\hline Properties & Values \\
\hline Mineralogy & 100 \\
Kaolin & \\
Particle size distribution & 0 \\
$\quad$ Gravel \% & 7 \\
Sand \% & 17 \\
Silt \% & 76 \\
$\quad$ Clay \% & 0.508 \\
Specific gravity & 5.5 \\
Carbonate content \% & 5.2 \\
pH & 189.2 \\
Electrical conductivity $(\mu \mathrm{S})$ & 3 \\
Cation exchange capacity $(\mathrm{mmol} / 100 \mathrm{~g})$ &
\end{tabular}

\section{Materials and methods}

\subsection{Soil and chemicals used}

Kaolin was used as the model soil for all the experiments. Kaolin is the representative low permeable soil used in many laboratory scale experiments. Laboratory grade kaolin was obtained from VWR International (Finland). Physical and chemical properties of kaolin were determined based on the methods prescribed by soil science methods and applications [23] and are shown in Table 1.

HCB was purchased from VWR International (Finland). Physical and chemical properties of HCB are shown in Table 2.

$30 \%$ hydrogen peroxide was supplied by J.T. Baker (Finland) and the required dilutions were made using deionized water.

$\beta$-Cyclodextrin was purchased from Sigma-Aldrich. 1\% (by weight) cyclodextrin solutions were used for all the experiments.

\subsection{Electrokinetic apparatus and test specimen}

The apparatus consisted of a single chamber with dimensions $20 \mathrm{~cm} \times 14 \mathrm{~cm} \times 8 \mathrm{~cm}$ and was made of HDPE. Approximately $500 \mathrm{~g}$ of contaminated kaolin was carefully stacked into the chamber. The moisture content of the kaolin was maintained at around $40 \%$. The graphite electrodes used had a surface area of $32.97 \mathrm{~cm}^{2}$. Electrodes were inserted into the soil at either end of the soil chamber at a distance of about $1.5 \mathrm{~cm}$ from the wall of the chamber.

Contaminated kaolin used as the test specimen was prepared by artificially spiking the kaolin with $\mathrm{HCB}$. For this, $\mathrm{HCB}$ /hexane solution was prepared so as to get a target concentration of $100 \mathrm{mg} / \mathrm{kg}$ in the contaminated soil. It was then added to dry kaolin, mixed well and left in the fume hood till all the hexane evaporated and the soil mass was dry. The dry contaminated soil was thoroughly mixed to get a homogeneous mixture and then brought to the required moisture content. The test specimen was then stacked into the soil chamber and samples were taken from different points to determine the initial $\mathrm{pH}$ and $\mathrm{HCB}$ concentration.

Table 2

Table 2
Physical and chemical properties of $\mathrm{HCB}$

\begin{tabular}{ll}
\hline Property & Value \\
\hline Molecular mass & 284.78 \\
Melting point $\left({ }^{\circ} \mathrm{C}\right)$ & 231 \\
Boiling point $\left({ }^{\circ} \mathrm{C}\right)$ & 325 \\
Vapour pressure $\mathrm{mm} \mathrm{Hg}$ at $20^{\circ} \mathrm{C}$ & $1.09 \times 10^{-5}$ \\
Water solubility $\mathrm{mg} / \mathrm{L}$ at $20^{\circ} \mathrm{C}$ & 0.005815 \\
Log octanol $/$ water partition coefficient & 5.73 \\
Density at $23^{\circ} \mathrm{C}\left(\mathrm{g} / \mathrm{cm}^{3}\right)$ & 2.044 \\
Flash point $\left({ }^{\circ} \mathrm{C}\right)$ & 242 \\
\hline
\end{tabular}




\subsection{Operating conditions}

Experiments were conducted in two series: first series experiments consisted of three tests with different concentrations of $\mathrm{H}_{2} \mathrm{O}_{2}$ in the absence of cyclodextrin. Test 1 with $30 \% \mathrm{H}_{2} \mathrm{O}_{2}$, Test 2 with $15 \%$ $\mathrm{H}_{2} \mathrm{O}_{2}$, and Test 3 with $5 \% \mathrm{H}_{2} \mathrm{O}_{2}$. Second series tests also consisted of three tests with the same different concentrations of $\mathrm{H}_{2} \mathrm{O}_{2}$, but in the presence of cyclodextrin.

For the first series experiments, the test specimen was directly stacked into the soil chamber. Electrodes were then inserted into the soil and connected to the power supply. $\mathrm{H}_{2} \mathrm{O}_{2}$ solutions (30\% for Test $1,15 \%$ for Test 2 and $5 \%$ for Test 3 ) were periodically added from the anode area.

For the second series experiments, the test specimen was homogeneously mixed with cyclodextrin solution before stacking them into the soil chamber. Then, the electrodes inserted into the soil were connected to the power supply and $\mathrm{H}_{2} \mathrm{O}_{2}$ solutions ( $30 \%$ for Test $4,15 \%$ for Test 5 and $5 \%$ for Test 6 ) were periodically added from the anode area.

All the experiments were carried out without adding any Fe to the system. Inherent iron in kaolin was expected to catalyze the $\mathrm{H}_{2} \mathrm{O}_{2}$ during the Fenton's oxidation. An applied voltage of $30 \mathrm{~V}$ was used for all the experiments. Blank tests were also run in order to estimate the contaminant loss by evaporation. All the tests were run for 15 consecutive days.

A sorption test was also carried out to determine the sorption of HCB by the kaolin used for experiments. The details of the sorption experiments are explained in Section 3.1.

\subsection{Chemical analyses}

$\mathrm{pH}$ and redox potential of the soil were measured at the end of the experiment. $\mathrm{pH}$ was measured by using a $\mathrm{pH}$ meter $\mathrm{pH} 730$ inoLab WTW series) and redox potential by redox meter. The final soil mass at the end of the experiment, was divided into each $2 \mathrm{~cm}$ sections for $\mathrm{HCB}$ analysis. $\mathrm{HCB}$ was extracted from the soil sample by ultrasonication based on a method adopted from Yuan et al. [24]. The extract so obtained was analyzed using a gas chromatograph coupled to an inert mass selective detector (Agilent 5975). The column used was HP-5 capillary column $(30 \mathrm{~mm} \times 0.32 \mathrm{~mm}$ i.d.) with a $0.25 \mu \mathrm{m}$ film thickness. Helium at constant flow rate $(25 \mathrm{~cm} / \mathrm{s})$ was used as carrier gas. The oven temperature was programmed from 40 to $270^{\circ} \mathrm{C}$ at $10^{\circ} \mathrm{C} / \mathrm{min}$. The injector temperature used was $250^{\circ} \mathrm{C}$ and the injection volume was $1 \mu \mathrm{L}$. All the analyses were done in duplicate soil samples.

\section{Results and discussions}

\subsection{Sorption of hexachlorobenzene to kaolin}

Adsorption of the contaminant particles and partitioning into soil organic matter may significantly interfere with the contaminant mobility through the soil. The sorption capacity of HCB to the kaolin used was studied by conducting a series of batch experiments. $1 \mathrm{~g}$ kaolin was carefully weighed and taken in glass tubes. $\mathrm{HCB} /$ hexane solutions of varying concentrations from 100 to $800 \mathrm{mg} / \mathrm{L}$ were added to these tubes. The tubes were then tightly closed and subjected to constant shaking for $48 \mathrm{~h}$ at $123 \mathrm{rpm}$ using a mechanical stirrer and then centrifuged at $5000 \mathrm{rpm}$ for $10 \mathrm{~min}$. Finally, the supernatant was collected and analyzed for the contaminant concentration. In the closed system where the sorption experiments were carried out, a vapour phase also existed and therefore HCB will be present in all the three phases at equilibrium and hence the difference between the initial and final concentra-

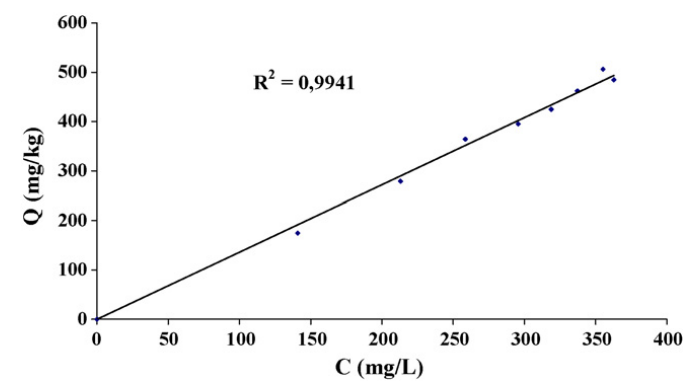

Fig. 1. Fitting of the linear isotherm to the experimental data obtained for the sorption of HCB by kaolin.

tions of the liquid would not give the amount of $\mathrm{HCB}$ sorbed to kaolin. Therefore, the amount of HCB sorbed to kaolin was determined by separately analyzing the kaolin.

The results of the sorption experiments are shown in Fig. 1. Sorption of HCB to kaolin seem to follow a linear equation. The sorption data could be fitted to the following equation:

\section{$Q=1.3599 C$}

where $Q$ is the mass of HCB sorbed per unit mass of kaolin $(\mathrm{mg} / \mathrm{kg})$ and $C$ is the concentration of HCB in solution at equilibrium $(\mathrm{mg} / \mathrm{L})$.

This is in good agreement with the results obtained by Schwarzenbach and Westall [25] and Means et al. [26] who stated that the sorption of nonpolar organic compounds of low to intermediate lipophilicity by aquifer materials and the sorption of other PAHs on different sediment and soil substrates followed linear equilibrium isotherms.

\section{2. pH profile and electroosmotic flow}

Figs. 2 and 3 show the soil $\mathrm{pH}$ profile across the soil section at the end of the experiments. The low $\mathrm{pH}$ developed near the anode and the high $\mathrm{pH}$ developed near the cathode are the typical $\mathrm{pH}$ trends shown during the electrolysis reactions of water. However, the soil $\mathrm{pH}$ in all the cases were found to be acidic (below 7) across the soil section excluding the area in the distance $2-4 \mathrm{~cm}$ from the cathode. This shows that the acidic front advanced faster than the basic front and neutralized the $\mathrm{OH}^{-}$ions migrating towards the anode area. The migration of $\mathrm{H}^{+}$ions is known to be 1.75 times faster than $\mathrm{OH}^{-}$

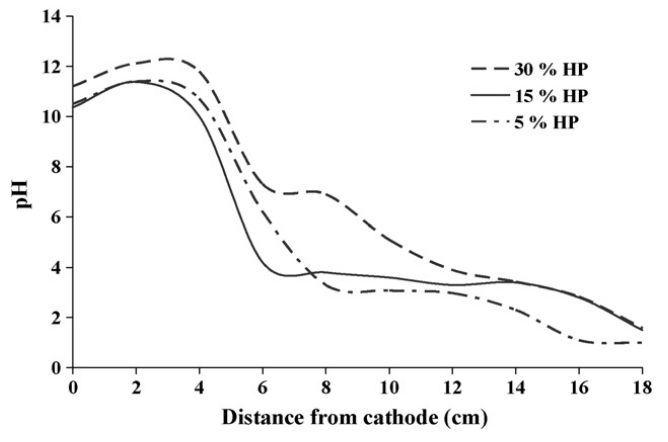

Fig. 2. Soil pH profile at the end of the first series experiments (conducted in the absence of cyclodextrin). (Test 1-30\% $\mathrm{H}_{2} \mathrm{O}_{2}$ (HP), Test 2-15\% $\mathrm{H}_{2} \mathrm{O}_{2}$ (HP), Test 3-5\% $\mathrm{H}_{2} \mathrm{O}_{2}$ (HP)) 


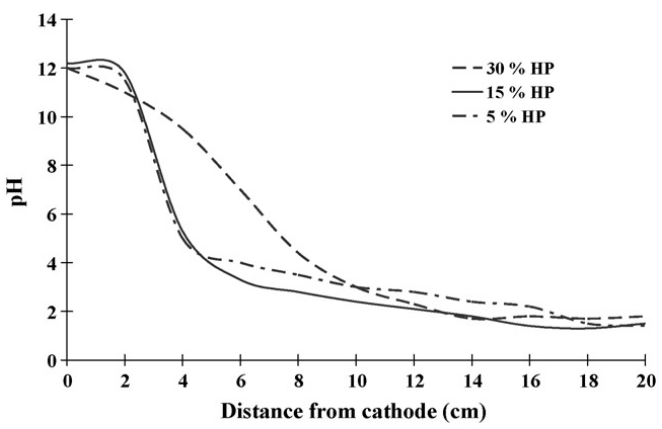

Fig. 3. Soil pH profile at the end of the second series experiments (conducted in the presence of cyclodextrin). (Test $4-30 \% \mathrm{H}_{2} \mathrm{O}_{2}$ (HP), Test $5-15 \% \mathrm{H}_{2} \mathrm{O}_{2}$ HP), Test $6-5 \%$ $\mathrm{H}_{2} \mathrm{O}_{2}(\mathrm{HP})$

ions [27]. During the experiments, the soil $\mathrm{pH}$ near the cathode went up to 12 and in the immediate vicinity of the anode the $\mathrm{pH}$ dropped below 2 .

Measurement of soil pH is important in these studies because, Fenton's reaction depends on the $\mathrm{pH}$ developed during the experiments.

Hydroxyl radical generation by Fenton's process is favored in neutral to acidic $\mathrm{pH}$ range whereas, in alkaline environments $\mathrm{H}_{2} \mathrm{O}_{2}$ decomposes to oxygen and water. Therefore, the soil $\mathrm{pH}$ developed during the experiments were conducive for Fenton's oxidation to take place.

However, extreme acid conditions might reduce the oxidation effectiveness because of the consumption of hydroxyl radicals through the following reaction [28]:

$\mathrm{HO} \bullet+\mathrm{H}^{+}+\mathrm{e}^{-} \rightarrow \mathrm{H}_{2} \mathrm{O}$

The physiochemical properties of soil depend on $\mathrm{pH}$ also. One such property is the zeta potential. Zeta potential decreases linearly with the logarithm of the $\mathrm{pH}$ of the soil medium [29]. According to Helmholtz-Smoluchowski equation, the direction of electroosmotic flow depends on the zeta potential of the soil [30].

However, the measured zeta potential at all the $\mathrm{pH}$ of the soil sample was found to be negative and hence the electroosmotic flow was always from anode to cathode.

\subsection{Redox potential}

The measured redox potential of the soil at the of the experiment is shown in Figs. 4 and 5. The values of redox potential reveal

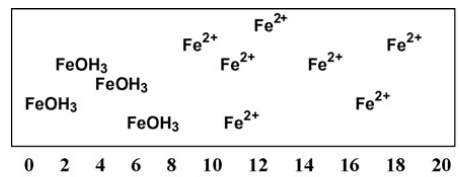

(a) Tests 1 and 4

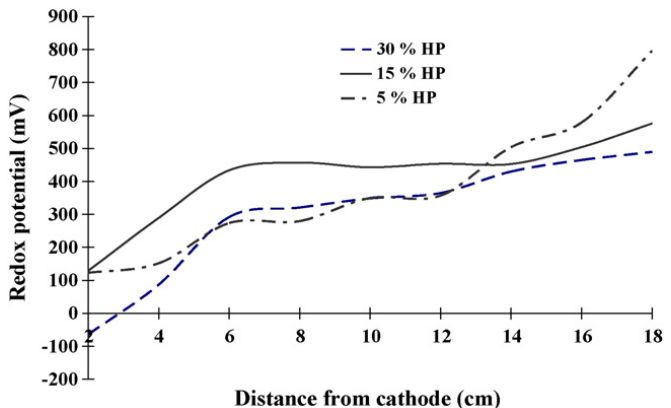

Fig. 4. Redox potential of soil at the end of the first series experiments (conducte in the absence of cyclodextrin). (Test $1-30 \% \mathrm{H}_{2} \mathrm{O}_{2}(\mathrm{HP})$, Test $2-15 \% \mathrm{H}_{2} \mathrm{O}_{2}(\mathrm{HP}$ ). Test $\left.3-5 \% \mathrm{H}_{2} \mathrm{O}_{2}(\mathrm{HP})\right)$.

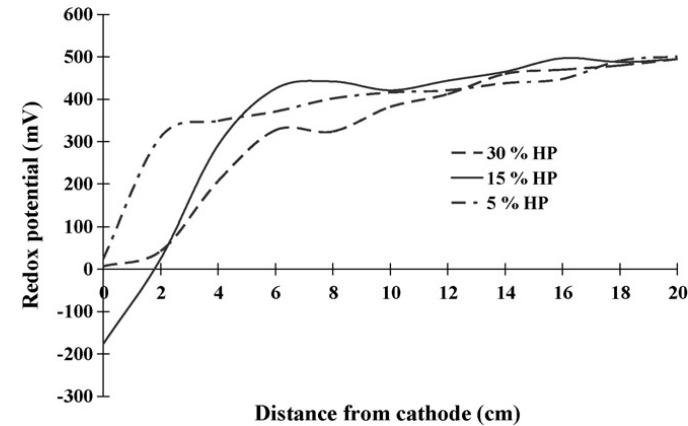

Fig. 5. Redox potential of the soil at the end of the second series experiments (conducted in the presence of cyclodextrin). (Test $4-30 \% \mathrm{H}_{2} \mathrm{O}_{2}$ (HP), Test $5-15 \% \mathrm{H}_{2} \mathrm{O}_{2}$ (HP), Test $6-5 \% \mathrm{H}_{2} \mathrm{O}_{2}(\mathrm{HP})$ )

that highly oxidizing conditions existed in the whole soil specimen except near cathode. The redox potentials did not vary much with different concentrations of $\mathrm{H}_{2} \mathrm{O}_{2}$ during both first series and second series experiments.

For different concentrations of $\mathrm{H}_{2} \mathrm{O}_{2}$ in first and second series experiments, the distribution of different forms of iron was found to be similar, i.e. experiments which used $30 \% \mathrm{H}_{2} \mathrm{O}_{2}$ showed similar distribution of iron forms both in the presence and absence of

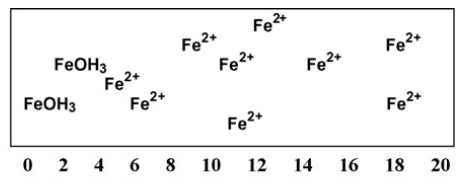

(b) Tests 2 and 5

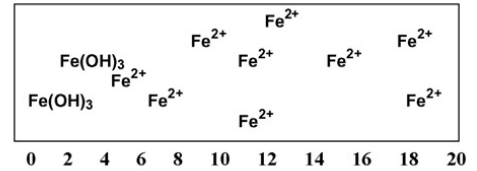

(c) Tests 3 and 6 


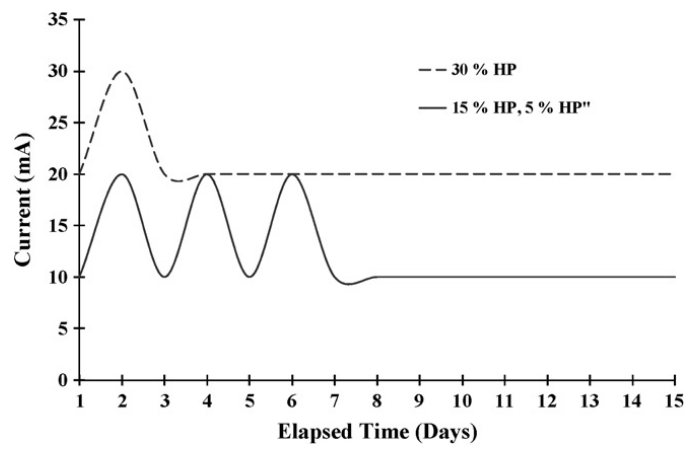

Fig. 7. Current developed with elapsed time during the first series experiments (conducted in the absence of cyclodextrin). (Test $1-30 \% \mathrm{H}_{2} \mathrm{O}_{2}$ (HP), Test $2-15 \% \mathrm{H}_{2} \mathrm{O}_{2}$ (HP), Test $3-5 \% \mathrm{H}_{2} \mathrm{O}_{2}(\mathrm{HP})$ ).

cyclodextrin. The same was observed in experiments with $15 \%$ and $5 \% \mathrm{H}_{2} \mathrm{O}_{2}$.

According to the $\mathrm{pH}-\mathrm{pE}$ speciation diagram, the dominant form of iron was shown to be $\mathrm{Fe}^{2+}$ throughout the soil section in all the experiments (Fig. 6), while near cathode $\mathrm{Fe}(\mathrm{OH})_{3}$ prevailed. This shows that the inherent iron was present as $\mathrm{Fe}^{2+}$ throughout the central and anode area of the system during the experiments. The presence of $\mathrm{Fe}(\mathrm{OH})_{3}$ was also obvious from brownish precipitates that appeared near the cathode area as the experiments progressed in all the systems.

\subsection{Current}

The current during the experiments increased initially and then dropped to a lower value and then remained constant till the end of the experiments (Figs. 7 and 8). This is a general phenomenon developed during electrokinetic tests, because of the dissolution of ionic species present in the soil when electric field is applied. In both first and second series experiments, the initial current developed was higher when $30 \% \mathrm{H}_{2} \mathrm{O}_{2}$ was used. A subsequent periodic increase in the current was observed during the first series experiments with $15 \%$ and $5 \% \mathrm{H}_{2} \mathrm{O}_{2}$. This resulted due to the periodic addition of $\mathrm{H}_{2} \mathrm{O}_{2}$ and deionized water to the system. However, this effect was not so pronounced in other tests. The current seemed to stabilize towards the end of the experiment and this might be because the system attained a steady state after 9-10 days of operation.

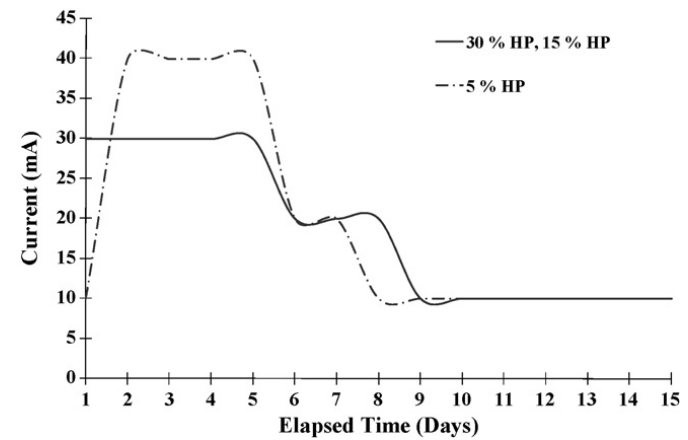

Fig. 8. Current developed with elapsed time during the second series experiments (conducted in the presence of cyclodextrin). (Test $4-30 \% \mathrm{H}_{2} \mathrm{O}_{2}$ (HP), Test $5-15 \% \mathrm{H}_{2} \mathrm{O}_{2}$ (HP), Test 6-5\% $\left.\mathrm{H}_{2} \mathrm{O}_{2}(\mathrm{HP})\right)$.
The maximum current developed was higher in the second series tests. This could be attributed to the presence of cyclodextrin in the system which increased the permeability and hence the migration of ionic species through the soil medium.

\subsection{Oxidation of $\mathrm{HCB}$ in the absence and presence of cyclodextrin}

HCB is a hydrophobic compound with a $\log K_{\mathrm{OW}}$ of 5.32 and hence in soil it exists in a sorbed state. During electrokinetics, the use of cyclodextrins or other enhancing agents is expected to bring about the movement of hydrophobic contaminants via electroosmosis by dissolving the sorbed contaminants in the pore fluid. Therefore, in the absence of enhancing agents, the contaminants remain in the sorbed state and the high concentration hydrogen peroxide used during the experiments create the vigorous conditions required for oxidizing the sorbed $\mathrm{HCB}$.

The distribution of $\mathrm{HCB}$ (as ratio of mass concentration of $\mathrm{HCB}$ in soil $(C)$ to the initial mass concentration of HCB in soil $\left.\left(C_{0}\right)\right)$ in the soil section at the end of the first series experiments is shown in Fig. 9.

In all the experiments (Tests 1-3 with different concentrations of $\mathrm{H}_{2} \mathrm{O}_{2}$ ), the $\mathrm{HCB}$ in the soil section $0-14 \mathrm{~cm}$ from the cathode has undergone significant degradation while, there is an accumulation or presence of undegraded HCB in the anode area $14-18 \mathrm{~cm}$ from the cathode.

One possible reason for this could be the deficiency of iron $\left(\mathrm{Fe}^{2+} / \mathrm{Fe}^{3+}\right)$ in the anode area. Since no iron was added to the system during the experiment, the system used inherent iron in the soil to catalyze the Fenton's reaction. When the electric field was applied, the iron available in the soil started migrating towards the cathode and hence the anode area was deficient of iron. Also, the extremely low $\mathrm{pH}$ developed at the anode $(<2.5)$ was not suitable for Fenton's oxidation to take place.

During Test 1 , when $30 \% \mathrm{H}_{2} \mathrm{O}_{2}$ was used, the average overall contaminant removal was $76 \%$ in the section $0-14 \mathrm{~cm}$ from the cathode, excluding the anode area and $64 \%$ if the entire soil section from cathode to anode is considered. Test 2, where $15 \% \mathrm{H}_{2} \mathrm{O}_{2}$ was used, resulted in an average overall removal of $50 \%$ in a distance $0-14 \mathrm{~cm}$ from the cathode and $33 \%$ in the whole soil section. Likewise, in Test 3, where $5 \% \mathrm{H}_{2} \mathrm{O}_{2}$ was used, the average overall removal in the section $0-14 \mathrm{~cm}$ from the cathode was $59 \%$ and $50 \%$ for the whole soil section.

Therefore, based on the experimental results, high concentration $\mathrm{H}_{2} \mathrm{O}_{2}$ is capable of oxidizing sorbed contaminants in the absence of soluble iron. This is possibly due to the generation of non-hydroxyl radicals at high concentrations of $\mathrm{H}_{2} \mathrm{O}_{2}$.

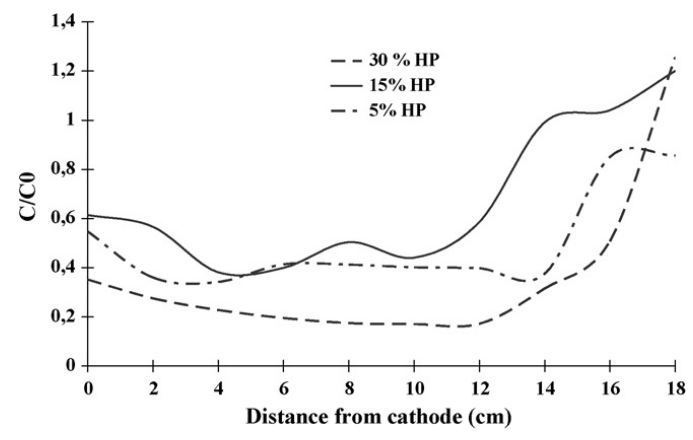

Fig. 9. Distribution of $\mathrm{HCB}$ in soil at the end of the first series experiments (conducted in the absence of cyclodextrin). (Test 1-30\% $\mathrm{H}_{2} \mathrm{O}_{2}$ (HP), Test 2-15\% $\mathrm{H}_{2} \mathrm{O}_{2}$ (HP), Test $3-5 \% \mathrm{H}_{2} \mathrm{O}_{2}(\mathrm{HP})$. 


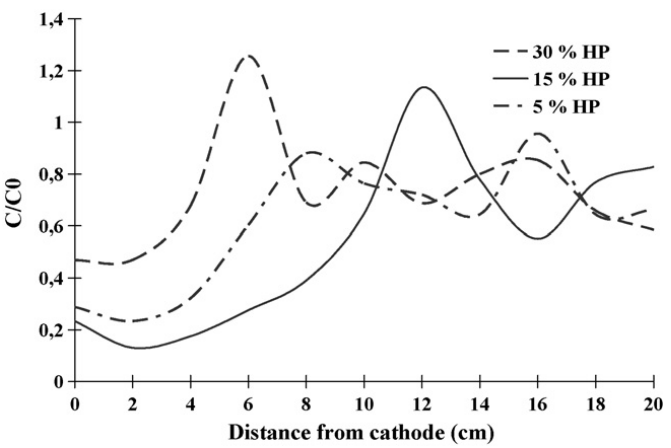

Fig. 10. Distribution of $\mathrm{HCB}$ in soil at the end of the second series experiment (conducted in the presence of cyclodextrin). (Test $4-30 \% \mathrm{H}_{2} \mathrm{O}_{2}$ (HP), Test $5-15 \%$ $\mathrm{H}_{2} \mathrm{O}_{2}(\mathrm{HP})$, Test $6-5 \% \mathrm{H}_{2} \mathrm{O}_{2}(\mathrm{HP})$ ).

Fig. 10 shows the distribution of $\mathrm{HCB}$ at the end of the second series experiments where cyclodextrin was used as enhancing agents.

It was observed that during the experiments, an aqueous phase existed near the cathode till a distance $0-4 \mathrm{~cm}$. In this region, the soil particles acted as colloids and moved toward the opposite direction under the electrophoretic action. This caused the soil to displace away from the cathode. This phenomena was predominant in the region $0-4 \mathrm{~cm}$ from cathode. From 4 to $20 \mathrm{~cm}$ distance, the soil was a compact layer and electroosmosis was the dominant transport mechanism in this region. This explains the accumulation of HCB in the middle region of the soil section. Also, the discontinuity in the flow path caused by the displacement of soil contributed to the accumulation of HCB in the middle part.

Compared to the first series experiments, the second series experiments did not show any apparent contaminant removal from the system. However, unlike the first series experiments, the contaminant particles seemed to move from the anode and there was no accumulation of HCB in the anode area. In these experiments, in the presence of cyclodextrin, HCB existed in the desorbed state and therefore moved towards the cathode with the electroosmotic flow.

Assuming that, when $\mathrm{H}_{2} \mathrm{O}_{2}$ was added to the system, the $\mathrm{HCB}$ particles were present as inclusion complexes with cyclodextrin, the lower rate of oxidation indicates that these inclusion complexes were more stable and resistant to oxidation. The slower rate of oxidation may also be because, a part of the $\mathrm{H}_{2} \mathrm{O}_{2}$ first attacks the organic fraction of the cyclodextrin inclusion complex and then release HCB, which is in an encapsulated state, which is then available for oxidation.

When the contaminants are in desorbed state, the generation of hydroxyl radicals is favored in the aqueous phase and hence the slower rate of oxidation could also be due to the absence of soluble iron to catalyse the Fenton oxidation in the system.

It was also reported that, though high concentration $\mathrm{H}_{2} \mathrm{O}_{2}$ is capable of oxidizing sorbed contaminants, they are ineffective in treating desorbed contaminants because of the quenching reactions particularly the reaction of hydroxyl radicals with $\mathrm{H}_{2} \mathrm{O}_{2}$ (Eq (8)), which is favored by higher $\mathrm{H}_{2} \mathrm{O}_{2}$ concentrations [10].

$\mathrm{OH}^{\bullet}+\mathrm{H}_{2} \mathrm{O}_{2} \rightarrow \mathrm{HO}_{2}^{\bullet}+\mathrm{H}_{2} \mathrm{O}$

Therefore, the slower rate of oxidation during the second series experiments might have occurred due to one or several of the above stated reasons.

\section{Conclusions}

The treatment of sorbed contaminants by Fenton-like processes using high concentrations of hydrogen peroxide catalyzed by inherent iron present in kaolin was investigated. The effect of the presence of cyclodextrin as an enhancing agent in these systems was also looked into. The results of the treatment which lasted for 15 consecutive days showed that the sorbed contaminant were effectively oxidized by high concentration hydrogen peroxide catalyzed by inherent iron present in the soil. Therefore, during electrokinetics hydrophobic compounds sorbed to the soil could be degraded without adding any enhancing agents. This is possible since, in this process the contaminants do not rely on their mobility or solubility in the pore water. However, the absence of enhancing agents and soluble iron in the system resulted in an accumulation of contaminant particles in the anode portion of the system. The same treatment tests conducted in the presence of cyclodextrin as an enhancing agent led to a slower rate of oxidation when compared to the rapid oxidation of contaminants in the absence of cyclodextrin.

\section{Acknowledgement}

The authors would like to thank TEKES for financially assisting the project.

\section{References}

[1] A.N. Alshawabkeh, A.T. Yeung, M.R. Bricka, Practical aspects of in-situ electrokinetic extraction, J. Environ. Eng. (1999) 27-33.

C.T. Jafvert, Surfactants/cosolvents, technology evaluation report, Prepared for Ground-water remediation technologies analysis center, 1996.

E. Fenyvesi, K. Gruiz, S. Verstichel, B. De Wilde, L. Leitgib, K.Csabai, Biodegradation of cyclodextrin in soil, Chemosphere 60 (2005) 1001-1008.

[4] K. Maturi, K.R. Reddy, Simultaneous removal of organic compounds and heavy metals from soils by electrokinetic remediation with a modified cyclodextrin, Chemosphere 63 (2006) 1022-1031.

[5] A. Oonnittan, R.A. Shrestha, M. Sillanpää, Remediation of hexachlorobenzene in soil by enhanced electrokinetic fenton process, J. Environ. Sci. Health. A 43 (8) (2008) 894-900

[6] E. Neyens, J. Baeyens, A review of classic Fenton's peroxidation as an advanced oxidation technique, J. Hazard. Mater. B98 (2003) 33-50

[7] W.R. Haag, C.C. David Yao, Rate constants for reaction of hydroxyl radicals with several drinking water contaminants, Environ. Sci. Technol. 26 (1992) 1005-1013.

[8] H.J.H. Fenton, Oxidation of tartaric acid in presence of iron, J. Chem. Soc. 65 (1894) 899-910

[9] Bryan W. Tyre, Richard J. Watts, Glenn C. Miller, Treatment of four biorefractory contaminants in soils using catalysed hydrogen peroxide, J. Environ. Qual. 20 1991) $832-838$

[10] R.J. Watts, S. Kong, M. Dippre, W.T. Barnes, Oxidation of sorbed hexachlorobenzene in soils using catalysed hydrogen peroxide, J. Hazard. Mater. 39 (1994)

[11] S.-H. Kong, R.J. Watts, J.-H. Choi, Treatment of petroleum-contaminated soils using iron mineral catalysed hydrogen peroxide, Chemosphere 37 (1998) using iron

[12] R.J. Watts, P.C. Stanton, J. Howsawkeng, A.L. Teel, Mineralization of a sorbed polycyclic aromatic hydrocarbon in two soils using catalysed hydrogen peroxpolycyclic aromatic hydrocarbon in two

[13] N. Kang, I. Hua, Enhanced chemical oxidation of aromatic hydrocarbons in soil systems, Chemosphere 61 (2005) 909-922.

[14] S. Jonsson, Y. Persson, S. Frankki, B. van Bavel, S. Lundstedt, P. Haglund, M. Tysklind, Degradation of polycyclic aromatic hydrocarbons (PAHs) in contamited sols by Fenton's reagent. a multivariate evaluation of the importance of soil 96 .

[15] H.N. Quan, A.L. Teel, R.J. Watts, Effect of contaminant hydrophobicity on hydrogen peroxide dosage requirements in the Fenton-like treatment of soils, J. Hazard. Mater. B102 (2003) 277-289.

[16] S.-S. Kim. J-H. Kim, S.-J. Han, Application of the electrokinetic-Fenton process for the remediation of kaolinite contaminated with phenanthrene, J. Hazard. Mater. B 118 (2005) 121-131.

[17] C.C. Yang, Y.-W. Long, Removal and degradation of phenol in a saturated flow by in-situ electrokinetic remediation and Fenton-like process, J. Hazard. Mater B69 (1999) 259-271.

[18] G.C.C. Yang, C.-Y. Liu, Remediation of TCE contaminated soils by in situ EK-Fenton process, J. Hazard. Mater. B85 (2001) 317-331. 
[19] J.-Y. Park, S.-J. Kim, Y.-J. Lee, K. Baek, J.-W. Yang, EK-Fenton process for removal of phenanthrene in a two-dimensional soil system, Eng. Geol. 77 (2005)

$217-224$.
20] J.-H. Kim, S.-J. Han, S.-S. Kim, J.-W. Yang, Effect of soil chemical properties on the remediation of phenanthrene-contaminated soil by electrokinetic-Fenton process, Chemosphere 63 (2006) 1667-1676.

R.J. Watts, P.C. Stanton, Mineralization of sorbed and NAPL-phase hexadecane by catalyzed hydrogen peroxide, Water Res. 33 (1999) 1405-1414

22] E. Ferrarese, G. Andreottola, I.A. Oprea, Remediation of PAH-contaminated sed(2008) 128-139.

D.L. Rowell, Soil Science: Methods and Applications, Longman Scientific \& Tech-

24] S. Yuan, M. Tian, X. Lu, Electrokinetic movement of hexachlorobenzene in clayed soils enhanced by Tween 80 and $\beta$-cyclodextrin, J. Hazard. Mater. 137 (2006) 1218-1225.
[25] R.P. Schwarzenbach, J. Westall, Transport of nonpolar organic compounds from surface water to groundwater. Laboratory sorption studies, Environ. Sci. Technol. 15 (1981) 1360-1367.

26] J.C. Means, S.G. Wood, J.J. Hassett, W.L. Banwart, Sorption of polynuclear aromatic hydrocarbons by sediments and soils, Environ. Sci. Technol. 14(12) (1980) $1524-1528$

27] B. Narasimhan, R. Ranjan, Electrokinetic barrier to prevent subsurface contaminant migration: theoretical model development and validation, J. Contam. Hydrol. $42(2000) 1-17$.

P. Lens, T. Grotenhuis, M. Grzegorz, H. Tabak, Soil and Sediment Remediation,

[29] Y.B. Acar, A.N. Alshawabkeh, Principles of electrokinetic remediation, Environ. Sci. Technol. 27 (1993) 2638-2647.

[30] H.D. Sharma, K.R. Reddy, Geoenvironmental Engineering, John Wiley \& Sons, Inc., New Jersey, 2004 

PUBL. 4

Anshy Oonnittan, Pirjo Isosaari, Mika Sillanpää, Oxidant availability and its effect on HCB removal during Electrokinetic Fenton process, Separation and purification technology, Separation and purification technology 76 (2010) 146-150.

(C) 2010 Elsevier B.V. All rights reserved.

Reprinted with the permission of Elsevier. 



\title{
Oxidant availability in soil and its effect on HCB removal during electrokinetic Fenton process
}

\author{
Anshy Oonnittan ${ }^{\mathrm{a}, *}$, Pirjo Isosaari ${ }^{\mathrm{a}, \mathrm{b}}$, Mika Sillanpääa, ${ }^{\mathrm{a}, \mathrm{c}}$ \\ a Laboratory of Applied Environmental Chemistry, University of Eastern Finland, Patteristonkatu 1, FI-50100 Mikkeli, Finland \\ ${ }^{\mathrm{b}}$ Department of Civil and Environmental Engineering, Aalto University School of Science and Technology, P.O. Box 16200, FI-00076 Aalto, Finland \\ ${ }^{\mathrm{c}}$ Faculty of Technology, Lappeenranta University of Technology, Patteristonkatu 1, FI-50100 Mikkeli, Finland
}

\section{A R T I C L E I N F O}

\section{Article history:}

Received 16 August 2010

Received in revised form

29 September 2010

Accepted 29 September 2010

\section{Keywords:}

Electrokinetics

Electrokinetics

Foil-oxidant interaction

Hexachlorobenzene

HCB

Soil remediation

\section{A B S T R A C T}

Electrokinetic technology in its various forms has already shown its potential as a promising technology for the remediation of organic compounds in soil. Efforts to improve and optimise the process have eventually led to the coupling of electrokinetics with other remediation techniques like chemical oxidation. This paper reports the results of a series of electrokinetic Fenton experiments carried out to investigate the effect of oxidant delivery and availability on contaminant removal and its subsequent impact on the treatment duration. In doing so, we have tried to show that the treatment duration can be considerably reduced by the proper introduction of the oxidants to the soil for a better oxidant availability throughout the soil section. Experiments were conducted at laboratory scale using kaolin spiked with hexachlorobenzene (HCB). Though each experiment resulted in different removal rates, under specific experimental conditions, a maximum of $57 \%$ contaminant removal was obtained. However, the oxidation reactions in these experiments did not show any $\mathrm{pH}$ dependence in the range 2.9-5. A more uniform and better HCB degradation was possible in a shorter duration by the proper introduction of oxidant into the soil.

(c) 2010 Elsevier B.V. All rights reserved.

\section{Introduction}

Coupled technologies are now increasingly being researched due to their potential for achieving better remediation goals and operational performances. Various research groups have established the success of electrokinetic technology for the remediation of low permeable soil contaminated with heavy metals and organic compounds at laboratory level [1-3]. Though, laboratory scale studies have been in progress since nineties, published reports suggest that only few case studies and field performances have been done so far [4]. The growing awareness of the risks, both ecological and to human health, posed by persistent organic pollutants (POPs) in soil has put the research community in a constant search for effective and efficient ways to address the limitations of existing technologies for the remediation of soil. One such approach has led to the integration of electrokinetics with Fenton oxidation for the remediation of POPs in soil [5-7]. Fenton oxidation has proved to be effective for the remediation of soil contaminated with organic

* Corresponding author at: Laboratory of Applied Environmental Chemistry. Patteristonkatu 1 FIN-50100, Mikkeli, Finland. Tel.: +358 445567480; fax: +358 153556513

E-mail addresses: anshy.plamthottathil@uef.fi, anshy_o@yahoo.com (A. Oonnittan).

1383-5866/\$ - see front matter @ 2010 Elsevier B.V. All rights reserved. doi:10.1016/j.seppur.2010.09.034 compounds [8-11]. The attractiveness of this coupled technology is that it addresses one of the major shortcomings of electrokinetic remediation by removing as well as destroying/degrading the contaminants, thus avoiding a further treatment or disposal of the waste stream. Also, Fentons oxidation is capable of oxidising the most recalcitrant organic compounds [12-15]. Electrokinetic Fenton process can be regarded as a relatively clean technology, since it employs a mixture of hydrogen peroxide and ferrous salts to achieve the remediation. Hydrogen peroxide which is environmentally benign is easily available, cheap and used commonly in various applications in environmental engineering $[15,16]$.

The conventional Fenton's reagent comprises of low concentration hydrogen peroxide $\left(\mathrm{H}_{2} \mathrm{O}_{2}\right)$ and ferrous salts. In the presence of an oxidising substance the Fenton's reagent generates hydroxyl radicals at the specified reaction conditions [17]. These hydroxyl radicals are active in aqueous form and hence are unable to attack sorbed contaminants [18]. However, the use of high concentration hydrogen peroxide to oxidise sorbed contaminants is well documented $[9,12]$. This is because the use of high concentrations of $\mathrm{H}_{2} \mathrm{O}_{2}$ that favours the generation of highly reactive species other than hydroxyl radical like hydroperoxide radicals $\left(\mathrm{HO}_{2}^{*}\right)$, superoxide anions $\left(\mathrm{O}_{2}{ }^{*-}\right)$ and hydroperoxide anions $\left(\mathrm{HO}_{2}{ }^{*-}\right)$. The generation of these non hydroxyl radicals in the presence of high concentration hydrogen peroxide leads to aggressive reaction conditions which ultimately destroy the sorbed contaminants $[19,20]$. 
Table 1

Oxidant delivery mode and point of application in different experiments.

\begin{tabular}{|c|c|c|c|c|c|c|c|}
\hline Test & $\begin{array}{l}\text { Voltage } \\
(\mathrm{V} / \mathrm{cm})\end{array}$ & Anolyte & Injection well & Catholyte & Mode of oxidant delivery & $\begin{array}{l}\text { Dimension of the } \\
\text { soil chamber } \\
\text { used }(\mathrm{cm})\end{array}$ & $\begin{array}{l}\text { Duration } \\
\text { (days) }\end{array}$ \\
\hline EK-1 & 1.5 & $\mathrm{H}_{2} \mathrm{O}_{2}$ & Nil & Deionised water & From anode & $20 \times 7.5 \times 12$ & 20 \\
\hline EK-2 & 1.5 & $\mathrm{H}_{2} \mathrm{O}_{2}+\mathrm{FeSO}_{4}$ & Nil & Deionised water & $\begin{array}{l}\text { Serial addition one after } \\
\text { the other from the anode }\end{array}$ & $20 \times 7.5 \times 12$ & 20 \\
\hline EK-3 & 1.5 & $\mathrm{H}_{2} \mathrm{O}_{2}+\mathrm{FeSO}_{4}$ & Nil & Deionised water & $\begin{array}{l}\mathrm{FeSO}_{4} \text { added as the anolyte } \\
\text { and then added } \mathrm{H}_{2} \mathrm{O}_{2} \text { after } \\
\text { five days to the anode }\end{array}$ & $20 \times 7.5 \times 12$ & 15 \\
\hline EK-4 & 1.5 & $\mathrm{H}_{2} \mathrm{O}_{2}+\mathrm{FeSO}_{4}$ & $\begin{array}{l}\text { Two wells at distances } 4-6 \mathrm{~cm} \\
\text { from both the walls, } \\
\text { cylindrical, } 2 \mathrm{~cm} \text { diameter. }\end{array}$ & Deionised water & $\begin{array}{l}\mathrm{FeSO}_{4} \text { added as the anolyte } \\
\text { and then added } \mathrm{H}_{2} \mathrm{O}_{2} \text { after } \\
\text { five days to the anode and } \\
\text { wells }\end{array}$ & $20 \times 7.5 \times 12$ & 15 \\
\hline EK-5 & 2 & $\mathrm{H}_{2} \mathrm{O}_{2}+\mathrm{FeSO}_{4}$ & $\begin{array}{l}\text { One well at the center of the } \\
\text { soil mass, cylindrical, } 2 \mathrm{~cm} \\
\text { diameter. }\end{array}$ & Deionised water & $\begin{array}{l}\mathrm{FeSO}_{4} \text { added as the anolyte } \\
\text { and then added } \mathrm{H}_{2} \mathrm{O}_{2} \text { after } \\
\text { two days to the anode and } \\
\text { well. }\end{array}$ & $15 \times 15 \times 15$ & 10 \\
\hline
\end{tabular}

The success and performance of such in situ processes rely on certain key factors including oxidant selection, oxidant loading and oxidant delivery. Numerous studies have been conducted on the oxidant loading or in other terms the dosing of Fenton's reagent for the oxidation of a variety of soil contaminants like phenanthrene, pyrene and chrysene [20]. On the other hand, little attention has been given on the studies on oxidant delivery method, especially during electrokinetic treatment of soil contaminated with POPs. Oxidant delivery is important since it determines the extent to which the contaminated soil comes into contact with the oxidant Therefore, the oxidant should be delivered to the soil in such a way so as to facilitate effective soil-oxidant interaction. In electrokinetic Fenton process, the oxidant is transported through the soil matrix by electroosmosis. During the course of its transport, the oxidant comes into contact with the soil and attacks the contaminant. Therefore the availability of oxidants in its active form is of paramount importance. Along with other prerequisites, the rate of transport and availability of the oxidant is a deciding factor for the treatment duration required for the contaminated soil.

This paper presents the results of a study carried out to investigate and analyse the effects of soil-oxidant interaction and the mode of oxidant delivery on the treatment performance by electrokinetic Fenton process. Spiked kaolin was subjected to electrokinetic Fenton process at varying operating conditions. The different test conditions included different modes of oxidant delivery and different points of delivery. The results were deciphered by the final contaminant concentrations in soil and other parameters such as soil $\mathrm{pH}$ and redox, current, and cumulative flow.

\section{Materials and methods}

\subsection{Preparation of experiments}

Kaolin obtained from VWR International (BDH Prolabo, bole white washed) was used as the model low permeability soil in all experiments. Main characteristics of this kaolin, as analyzed at our laboratory have been reported earlier [21]. Kaolin represents a typical model soil for electrokinetic experiments due to its physico-chemical characteristics such as low cation exchange and buffering capacities. The representative POP used in this study was HCB and was obtained from Aldrich (99\% purity). Though, the production and use of HCB is banned globally except in few developing countries, its high water-octanol partition coefficient and chemical stability makes it an ideal model contaminant as a persistent hydrophobic contaminant. Other chemicals used in the experiments included hydrogen peroxide (Normapur ${ }^{\circledR} 30 \%$ from BDH Prolabo or Perhydrol ${ }^{\circledR} 30 \%$ from Merck KGaA, both analytical grades) and ferrous sulphate $\left(\mathrm{FeSO}_{4} \cdot 7 \mathrm{H}_{2} \mathrm{O}\right.$, J.T. Baker analytical grade). $\mathrm{FeSO}_{4}$ solution was freshly prepared before use. The required dilutions were made with deionised water (DW).

The test soil was prepared by spiking kaolin with HCB. For that, clean kaolin was mixed with a stock solution of HCB in hexane (Suprasolv ${ }^{\circledR}$ for gas chromatography, from Merck KGaA) to get the desired initial concentration $(100 \mathrm{mg} / \mathrm{kg})$ that was quantified by gas chromatography-mass spectrometry (GC-MS) after spiking. After mixing the HCB solution with kaolin and stirring it homogenously, it was left in the fume hood until all the hexane evaporated and resulted in a dry homogeneous mixture of HCB contaminated kaolin.

Deionised water was added to weighed quantities of spiked kaolin to attain the desired moisture level. The saturated kaolin was then carefully stacked to the soil chamber of the electrokinetic testing apparatus.

The apparatus used for the experiments EK-1 to EK-4 consisted of a single acrylic cell divided into three chambers, a soil chamber with electrode chambers on either side. The dimension of the soil chamber was $20 \times 7.5 \times 12 \mathrm{~cm}$ (length $\times$ width $\times$ height). The apparatus used for EK- 5 also was of the same design but different dimensions of $15 \times 15 \times 15 \mathrm{~cm}$. In some experiments, injection wells $(2 \mathrm{~cm}$ diameter) made of perforated polyvinyl chloride tubes covered with nylon cloth were inserted to the soil chamber. The electrode chambers, filled with an anolyte or catholyte solution, were separated from the soil by nylon cloth. Electrodes made of platinum-coated graphite were immersed in the electrolytes and connected to a direct current (DC) power supply.

\subsection{Operating conditions}

The operating conditions for the experiments are summarized in Table 1. Each experiment differed in either the mode or point of oxidant delivery. The catholyte solution was always deionised water. In EK-1 test without iron addition, $\mathrm{H}_{2} \mathrm{O}_{2}$ in the concentration range $10-12 \%$ was used as the anolyte. In this case, inherent iron in kaolin was expected to catalyse the oxidation reaction. In tests with iron addition, Fe was added as ferrous sulphate solution prepared with a Fe to substrate mass ratio of $1: 10$

The first three experiments, EK-1, EK-2 and EK-3 were carried out in the apparatus without injection wells, and the oxidant (and Fe catalyst) was added from the anode. In EK-4 and EK-5, oxidant was added from the anode as well as one or two injection wells. EK5 was conducted at a higher voltage gradient, the rationale behind which was improved performance in shorter duration. The apparatus used for this experiment was larger, and hence the water volume flushed through the test specimen was also higher. 


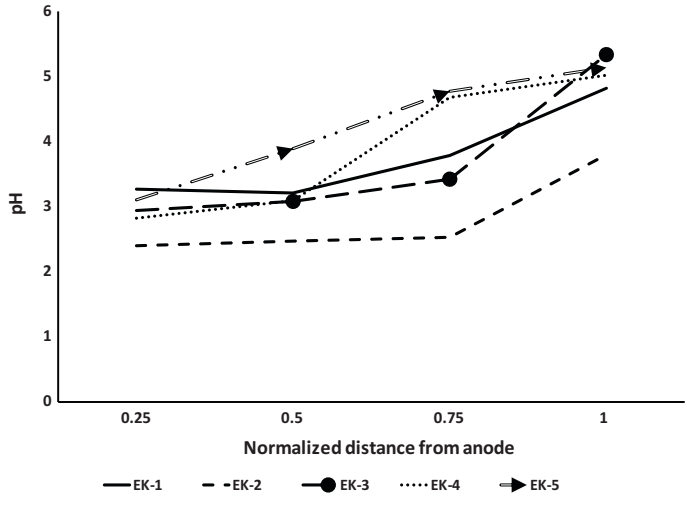

Fig. 1. Soil pH at the end of the experiments.

\subsection{Chemical analyses}

The experiments were subjected to daily monitoring of electrode solution $\mathrm{pH}$, current and cumulative flow. $\mathrm{pH}$ and redox were measured using a portable $\mathrm{pH} /$ conductivity meter WTW 340i equipped with SenTix 61 and SenTix ORP sensors. Cumulative flow was determined by measuring and balancing the additions made to the anolyte and the volume removed from the catholyte each day. At the end of each experiment, the anolyte and catholyte were removed and then the treated kaolin was divided into four equal sections. The $\mathrm{pH}$ and redox of the soil samples were measured in a suspension of the sample in deionised water in the ratio 1:25. After measuring the $\mathrm{pH}$ and redox potential of the soil sections, the soil samples were dried and analysed for HCB. Soil samples were extracted using ultrasonication based on the method followed by Yuan et al. [22]. $5 \mathrm{ml}$ of hexane was added to $1 \mathrm{~g}$ of kaolin, sonicated for $30 \mathrm{~min}$, then centrifuged, and the supernatant was separated for analysis. The extracts were then analysed with a GC-MS according to Method USEPA-8270 C [23]. Quantification was based on a linear curve made with four standard solutions of HCB supplied by Supelco. All the extractions and sample runs were done in duplicate to ensure the reliability of the measurements.

\section{Results and discussion}

\section{1. $p H$ and redox potential}

Fig. 1 shows the soil $\mathrm{pH}$ at the end of the experiments. The initial $\mathrm{pH}$ in kaolin was 5.2. Under applied voltage gradient, the $\mathrm{H}^{+}$ions formed at the anode move at a faster rate, nearly double that of the rate of $\mathrm{OH}^{-}$ions [24]. Therefore the advancement of the acidic front will be faster than the corresponding basic front from the cathode. This holds true in most of the cases unless the soil has a very high buffering capacity which impedes the rate of movement of the acidic front. This could be the reason why the developed $\mathrm{pH}$ in the soil in any case was not basic even near the cathode. In the absence of any enhancement agents or additions to the soil, the $\mathrm{pH}$ development primarily depends on the soil characteristics and the applied voltage.

The soil pH shows a similar trend in tests 1,2 and 3 where there were no oxidant additions to the soil through the injection wells. The $\mathrm{pH}$ shows a stable value till a distance of $15 \mathrm{~cm}$ from the anode from where the $\mathrm{pH}$ steadily increased and reached the maximum near the cathode. Throughout the soil section, the $\mathrm{pH}$ was lowest in EK-2. This was probably due to the longer treatment time but also the rapid oxidation of $\mathrm{Fe}^{2+}$ in the anolyte and subsequent reactions

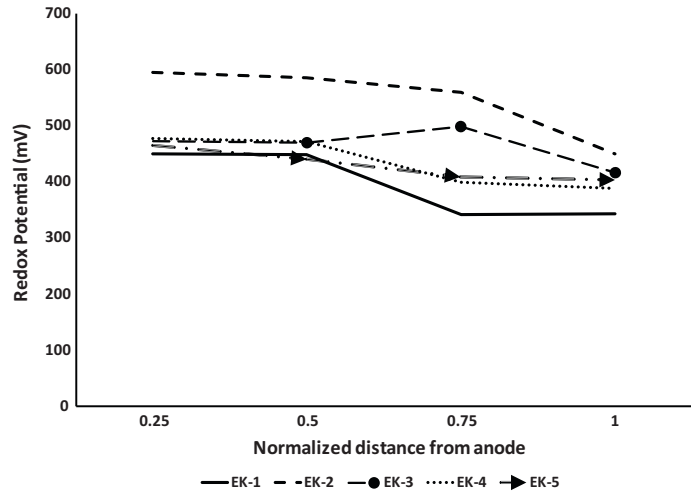

Fig. 2. Redox potential of the soil sections at the end of the experiments.

with excess $\mathrm{H}_{2} \mathrm{O}_{2}$.

$\mathrm{Fe}^{3+}+\mathrm{H}_{2} \mathrm{O}_{2} \rightarrow \mathrm{Fe}^{2+}+\mathrm{OOH} \cdot+\mathrm{H}^{+}$

However, if the added $\mathrm{Fe}^{2+}$ migrates into the soil first and then undergoes oxidation, the reaction might produce $\mathrm{OH}^{-}$instead of $\mathrm{H}^{+}$, resulting in a higher soil $\mathrm{pH}$

$\mathrm{Fe}^{2+}+\mathrm{H}_{2} \mathrm{O}_{2} \rightarrow \mathrm{Fe}^{3+}+\mathrm{OH} \cdot+\mathrm{OH}^{-}$

The developed $\mathrm{pH}$ in the middle sections of EK-4 and EK-5 was higher than in the other experiments. Injection of Fenton's reagent into the wells might has had a diluting effect. In EK-4, oxidant was injected to the soil through the two injection wells placed in the soil matrix. Similarly, the addition of $\mathrm{H}_{2} \mathrm{O}_{2}$ to the soil in EK-5 through the centrally placed injection well would have caused the $\mathrm{pH}$ to rise in the middle section. Therefore, the addition of $\mathrm{H}_{2} \mathrm{O}_{2}$ through the injection wells would have been the major factor which contributed to the rise in soil $\mathrm{pH}$. However, in all the experiments the soil $\mathrm{pH}$ remained below 5.3 .

The redox potential gives a good indication of the overall redox reaction potential of a system; though it does not characterize the capacity of a system for oxidation or reduction [1]. The redox reactions change the speciation and solubility of many elements. The redox values across the soil section indicate that a strong oxidising condition existed throughout the soil section (Fig. 2). The redox values show a good correlation with the corresponding $\mathrm{pH}$ values. However, in EK-1 the redox was lower than what could have been predicted based on $\mathrm{pH}$, which may indicate that the production of oxidizing radicals from $\mathrm{H}_{2} \mathrm{O}_{2}$ was not efficient without added $\mathrm{Fe}$. From the Pourbaix diagram for $\mathrm{Fe}$, it can be depicted that in the $\mathrm{pH}$ range of the soil, $\mathrm{Fe}^{2+}$ was the predominant form in which iron existed [25].

\subsection{Current}

The highest current during each run was observed at the start of the experiment (Fig. 3). This is obviously because of the high initial ionic conductivity of the pore water which eventually depleted resulting in lower current values as the experiment progressed. The presence of $\mathrm{Fe}$ in the system has also contributed to the high initial current in experiments EK-2, 3, 4 and 5. Even in EK-1, which was run without added $\mathrm{Fe}$, a current of $8 \mathrm{~mA}$ (about $0.3 \mathrm{~mA} / \mathrm{cm}^{2}$ ) was developed within few hours after the start of the experiment. However, the high current developed lasted only for four to five days in all the experiments. The current decreased as the soil resistivity increased. Subsequent addition of $\mathrm{H}_{2} \mathrm{O}_{2}$ either to the anode or to 


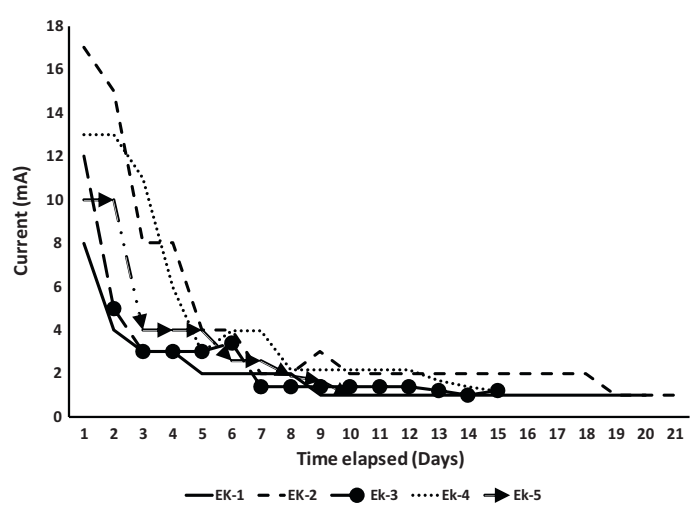

Fig. 3. Current developed during the experiments with elapsed time.

the injection wells did not cause any significant rise in the current values.

\subsection{Cumulative flow and residual contaminant concentration in soil}

The cumulative flow (CF) obtained at the cathode during each experiment is plotted in Fig. 4. In all experiments, the anolyte level either decreased or remained constant during the course of the treatment, which clearly indicated that the electroosmosis was always towards the cathode side. The increase in flow was gradual and attained a stable value which shows that there was little or no significant flow towards the end of the experiments. Similar values of $\mathrm{CF}$ were obtained from experiments EK-1, 3 and 4, whereas, EK-2 resulted in a relatively lower value of CF. This could be due to the operating conditions followed in the experiment where the addition of oxidant as a mixture of $\mathrm{H}_{2} \mathrm{O}_{2}$ and $\mathrm{FeSO}_{4}$ resulted in the generation of iron (hydr) oxides which retarded the electroosmosis and in turn the cumulative flow. No correlation was observed between CF and the developed current in any of the experiments except that the stabilised values of $\mathrm{CF}$ towards the end of the experiment could be related to the constant low current values. However, the exceptionally high CF in EK-5 would have resulted from the increased field strength due to the higher voltage gradient used in the experiment and also from the increased slurry volume. In experiments where oxidant was added to the soil

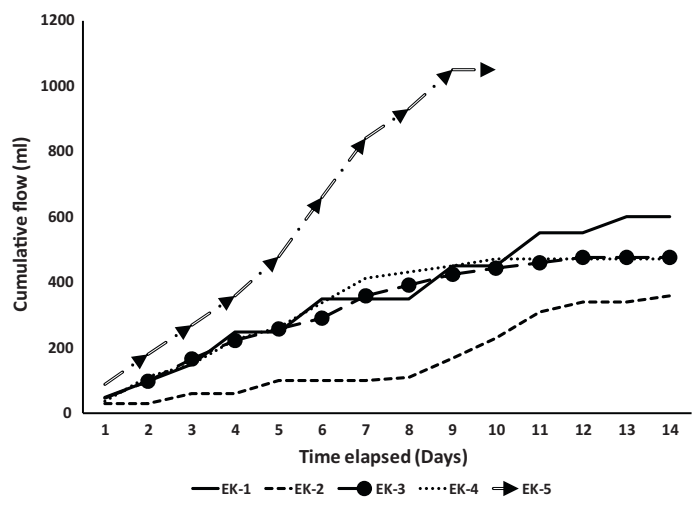

Fig. 4. Cumulative flow obtained at the cathode during the experiments.

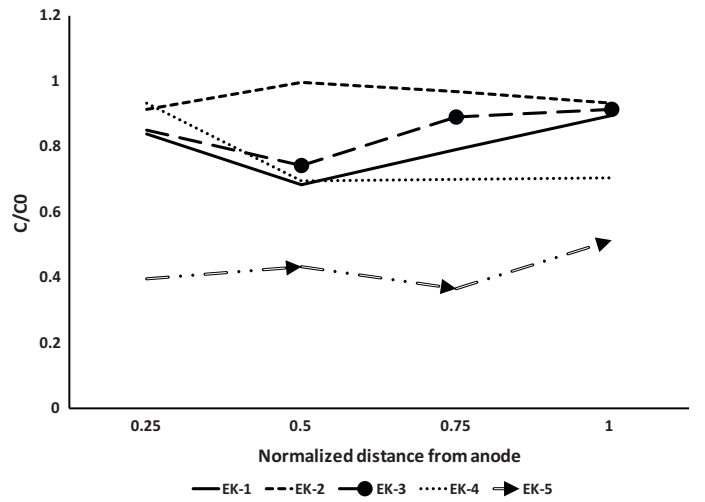

Fig. 5. Distribution of residual $\mathrm{HCB}$ in soil at the end of experiments.

through the injection wells, the oxidant solution had to be transported towards the cathode-like in the other experiments, in orde to be collected from the cathode compartment and included in CF. However, the total flow constituted the flow due to electroosmosis but probably also hydraulic flow contributed by the oxidan addition. In low-permeability clays, electroosmosis usually plays a much more significant role than hydraulic flow. Hence, no difference in CF was observed in EK-3 and EK-4. The coefficient of electroosmotic conductivity based on the average electroosmotic flow was found to range between $8 \times 10^{-6}$ and $2 \times 10^{-5} \mathrm{~cm}^{2} / \mathrm{s} \mathrm{V}$ in these experiments.

Fig. 5 shows the contaminant distribution (expressed as the ratio of final HCB concentration in soil to initial HCB concentration in soil, $C / C_{0}$ ) along the soil sections. In EK-1, the concentration profile shows that some contaminant degradation occurred throughout the soil section. However, the profile indicates that the soil section between $5 \mathrm{~cm}$ and $15 \mathrm{~cm}$ from the anode had undergone better oxidation when compared to the soil near the electrodes. In contrast, the concentration profile in EK-2 shows that the soil section between 5 and $15 \mathrm{~cm}$ had undergone little or no oxidation at all Tests EK-1 and EK-2 were performed under similar operating conditions except for the type of oxidant used in both cases. In EK-1, the oxidant comprised of $\mathrm{H}_{2} \mathrm{O}_{2}$ in concentrations ranging from $8 \%$ to $12 \%$ in the anode chamber, whereas, in EK-2, the oxidant comprised of $\mathrm{H}_{2} \mathrm{O}_{2}$ and $\mathrm{FeSO}_{4}$ added serially one after the other. Therefore, the remediation mechanism in this case can be explained as follows. In EK-1, $\mathrm{H}_{2} \mathrm{O}_{2}$ added to the anode chamber was transported through the soil matrix with the electroosmosis, where it came into contact with the oxidising material, in this case $\mathrm{HCB}$, in the presence of inherent $\mathrm{Fe}$ in the soil. Contaminant oxidation occurred in all regions where the conditions were suitable for Fenton-like oxidation. The increased rate of oxidation in the anode and middle part of the soil section indicates that oxidising conditions were more prevalent in these parts. The term oxidising conditions in this case implies the presence/availability of oxidants at the optimum reaction conditions. The scenario, however, was quite different in EK-2. Since, $\mathrm{FeSO}_{4}$ was added to $\mathrm{H}_{2} \mathrm{O}_{2}$ in the absence of $\mathrm{HCB}$ or other oxidising material, a part of $\mathrm{H}_{2} \mathrm{O}_{2}$ was lost by oxidation of the free $\mathrm{Fe}^{2+}$ to ferric oxides/hydroxides immediately in the anode chamber. This would have led to a shortage of $\mathrm{H}_{2} \mathrm{O}_{2}$ or reduced availability of the oxidant to the soil.

Again, EK-3 shows a more or less similar trend in the concentration profile as in EK-1. Though, the oxidant in this case comprised of $\mathrm{H}_{2} \mathrm{O}_{2}$ and $\mathrm{FeSO}_{4}$, the mode of addition of the oxidant was different from what was followed in EK-2. Here, ferrous sulphate was flushed through the soil matrix five days before adding $\mathrm{H}_{2} \mathrm{O}_{2}$ to the 
anode chamber. This ensured that at any time, $\mathrm{H}_{2} \mathrm{O}_{2}$ comes into contact with Fe only in the presence of oxidising material, which would have resulted in the degradation of HCB present in the soil. There was hardly any difference in contaminant removal in EK-1 and EK-3, especially considering the longer treatment time in EK-1 (or, EK-3 was even more efficient), showing that addition of Fe did not result in significant enhancement of the process. It was reported by Reddy and Chandhuri [7] that the preflushing of ferrous iron had no added benefits in the Fenton-like reactions performed to oxidise PAHs.

EK-4 was conducted under similar conditions as in EK-3, except for the mode of delivery of the oxidant. Here, the oxidant was added to the anode chamber as well as to the injection wells which were placed in the soil matrix. The test resulted in an average overall contaminant removal of $24 \%$. There had been significant oxidation the middle section but also near the cathode, which was different from EK-1 and EK-3. In EK-4, since there was $\mathrm{H}_{2} \mathrm{O}_{2}$ addition from both the anode and injection wells, the oxidant availability was higher for the soil adjacent to the wells and cathode. Therefore, the increased rate of oxidation could be attributed to the increased availability of the oxidant. The oxidation rate did not however, show any $\mathrm{pH}$ dependence. The optimum $\mathrm{pH}$ for Fenton oxidation is around 3 , and the rate of $\mathrm{H}_{2} \mathrm{O}_{2}$ decomposition increases with increasing $\mathrm{pH}$ $[14,26]$. In this study, increase in $\mathrm{pH}$ to 5 near the cathode did not impair HCB oxidation.

In EK-5, HCB removal efficiency was high throughout the soil section, with only minor loss of efficiency as the distance from the injection points (anode and injection well in the middle, $7.5 \mathrm{~cm}$ from the anode) increased, which was probably due to the limited transportation or loss in reactivity of $\mathrm{H}_{2} \mathrm{O}_{2}$. The exceptionally high cumulative flow rate observed in EK-5 might have contributed to the higher degree of oxidation of the contaminant by bringing about better contact between the oxidant and HCB.

Another important observation from the concentration profiles was the low HCB oxidation near the anode region. One reason for the low HCB degradation in the region near the anode in experiments EK-1, 3, and 4 could be the depletion of ferrous ions in this region as the experiment proceeded. Under the operating conditions followed in EK-3 and 4, $\mathrm{H}_{2} \mathrm{O}_{2}$ was added to the system 5 days post Fe addition to the system. This was to ensure the presence of Fe throughout the soil specimen before adding $\mathrm{H}_{2} \mathrm{O}_{2}$ to the system. Nevertheless, it seems that, this kind of time interval between the addition of $\mathrm{Fe}$ and $\mathrm{H}_{2} \mathrm{O}_{2}$ would result in the depletion of $\mathrm{Fe}$ ions near the anode part. This reasoning can be further reinforced from the data obtained from EK-5, where significant oxidation had occurred near the anode region also. The two days time interval for the stepwise addition of $\mathrm{Fe}$ and $\mathrm{H}_{2} \mathrm{O}_{2}$ (at $2 \mathrm{~V} / \mathrm{cm}$ ) appears to be sufficient to ensure the presence of $\mathrm{Fe}$ in the soil upon the oxidant addition.

It is also noteworthy, when compared with the removal rate obtained in EK-5 that the oxidant injection from two injection wells in EK-4 did not result in higher removal rate even with longer treatment duration. This emphasizes the proper selection of injection points for the oxidant. The decomposition rate of $\mathrm{H}_{2} \mathrm{O}_{2}$ is shown to increase with increasing $\mathrm{pH}$ [14]. Therefore, it should be deduced that the injection of $\mathrm{H}_{2} \mathrm{O}_{2}$ from the second well near the cathode did not improve the performance of the oxidation reactions.

\section{Conclusion}

The results of the experiments clearly indicate the importance of efficient oxidant delivery methodologies for effective contaminant oxidation to occur. The success of in situ electrokinetic oxidation processes depend on how well the contact between the contaminant and the oxidant is facilitated under optimised reaction conditions. However, this should not result in the over-estimation of the oxidant requirements by using multiple oxidant injection points. Though HCB oxidation in the presence of high concentration $\mathrm{H}_{2} \mathrm{O}_{2}$ in these experiments did not show any $\mathrm{pH}$ dependence in the range 2.9-5, the stability of $\mathrm{H}_{2} \mathrm{O}_{2}$ is known to decrease with increasing $\mathrm{pH}$. Therefore injecting $\mathrm{H}_{2} \mathrm{O}_{2}$ near the cathode might not give the desired results. It could also be deducted from the results that simultaneous addition of ferrous solution and $\mathrm{H}_{2} \mathrm{O}_{2}$ in the absence of oxidising material (contaminant) is not recommended especially if duration of the treatment is of primary concern.

\section{Acknowledgements}

This study was funded by EU, City of Mikkeli and the Academy of Finland, decision 114259 .

\section{References}

[1] Y.B. Acar, R.J. Gale, A.N. Alshawabkeh, R.E. Marks, S. Puppala, M. Bricka, R. Parker Electrokinetic remediation: basics and technology status, J. Hazard. Mater. 40 (1995) 117-137.

[2] K.R. Reddy, A.B. Shirani, Electrokinetic remediation of metal contaminated glacial tills, Geotech. Geol. Eng. 15 (1997) 3-29.

[3] J. Virkutyte, M. Sillanpää, P. Latostenmaa, Electrokinetic soil remediation-a critical overview, Sci. Tot. Environ. 289 (2002) 97-121.

[4] K.R. Reddy, C. Cameselle, Electrochemical Remediation Technologies for Polluted Soils, Sediments and Groundwater, Wiley Publishers, 2009, pp. 87-88.

[5] G.C.C. Yang, Y.-W. Long, Removal and degradation of phenol in a saturated flow by in situ electrokinetic remediation and Fenton-like process, J. Hazard. Mater. B69 (1999) 259-271.

[6] P. Isosaari, R. Piskonen, P. Ojala, S. Voipio, K. Eilola, E. Lehmus, M. Itävaara Integration of electrokinetics and chemical oxidation for the remediation of creosote-contaminated clay, J. Hazard. Mater. 144 (2007) 538-548.

[7] K.R. Reddy, K.S. Chandhuri, Fenton-like oxidation of PAHs in clayey soils using electrokinetics, Geotech. Geol. Eng. 135 (2009) 1429-1439.

[8] B.W. Tyre, R.J. Watts, G.C. Miller, Treatment of four biorefractory contaminants in soils using catalysed hydrogen peroxide, J. Environ. Qual. 20 (1991) 832838.

[9] R.J. Watts, S. Kong, M. Dippre, W.T. Barnes, Oxidation of sorbed hexachlorobenzene in soils using catalysed hydrogen peroxide, J. Hazard. Mater. 39 (1994) $33-47$.

[10] S.-H. Kong, R.J. Watts, J--H. Choi, Treatment of petroleum-contaminated soils using iron mineral catalysed hydrogen peroxide, Chemosphere 37 (1998)

[11] N. Kang, I. Hua, Enhanced chemical oxidation of aromatic hydrocarbons in soil systems, Chemosphere 61 (2005) 909-922.

R.J. Watts, P.C. Stanton, Mineralization of sorbed and NAPL-phase hexadecane by catalyzed hydrogen peroxide, Water Res. 33 (1999) 1405-1414.

[13] J.J. Pignatello, K. Baehr, Ferric complexes as catalysts for fenton degradation of 94) $365-370$.

[14] KakarlaF K.C.P., J.R. Watts, Depth of Fenton-like oxidation in remediation of surface soil, J. Environ. Eng. (1997) 11-17.

[15] K. Pirkanniemi, S. Metsärinne, M. Sillanpää, Degradation of EDTA and novel complexing agents in pulp and paper mill process and waste waters by Fenton's complexing agents in pulp and paper mill process
reagent, J. Hazard. Mater. 147 (2007) 556-561.

[16] K. Pirkanniemi, M. Sillanpää, Heterogeneous water phase catalysis as an environmental application: a review, Chemosphere 48 (2002) 1047-1060.

[17] W.R. Haag, C.C.D. Yao, Rate constants for reaction of hydroxyl radicals with several drinking water contaminants, Environ. Sci. Technol. 26 (1992) 1005-1013. E. Neyens, J. Baeyens, A review of classic Fenton's peroxic
oxidation technique, J. Hazard. Mater. B98 (2003) 33-50.

19] E. Ferrarese, G. Andreottola, I.A. Oprea, Remediation of PAH-contaminated sediments by chemical oxidation, J. Hazard. Mater. 152 (2008) 128-139.

20] F.J. Rivas, Polycyclic aromatic hydrocarbons sorbed on soils: A short review of chemical oxidation based treatments, J. Hazard. Mater. B138 (2006) 234-251.

21] A. Oonnittan, R.A. Shrestha, M. Sillanpää, Removal of hexachlorobenzene from soil by electrokinetically enhanced chemical oxidation, J. Hazard. Mater. 162 (2009) 989-993.

[22] S. Yuan, M. Tian, X. Lu, Electrokinetic movement of hexachlorobenzene in clayed soils enhanced by Tween 80 and cyclodextrin, J. Hazard. Mater. 137 (2006) $1218-1225$

[23] USEPA, Test Methods for Evaluating Solid Wastes, SW 846, 3rd ed. Office of Soil Waste, Washington, DC.

[24] B. Narasimhan, R. Ranjan, Electrokinetic barrier to prevent subsurface contaminant migration: theoretical model development and validation, J. Contam. Hydrol. 42 (2000) 1-17.

[25] B.J. Wiersma, Hydrogen generation during the corrosion of carbon steel in oxalic acid, savannah river national laboratory, Strat. Mater. Technol. Department (2004).

[26] M. Pazos, E. Rosales, T. Alcántara, J. Gómez, M.A. Sanromán, Decontamination of soils containing PAHs by electroremediation: a review, J. Hazard. Mater. 177 (2010) 1-11. 

PUBL. 5

Anshy Oonnittan, Pirjo Isosaari, Mika Sillanpää, Effect of polarity reversal on HCB removal during Electrokinetic Fenton process, submitted. 



\title{
Effect of polarity reversal on HCB removal during Electrokinetic Fenton process
}

\author{
Anshy Oonnittan $^{\mathrm{a}^{*}}$, Pirjo Isosaari $^{\mathrm{a}, \mathrm{b}}$ and Mika Sillanpää ${ }^{\mathrm{a}, \mathrm{c}}$ \\ ${ }^{a}$ Laboratory of Applied Environmental Chemistry, University of Eastern Finland, Patteristonkatu \\ 1, FI-50100 Mikkeli, Finland. \\ ${ }^{\mathrm{b}}$ Department of Civil and Environmental Engineering, Aalto University School of Science and \\ Technology, P.O. Box 16200, FI-00076 Aalto, Finland. \\ ${ }^{\mathrm{c}}$ Faculty of Technology, Lappeenranta University of Technology, Patteristonkatu 1, FI-50100 \\ Mikkeli, Finland
}

* Address correspondence to Anshy Oonnittan, Laboratory of Applied Environmental Chemistry,
Patteristonkatu 1 FIN-50101, Mikkeli, Finland. Tel.: +358445567480; fax: +358153556513; E-
mail: anshy.plamthottathil@uef.fi Abstract

Experimental evidences show that electrokinetic Fenton process is very effective for the cleanup of soil contaminated with organic compounds, especially hydrophobic and persistent organic pollutants. Despite the technological progresses in recent years, there are still several performance related issues to be addressed, such as its implication on the final soil quality and different oxidant delivery schemes. This paper reports the results of a series of experiments carried out to explore the possibilities of using polarity reversal as an enhancement during electrokinetic Fenton treatment of soil contaminated with persistent organic pollutants. Laboratory scale experiments were conducted with kaolin and Hexachlorobenzene (HCB) as the model soil and contaminant. Experiments were performed both with and without added iron (Fe). 
Reversing the polarity of electrodes after a period of time during the experiments was found to be effective in aiding the reachability of the oxidant to the soil specimen in a shorter duration. An overall $\mathrm{HCB}$ removal of $10 \%$ in 10 days was increased to $33 \%$ with one polarity reversal during the treatment. However, its use with different oxidant delivery methods is to be considered carefully, since it was observed that the addition of hydrogen peroxide $\left(\mathrm{H}_{2} \mathrm{O}_{2}\right)$ from the anode chamber was crucial for HCB degradation to occur.

\section{Keywords:}

Electrokinetics, Hexachlorobenzene, Polarity reversal, Fenton oxidation, Soil remediation.

\section{Introduction}

Remediation of soil contaminated with hydrophobic organic compounds has always been a high priority issue, especially due to its impact on human health and environment. Widely practiced conventional techniques which depend on the hydraulic permeability of soil are not applicable for treating low permeable soil such as clay. Electrokinetic technology has specifically been targeted to treat low permeable soil and has shown success, though mostly at laboratory scale [1]. Degradation of organic contaminants can be achieved by suitably coupling electrokinetics with a chemical oxidation process. Remediation of sorbed organic compounds, especially polycyclic aromatic hydrocarbons (PAHs) has been extensively studied [2]. Studies on remediation of soil polluted with organochlorine pesticides (OCPs) like HCB by electrokinetic oxidation treatment are limited. Lab scale tests performed by Pham et al and others demonstrated that PAHs and OCPs exhibit different behavior when subjected to oxidation by ultrasonication coupled with 
electrokinetics $[3,4]$. The extremely stable nature of its chemical composition makes OCPs such as HCB difficult to undergo oxidation. This calls for the application of more aggressive and intense chemical oxidation reactions for the degradation of such recalcitrant organic contaminants. In this regard, electrokinetic treatment using high concentration $\mathrm{H}_{2} \mathrm{O}_{2}$ has shown some promise $[5,6]$. Several early studies have reported the use of high concentration $\mathrm{H}_{2} \mathrm{O}_{2}$ for the degradation of hydrophobic organic contaminants sorbed to soil [7, 8]. The Fenton like reactions that are known to occur when using high concentration $\mathrm{H}_{2} \mathrm{O}_{2}$ can effectively oxidize refractory organic compounds like HCB which are sorbed to soil $[9,10,11]$.

Though, the application of Fenton oxidation in association with electrokinetics for the removal and destruction of soluble organic compounds such as trichloroethylene and phenol was reported from late 1990s, the feasibility of Electrokinetic Fenton like oxidations using high concentration $\mathrm{H}_{2} \mathrm{O}_{2}$ for the treatment of soil contaminated with relatively insoluble PAHs at laboratory scale were reported only from the year $2005[12,13,14]$.The outcome of these studies gave mixed results as each studies followed different process and reaction conditions. It was pointed out by Isosaari et al [15] that higher oxidation rates were observed near the oxidation injection points in their experiments. This emphasizes the importance of oxidant delivery during these processes. Nevertheless, as mentioned above, studies on OCP degradation using this technology is limited and cannot be correlated with PAH degradation.

However, the environmental impacts of Fenton treatment as discussed by Yap et al [16] can be a major bottle neck for its application for soil treatment. Electrokinetically treated soils in most cases result in an acidic soil which is especially true in case of low buffering soil. Since, metal dissolution increases with decreasing $\mathrm{pH}$ and also due to the unavailability of plant nutrients at low $\mathrm{pH}$, the final $\mathrm{pH}$ of the treated soil can be a limiting factor for its subsequent use [17]. 
Therefore, it is important to restore the soil properties in the post treated soil in order to sustain the microbial activities and soil vegetation.

During electrokinetic treatment, the oxidant moves with the electroosmotic flow through the soil section. The direction of electroosmotic flow can be controlled by suitably changing the electrode polarity. The use of non uniform electrokinetics by reversing the electrode polarity has been studied in conjunction with other techniques like bioremediation to enhance the process as well as to maintain the $\mathrm{pH}$ of the soil. [18] Also, it was found that non-uniform electrokinetic transport processes induced by periodic reversal of electrode polarity improve the mobility of organic pollutants like phenol and dichlorophenol. [19] However, the applicability of polarity reversal for the control of oxidant delivery and to avoid a steep $\mathrm{pH}$ gradient in the resulting soil during electrokinetic Fenton process has not been studied so far.

The aim of this study is to study the applicability of polarity reversal for the control of oxidant delivery and also to avoid a steep $\mathrm{pH}$ gradient in the final soil. It was hypothesized that such a polarity reversal would be beneficial since it can enhance the process by propagating the oxidant through the soil matrix in a better way and also result in a more uniform $\mathrm{pH}$ throughout the soil section. Electrokinetic experiments were carried out by changing the polarity of electrodes towards the end of the experiment. The overall performance was evaluated in terms of HCB degradation and by following other parameters like soil $\mathrm{pH}$ and catholyte accumulation.

\section{Materials and Method}

\subsection{Preparation of the experiments}


The soil used for the experiments was Kaolin obtained from VWR International (BDH Prolabo, bole white washed), which is a typical laboratory model for low permeability soil. The major physical and chemical characteristics of the model kaolin used have been published in our earlier publication [20]. The representative POP, selected for the study was Hexachlorobenzene (Aldrich (99\% purity)), one of the most hydrophobic persistent organic contaminants.

Other chemicals used in the experiments included $\mathrm{H}_{2} \mathrm{O}_{2}$ (Normapur ${ }^{\circledR} 30 \%$ from BDH Prolabo or Perhydrol ${ }^{\circledR} 30 \%$ from Merck KGaA, both analytical grades) and ferrous sulphate $\left(\mathrm{FeSO}_{4} \mathrm{X}\right.$ $7 \mathrm{H}_{2} \mathrm{O}$, J. T Baker, analytical grade). $\mathrm{FeSO}_{4}$ solution was freshly prepared before use. The required dilutions were made with deionised water (DW).

For the preparation of the test specimen, weighed quantities of kaolin were mixed with $\mathrm{HCB}$ stock solution prepared in Hexane to achieve the target concentration $(100 \mathrm{mg} / \mathrm{kg})$. After homogeneously mixing the soil, it was kept aside until all the hexane evaporated and the soil was dried completely. The spiked soil was then adjusted to the desired moisture level and then carefully stacked to the soil compartment of the electrokinetic cell.

The apparatus used for all the experiments was of same design and dimension and consisted of a single acrylic cell divided into three chambers, a soil chamber with electrode chambers on either side. The dimension of the soil chamber was $15 \times 15 \times 15 \mathrm{~cm}$. In some experiments, injection wells ( $2 \mathrm{~cm}$ diameter) made of perforated polyvinyl chloride tubes covered with nylon cloth were inserted to the soil chamber. The electrode chambers, filled with an anolyte or catholyte solution, were separated from the soil by nylon cloth. Electrodes made of platinum-coated graphite were immersed in the electrolytes and connected to a direct current (DC) power supply.

\subsection{Operating conditions}


Table 1

Table 1 summarizes the operating conditions followed in each experiment. All the experiments except EK-3 were subject to a polarity reversal after specified duration as mentioned in the table. For reversing the electrode polarity, the electrode chambers were emptied and a cleaning to a reasonable level was done using deionised water before the electrode chambers were filled again with the anolyte and catholyte and the electrodes were connected to the power supply with new changed polarity. Injection wells were employed in EK-2 and 5 for the addition of $\mathrm{H}_{2} \mathrm{O}_{2}$ to the soil. These injection wells were kept undisturbed during the whole operation and the solution collected in the injection well was not removed during the polarity reversal. Ek-5 was run for a longer duration with polarity reversal after 10 days and also using excess oxidant by injecting through the injection well. All the experiments were run in same kind of apparatus with similar dimensions and under constant applied voltage of $30 \mathrm{~V}$. In experiments where Fe was used, it was added as ferrous sulphate solution prepared stochiometrically with Fe to substrate (HCB) mass ratio of 1:10. The anolyte consisted of 10 to $12 \% \mathrm{H}_{2} \mathrm{O}_{2}$ in all the cases where $\mathrm{H}_{2} \mathrm{O}_{2}$ was added to the anode. Measured quantity of anolyte was periodically added to the anode chamber in order to compensate for the flow towards the cathode region before and after the polarity reversal throughout the experiment.

\subsection{Chemical Analyses}


$\mathrm{pH}$ and redox were measured using a portable $\mathrm{pH} /$ conductivity meter WTW 340i equipped with SenTix 61 and SenTix ORP sensors. The $\mathrm{pH}$ and redox values of the electrode fluids and the cumulative flow to the cathode chamber were monitored on a daily basis. At the end of each experiment, the soil mass was divided into five equal sections and the analyses were performed. The $\mathrm{pH}$ and redox potential of the soil samples were measured in a suspension of the sample in deionised water in the ratio 1:25. These soil samples were then extracted using ultrasonication as described by Yuan et al [21] and the extracts were analyzed for HCB following the method USEPA- $8270 \mathrm{C}$ [22]. The residual $\mathrm{H}_{2} \mathrm{O}_{2}$ concentration in the soil samples was determined using permanganate method. All the analyses were done in duplicate to ensure the reproducibility of the results.

\section{Results and Discussions}

It may be noted that all the measurements were taken along the normalized distance from the anode of the apparatus as originally designed. Therefore, in experiments with polarity reversal, the cathode end was the anode portion at the end of the experiment.

\subsection{Soil pH and Redox Potential}

The soil $\mathrm{pH}$ as plotted in Fig: 1 shows the final $\mathrm{pH}$ of the soil section at the end of each experiment. The $\mathrm{pH}$ in EK-1 ranged from 3 to 4.4 with the maximum towards the center portion. EK-2 resulted in a more stabilized pH spanning between 3.6 and 4 .

Theoretically, the soil $\mathrm{pH}$ during unenhanced electrokinetics exhibits a general trend ranging anywhere from 2 to 10 depending upon the soil buffering capacity. Since $\mathrm{H}+$ ions move at a 
greater speed than $\mathrm{OH}^{-}$ions, the acidic front advances almost to the near central part of the soil section and this gives rise to a $\mathrm{pH}$ gradient along the soil cross section. [23] This kind of $\mathrm{pH}$ distribution with a steep $\mathrm{pH}$ gradient was observed in EK-3 where the $\mathrm{pH}$ fell between 2.8 and 5.8. The soil $\mathrm{pH}$ in EK- 4 was in the range 3.1 to 4.6 and the corresponding values in EK-5 were 3.5 to 4.4. It can be observed that the $\mathrm{pH}$ values near the cathode region in all the experiments subjected to reversal of electrode polarity showed a lower value than the corresponding values observed in EK -3. Hence, the reversal of polarity aided in preventing the development of a steep $\mathrm{pH}$ gradient in the resulting soil section. However, the final soil $\mathrm{pH}$ was still acidic. Therefore, further optimization in terms of treatment duration or applied voltage is required to acquire a more uniform and higher $\mathrm{pH}$ throughout the soil section.

The redox potential values obtained from the final soil section (data not shown) were found to lie between 350 and $500 \mathrm{mV}$ and indicated that strong oxidizing conditions existed throughout the soil section in all the experiments

Figure 1

\subsection{Current}

The current developed during electrokinetic tests is indicative of its ionic mobility. Also, the current developed during any electrokinetic test under constant applied voltage largely vary with the composition of the analyte, catholyte and other additions made which contribute to the pore solution. The current values during the experiments (Figure 2) were in the mA range and in any case did not go beyond $20 \mathrm{~mA}$. The initial current observed during the start of each experiment dropped and then gradually attained a stable steady lower value. This is of course due to the 
initial dissolution of the salts associated with the soil particles and then the gradual depletion of the same in the system which lowered the electrical conductivity and hence the current. The initial high peaks and relatively higher current values observed in EK-4 and 5 could be attributed to the high ionic concentration in the system due to the addition of Fe as ferrous sulphate.

Figure 2

\subsection{Cumulative flow}

The cumulative flow observed at the cathode with elapsed time for each experiment is plotted in Fig: 5 . The cumulative flow was measured always from the respective cathode chambers during the experiments with and without polarity reversal. Therefore, the change in the direction of flow in experiments with polarity reversal is not reflected in the figure.

In all experiments, the flow was towards the cathode chamber, which indicated that the electroosmotic flow was always to the cathode.

In EK-1, 3 and 4, the anolyte, oxidant and the pore water constituted the soil solution and were transported by electroosmosis from the anode through the soil matrix to the cathode chamber. However, when the oxidant was added to the injection well located in the soil halfway from the anode chamber, the pore water along with the oxidant reached the cathode chamber before the soil solution from the anode chamber reaches the cathode chamber. This would have led to a higher rate of flow to the cathode chamber in EK- 2 and 5. Daily monitoring of cumulative flow revealed that the rate of flow was decreased after the polarity reversal of the electrodes in each 
case. This would have occurred due to sudden change in the $\mathrm{pH}$ dependent physio-chemical properties of the soil which retarded the electroosmotic flow.

Figure 3

\section{4 $\mathrm{HCB}$ degradation and residual $\mathrm{H}_{2} \mathrm{O}_{2}$ concentrations}

The residual $\mathrm{HCB}$ concentration as a ratio of final concentration of $\mathrm{HCB}$ in soil to the initial concentration of $\mathrm{HCB}$ in soil $\left(\mathrm{C} / \mathrm{C}_{0}\right)$ is plotted in Fig: 4.

EK-1, 2 and 3 experiments were performed with $\mathrm{H}_{2} \mathrm{O}_{2}$ as the oxidant without any added Fe. EK-3 could be considered as the reference experiment which was not subject to any polarity reversal during the experiment and $\mathrm{H}_{2} \mathrm{O}_{2}$ was added from the anode.

EK-1 resulted in an overall average removal of $33 \%$ during its 10 days run. A similar concentration profile with an overall average contaminant removal of $10 \%$ was obtained under similar operating conditions with 10 days treatment duration without polarity reversal in EK-3. Therefore, controlling the flow of $\mathrm{H}_{2} \mathrm{O}_{2}$ by reversing the electrode polarity seem to have resulted in a better contaminant degradation than expected with uni-directional flow of $\mathrm{H}_{2} \mathrm{O}_{2}$. However, the soil section from the center portion till the cathode in EK-2 did not undergo any degradation even with polarity reversal. The highest cumulative flow rate was obtained in this experiment. At any time during the experiment the flow of $\mathrm{H}_{2} \mathrm{O}_{2}$ was towards the cathode. Therefore, the oxidant was available to the soil section between the injection point and the cathode only during the first 5 days before reversing the electrode polarity. Hence it should be inferred that when the soiloxidant interaction occurred, the conditions were not favorable for HCB degradation to occur. This might be either due to the unavailability of $\mathrm{H}_{2} \mathrm{O}_{2}$ in its active form, since the stability and hence the decomposition rate of $\mathrm{H}_{2} \mathrm{O}_{2}$ increases with $\mathrm{pH}$, or due to the high $\mathrm{pH}$ conditions not 
favorable for oxidation reactions to occur. Though, in the region between the injection point and anode, the soil-oxidant interaction occurred after changing the polarity and when the anode was the new cathode the soil $\mathrm{pH}$ had already dropped during its initial five days run and the available $\mathrm{H}_{2} \mathrm{O}_{2}$ was still in its active form. This would have led to an increased rate of degradation in this region. The cumulative flow obtained from EK-2 was the maximum among the tests. The rate of volume flushed through the soil specimen was also high in EK-2, which ensured a better soiloxidant interaction. Despite these, the test did not result in significant contaminant removal throughout the soil specimen. It can be therefore inferred that the soil $\mathrm{pH}$ conditions favourable for the oxidation reactions to proceed and $\mathrm{H}_{2} \mathrm{O}_{2}$ stability coexist when $\mathrm{H}_{2} \mathrm{O}_{2}$ is added also from the anode chamber.

EK-4 was carried out in similar manner as EK-1, except for the addition of Fe from the anode and resulted in an average overall removal of $27 \%$. Comparing the data obtained from EK-1 and 4, it is evident that $\mathrm{HCB}$ degradation in soil using high concentrations of $\mathrm{H}_{2} \mathrm{O}_{2}$ did not benefit from the addition of $\mathrm{Fe}$.

EK-5 which was run for 20 days with polarity reversal after 10 days resulted in an average overall removal of $43 \%$. This was contrary to the expectation since similar or better performances were achieved in terms of contaminant removal in our earlier experiments which were run for shorter durations. [6] One possible reason for this could be the changes in the physicochemical nature of the soil induced by the polarity reversal of the electrodes. Therefore the role of extending the treatment duration under the operating conditions followed here is to be investigated more extensively. Also, the overall $\mathrm{HCB}$ degradation rate suggests that the experiment did not benefit much from the quantity of volume flushed which resulted from the simultaneous addition of $\mathrm{H}_{2} \mathrm{O}_{2}$ from the anode as well as the injection well in the soil. Except for experiments 2 and 3, no significant peaks in residual $\mathrm{HCB}$ were seen in the soil section. The 
HCB present in the soil seem to have undergone degradation in a more or less uniform manner due to effective control and flow of the oxidant which has resulted from the polarity reversal of the electrodes. Cathodic degradation has been in some cases pointed out as the cause of contaminant degradation in the soil section near the cathode [24]. The possibility of cathodic degradation of HCB near the cathode area under the conditions followed in this set of experiments has been ruled out, though the HCB concentration profile near the cathode chamber in all experiments shows a down slopping. This is because the redox values obtained from the soil samples do not show a reducing environment throughout the soil section in any of the experiments.

The data obtained for the residual $\mathrm{H}_{2} \mathrm{O}_{2}$ in the soil samples are shown in fig: 5 .

The $\mathrm{H}_{2} \mathrm{O}_{2}$ concentrations in the final soil sample were in good agreement with the mode of addition of $\mathrm{H}_{2} \mathrm{O}_{2}$. The concentration of $\mathrm{H}_{2} \mathrm{O}_{2}$ required for the oxidation of sorbed contaminants increases with the hydrophobicity of the contaminants [25]. As seen from the curves of EK-2 and 5, the addition of $\mathrm{H}_{2} \mathrm{O}_{2}$ from the injection well in the soil resulted in a higher residual peroxide concentration across the soil section. Since, polarity reversal of the electrodes is employed to aid in the reachability of $\mathrm{H}_{2} \mathrm{O}_{2}$ to all sections of the soil specimen, $\mathrm{H}_{2} \mathrm{O}_{2}$ addition through the injection well might result in an over consumption of the oxidant.

Figure 4

Figure 5

\section{Conclusion}


Electrokinetic Fenton experiments have been performed for the removal of $\mathrm{HCB}$ from contaminated kaolin. The direction of $\mathrm{H}_{2} \mathrm{O}_{2}$ flow was controlled by reversing the electrode polarity after a specific time during the experiment. Experiments were performed using $\mathrm{H}_{2} \mathrm{O}_{2}$ with native Fe present in kaolin and supplemental Fe added as ferrous sulphate. Results indicate the potential of polarity reversal as an enhancement during such processes, since better and more uniform HCB degradation was attained during its 10 days operation with polarity reversal than that was attained with the unidirectional flow of $\mathrm{H}_{2} \mathrm{O}_{2}$ under normal electrokinetic process without polarity reversal. Under similar operating conditions, the rate of HCB degradation in experiments with supplemental $\mathrm{Fe}$ was found to be slower than the experiments run with $\mathrm{H}_{2} \mathrm{O}_{2}$ catalyzed by the native Fe in kaolin. However, more experiments should be carried out before validating the impact of extended treatment duration, since the experiment with polarity reversal run for longer duration did not result in higher HCB degradation.

\section{Acknowledgements}

This study was funded by EU, City of Mikkeli and the Academy of Finland, decision 114259.

\section{References}

1. K. R. Reddy \& C. Cameselle, Electrochemical remediation technologies for polluted soils, sediments and groundwater, Wiley Publishers, 2009. 
2. M. Pazos, E. Rosales, T. Alcántara, J. Gómez, M.A. Sanromán, Decontamination of soils containing PAHs by electroremediation: A review. J. Hazard. Mater. 177 (2010) 1-11.

3. T. D. Pham, R. A. Shrestha, J. Virkutyte, M. Sillanpää, Combined ultrasonication and electrokinetic remediation for persistent organic removal from contaminated kaolin, Electrochim. Acta 54 (2009) 1403-1407.

4. R. A. Shrestha, T. D. Pham, M. Sillanpää, Effect of ultrasound on removal of persistent organic pollutants from different types of soils, J. Hazard. Mater. 170 (2009) 871-875.

5. A. Oonnittan, R. A. Shrestha, M. Sillanpää, Effect of Cyclodextrin on the Remediation of Hexachlorobenzene in Soil by Electrokinetic Fenton Process, Sep. Purif. Technol. 64 (2009) 314-320.

6. A. Oonnittan, P. Isosaari, M. Sillanpää, Oxidant availability and its effect on HCB removal during Electrokinetic Fenton process, Sep. Purif. Technol. 76 (2010) 146-150.

7. R. J. Watts, S. Kong, M. Dippre, W. T. Barnes, Oxidation of sorbed hexachlorobenzene in soils using catalysed hydrogen peroxide, J. Hazard. Mater. 39 (1994) 33-47.

8. B. W. Tyre, R. J. Watts, G. C. Miller, Treatment of four biorefractory contaminants in soils using catalysed hydrogen peroxide, J. Environ. Qual. 20 (1991) 832-838.

9. E. Ferrarese, G. Andreottola, I.A. Oprea, Remediation of PAH-contaminated sediments by chemical oxidation, J. Hazard. Mater. 152 (2008) 128-139.

10. F. J. Rivas, Polycyclic aromatic hydrocarbons sorbed on soils: A short review of chemical oxidation based treatments, J. Hazard. Mater. B138 (2006) 234-251.

11. F. K. Kawahara, B. Davila, S. R. Al-Abed, S. J. Vesper, J. C, Ireland, S. Rock, Polynuclear aromatic hydrocarbon $(\mathrm{PAH})$ release from soil during treatment with Fenton's reagent, Chemosphere 31 (1995) 4131-4142. 
12. G.C.C. Yang and Y-W. Long, Removal and degradation of phenol in a saturated flow by in situ electrokinetic remediation and Fenton-like process, J. Hazard. Mater. B 69 (1999) $259-271$.

13. G.C.C. Yang and C-Y. Liu, Remediation of TCE contaminated soils by in situ EK-Fenton process, J. Hazard. Mater. B 85 (2001) 317-331.

14. Ji-Y Park., S-J Kim, Y-J. Lee, K. Baek, Ji-W. Yang, EK-Fenton process for removal of phenanthrene in a two-dimensional soil system, Eng. Geol. 77 (2005) 217-224.

15. P. Isosaari, R. Piskonen, P. Ojala, S. Voipio, K. Eilola, E. Lehmus, M. Itävaara , Integration of electrokinetics and chemical oxidation for the remediation of creosotecontaminated clay J. Hazard. Mater. 144 (2007) 538-548.

16. C. L. Yap, S. Gan, H. K. Ng, Fenton based remediation of polycyclic aromatic hydrocarbons - contaminated soils, Chemosphere, In Press

17. C. Sirguey, P. T. de Souza e Silva, C. Schwartz, M-O. Simonnot, Impact of chemical oxidation on soil quality, Chemosphere 72 (2008) 282-289.

18. Q. Luoa, X. Zhang, H. Wang, Y. Qian, The use of non-uniform electrokinetics to enhance in situ bioremediation of phenol-contaminated soil, J. Hazard. Mater. B121 (2005) 187-194.

19. Q. Luo, X Zhang, H. Wang, Y. Qian, Mobilization of phenol and dichlorophenol in unsaturated soils by non-uniform electrokinetics. Chemosphere (2005) 1289-98.

20. A. Oonnittan, R. A. Shrestha, M. Sillanpää, Removal of hexachlorobenzene from soil by electrokinetically enhanced chemical oxidation, J. Hazard. Mater.162 (2009) 989-993

21. S.Yuan, M. Tian, X. Lu, Electrokinetic movement of hexachlorobenzene in clayed soils enhanced by Tween 80 and cyclodextrin, J. Hazard. Mater. 137 (2006) 1218-1225. 
22. USEPA, Test Methods for Evaluating Solid Wastes, SW 846, 3rdedition. Office of Soil Waste, Washington, DC.

23. B.Narasimhan, R .Ranjan, Electrokinetic barrier to prevent subsurface contaminant migration: theoretical model development and validation. J. Contam. Hydrol. 42 (2000) 117.

24. J.Wan, S. Yuan, J. Chen, T. Li, L. Lin, X. Lu, Solubility-enhanced electrokinetic movement of hexachlorobenzene in sediments: A comparison of cosolvent and cyclodextrin, J. Hazard. Mater. 166 (2009) 221-226.

25. H. N. Quan, A. L. Teel, R. J. Watts, Effect of contaminant hydrophobicity on hydrogen peroxide dosage requirements in the Fenton-like treatment of soils, J. Hazard. Mater. B102 (2003) 277-289.

Figure Legend

Figure 1- Soil $\mathrm{pH}$ at the end of each experiment

Figure 2 - Current developed during the experiments with elapsed time.

Figure 3 - Cumulative flow observed at the cathode during each experiment.

Figure 4 - Residual HCB concentration in soil

Figure 5 - Residual $\mathrm{H}_{2} \mathrm{O}_{2}$ concentration in soil 


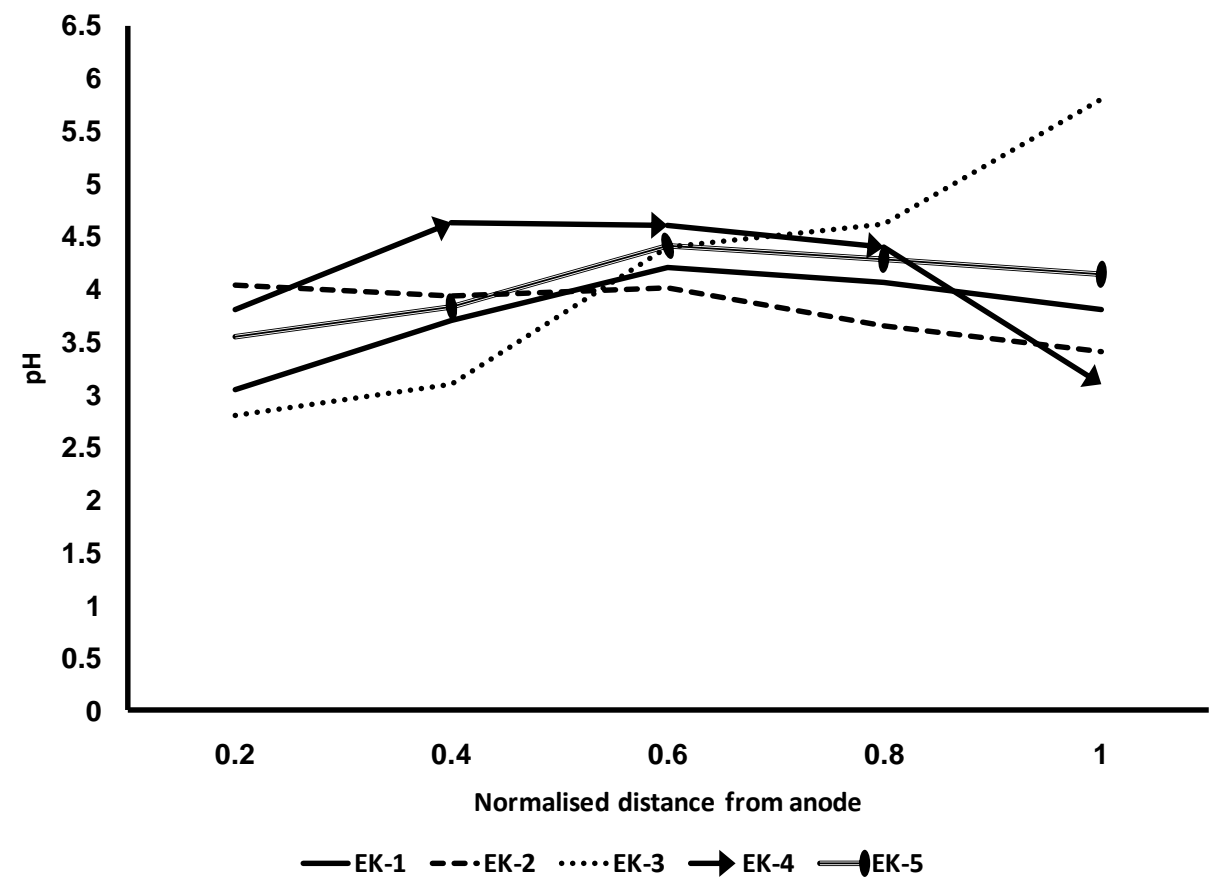

Fig: 1 


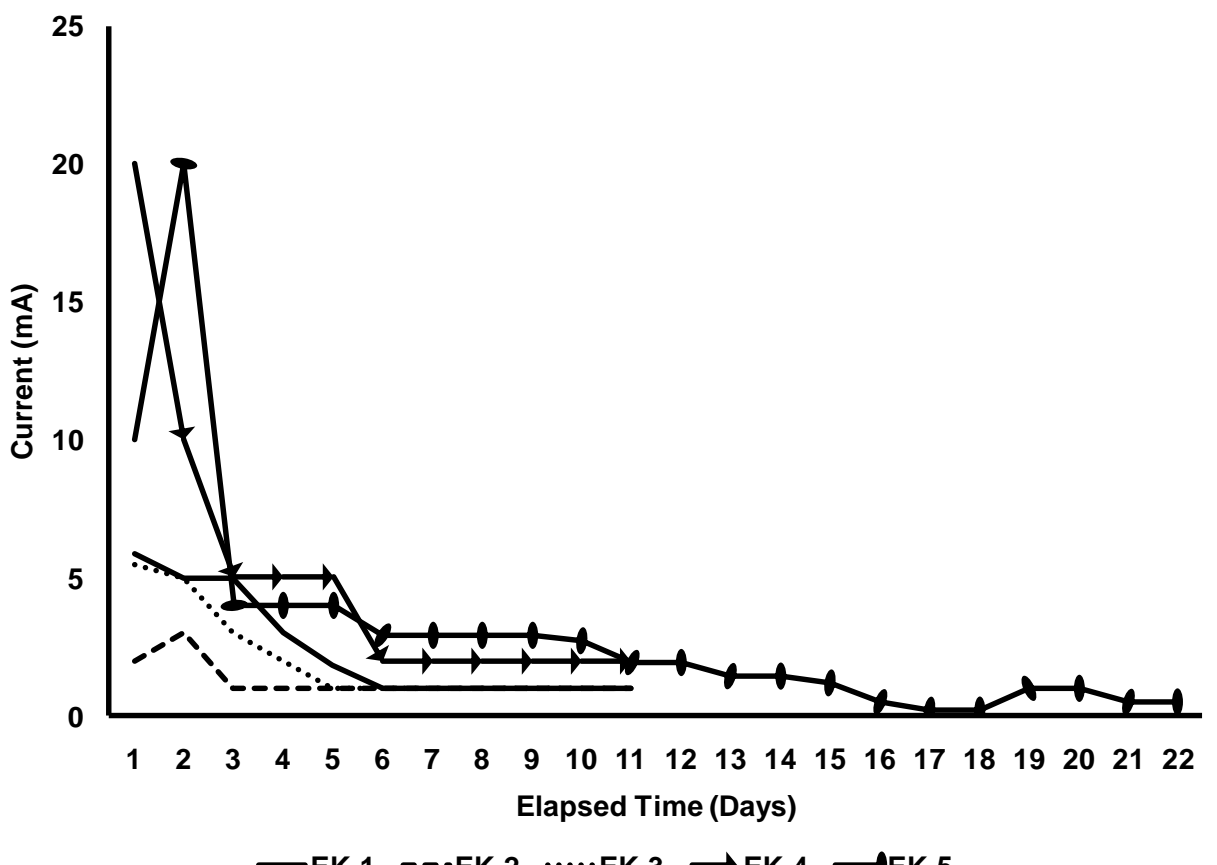

Fig: 2 


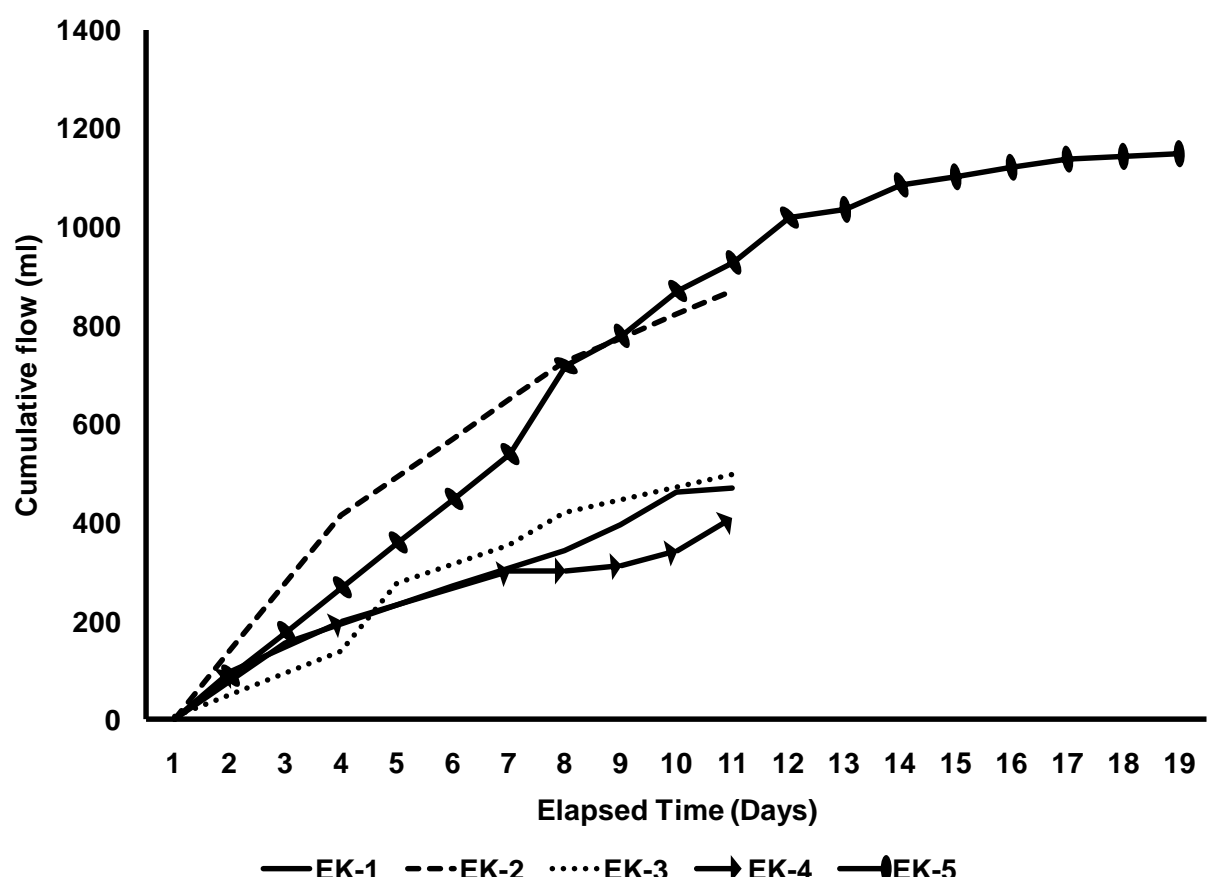

Fig: 3 


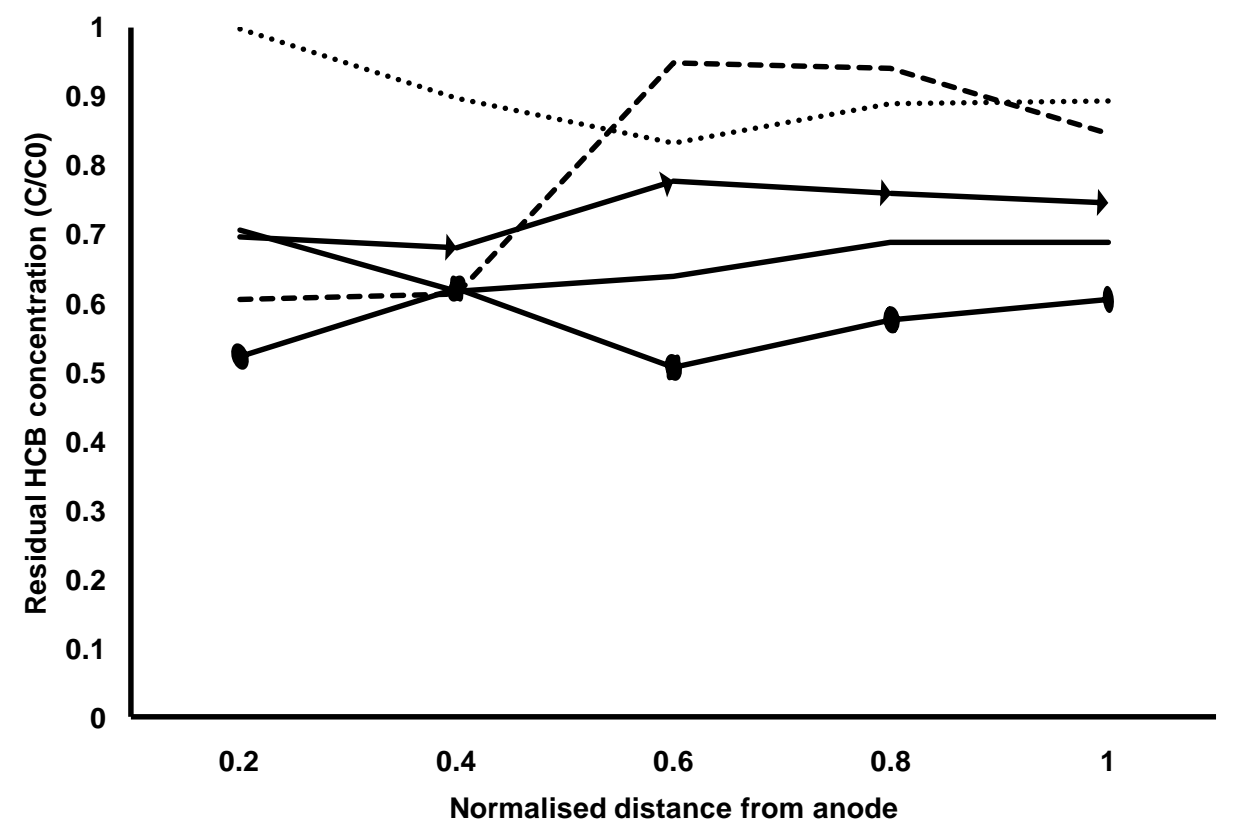

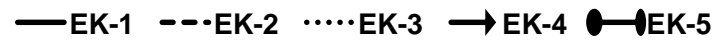

Fig: 4 


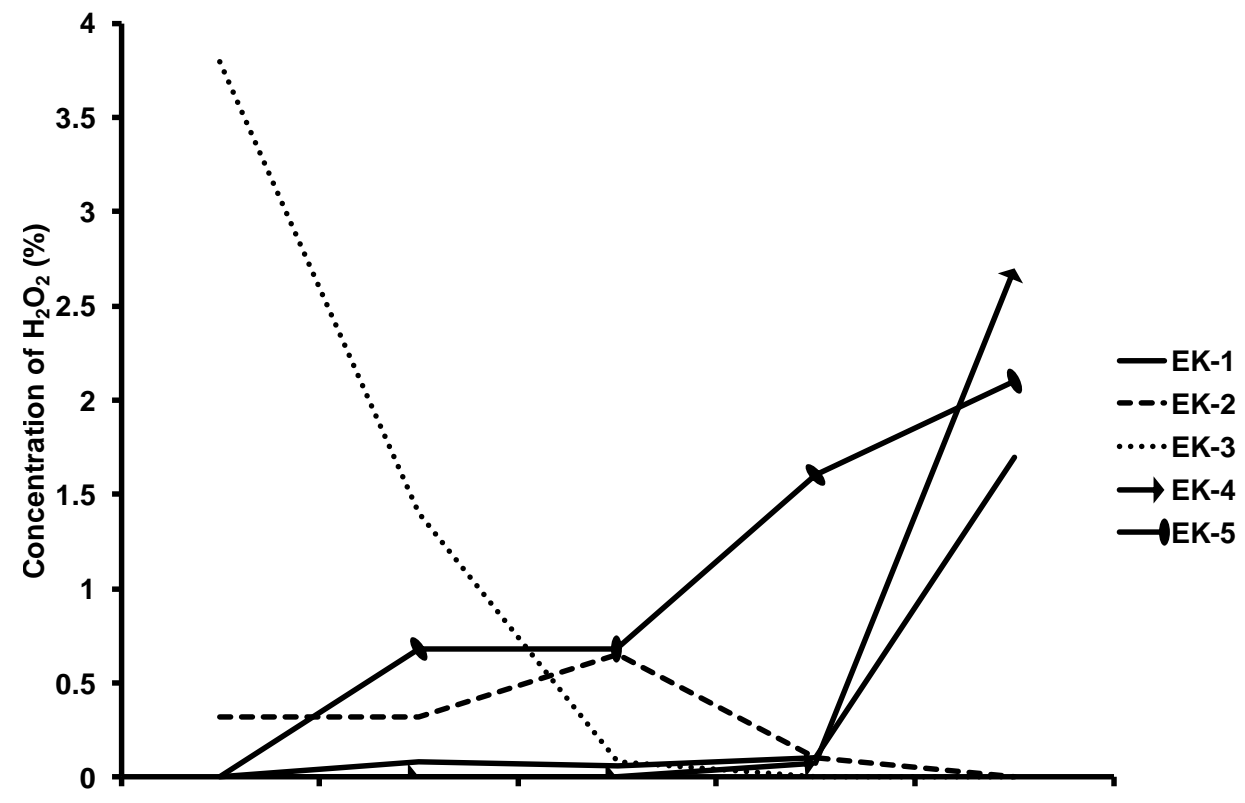

Fig: 5 
Table 1. Operating Conditions

\begin{tabular}{|c|c|c|c|c|c|c|c|}
\hline No. & $\begin{array}{l}\text { Voltage } \\
(V)\end{array}$ & Anolyte & Catholyte & $\begin{array}{l}\text { Mode of } \\
\text { oxidant } \\
\text { addition }\end{array}$ & Injection well & $\begin{array}{l}\text { Duration } \\
\text { (days) }\end{array}$ & $\begin{array}{l}\text { Polarity } \\
\text { reversal }\end{array}$ \\
\hline EK-1 & 30 & $\mathrm{H}_{2} \mathrm{O}_{2}$ & DW & $\begin{array}{l}\mathrm{H}_{2} \mathrm{O}_{2} \text { added } \\
\text { from the anode }\end{array}$ & nil & 10 & $\begin{array}{l}\text { After } 5 \\
\text { days }\end{array}$ \\
\hline EK-2 & 30 & DW & DW & $\begin{array}{l}\mathrm{H}_{2} \mathrm{O}_{2} \text { added to } \\
\text { the injection } \\
\text { well }\end{array}$ & $\begin{array}{l}\text { One in center, } \\
\text { cylindrical, } \\
2 \mathrm{~cm} \text { diameter }\end{array}$ & 10 & $\begin{array}{l}\text { After } 5 \\
\text { days }\end{array}$ \\
\hline EK-3 & 30 & $\mathrm{H}_{2} \mathrm{O}_{2}$ & DW & $\begin{array}{l}\mathrm{H}_{2} \mathrm{O}_{2} \text { added } \\
\text { from the anode }\end{array}$ & nil & 10 & nil \\
\hline EK-4 & 30 & $\begin{array}{l}\mathrm{FeSO}_{4} \\
\mathrm{H}_{2} \mathrm{O}_{2}\end{array}$ & DW & $\begin{array}{l}\mathrm{FeSO}_{4} \text { added as } \\
\text { the anolyte and } \\
\text { then added } \\
\mathrm{H}_{2} \mathrm{O}_{2} \text { after two } \\
\text { days to the } \\
\text { anode }\end{array}$ & nil & 10 & $\begin{array}{l}\text { After } 5 \\
\text { days }\end{array}$ \\
\hline EK-5 & 30 & $\begin{array}{l}\mathrm{FeSO} 4 \\
\mathrm{H}_{2} \mathrm{O}_{2}\end{array}$ & DW & $\begin{array}{l}\mathrm{FeSO} 4 \text { added as } \\
\text { the anolyte and } \\
\text { then added } \\
\mathrm{H}_{2} \mathrm{O}_{2} \text { after two } \\
\text { days to the } \\
\text { anode and } \\
\text { injection well }\end{array}$ & $\begin{array}{l}\text { One in center, } \\
\text { cylindrical, } \\
2 \mathrm{~cm} \text { diameter. }\end{array}$ & 20 & $\begin{array}{l}\text { After } 10 \\
\text { days }\end{array}$ \\
\hline
\end{tabular}




\section{ACTA UNIVERSITATIS LAPPEENRANTAENSIS}

425. VIRTA, MAARIT. Knowledge sharing between generations in an organization - Retention of the old or building the new 2011. Diss.

426. KUITTINEN, HANNA. Analysis on firm innovation boundaries. 2011. Diss.

427. AHONEN, TERO. Monitoring of centrifugal pump operation by a frequency converter. 2011. Diss.

428. MARKELOV, DENIS. Dynamical and structural properties of dendrimer macromolecules. 2011. Diss.

429. HÄMÄLÄINEN, SANNA. The effect of institutional settings on accounting conservatism - empirical evidence from the Nordic countries and the transitional economies of Europe. 2011. Diss.

430. ALAOUTINEN, SATU. Enabling constructive alignment in programming instruction. 2011. Diss.

431. ÅMAN, RAFAEL. Methods and models for accelerating dynamic simulation of fluid power circuits. 2011. Diss.

432. IMMONEN, MIKA. Public-private partnerships: managing organizational change for acquiring value creative capabilities. 2011. Diss.

433. EDELMANN, JAN. Experiences in using a structured method in finding and defining new innovations: the strategic options approach. 2011. Diss.

434. KAH, PAUL. Usability of laser - arc hybrid welding processes in industrial applications. 2011. Diss.

435. OLANDER, HEIDI. Formal and informal mechanisms for knowledge protection and sharing. 2011. Diss.

436. MINAV, TATIANA. Electric drive based control and electric energy regeneration in a hydraulic system. 2011. Diss.

437. REPO, EVELIINA. EDTA- and DTPA-functionalized silica gel and chitosan adsorbents for the removal of heavy metals from aqueous solutions. 2011. Diss.

438. PODMETINA, DARIA. Innovation and internationalization in Russian companies: challenges and opportunities of open innovation and cooperation. 2011. Diss.

439. SAVITSKAYA, IRINA. Environmental influences on the adoption of open innovation: analysis of structural, institutional and cultural impacts. 2011. Diss.

440. BALANDIN, SERGEY, KOUCHERYAVY, YEVGENI, JÄPPINEN, PEKKA, eds. Selected Papers from FRUCT 8.2011.

441. LAHTI, MATTI. Atomic level phenomena on transition metal surfaces. 2011. Diss.

442. PAKARINEN, JOUNI. Recovery and refining of manganese as by-product from hydrometallurgical processes. 2011. Diss.

443. KASURINEN, JUSSI. Software test process development. 2011. Diss.

444. PEKKANEN, PETRA. Delay reduction in courts of justice - possibilities and challenges of process improvement in professional public organizations. 2011. Diss.

445. VANHALA, MIKA. Impersonal trust within the organization: what, how, and why? 2011. Diss. 
446. HYNYNEN, KATJA. Broadband excitation in the system identification of active magnetic bearing rotor systems. 2011. Diss.

447. SOLONEN, ANTTI. Bayesian methods for estimation, optimization and experimental design. 2011 Diss.

448. JABLONSKA, MATYLDA. From fluid dynamics to human psychology. What drives financial markets towards extreme events. 2011. Diss.

449. MYÖHÄNEN, KARI. Modelling of combustion and sorbent reactions in three-dimensional flow environment of a circulating fluidized bed furnace. 2011. Diss.

450. LAATIKAINEN, MARKKU. Modeling of electrolyte sorption - from phase equilibria to dynamic separation systems. 2011. Diss.

451. MIELONEN, JARI. Making Sense of Shared Leadership. A case study of leadership processes and practices without formal leadership structure in the team context. 2011. Diss.

452. PHAM, ANH TUAN. Sewage sludge electro-dewatering. 2011. Diss.

453. HENNALA, LEA. Kuulla vai kuunnella - käyttäjää osallistavan palveluinnovoinnin lähestymistavan haasteet julkisella sektorilla. 2011. Diss.

454. HEINIMÖ, JUSSI. Developing markets of energy biomass - local and global perspectives. 2011. Diss.

455. HUJALA, MAIJA. Structural dynamics in global pulp and paper industry. 2011. Diss.

456. KARVONEN, MATTI. Convergence in industry evolution. 2011. Diss.

457. KINNUNEN, TEEMU .Bag-of-features approach to unsupervised visual object categorisation. 2011. Diss.

458. RUUSKANEN, VESA. Design aspects of megawatt-range direct-driven permanent magnet wind generators. 2011. Diss.

459. WINTER, SUSANNA. Network effects: scale development and implications for new product performance. 2011. Diss.

460. JÄÄSKELÄINEN, ANSSI. Integrating user experience into early phases of software development. 2011. Diss.

461. KÄÄRIÄINEN, TOMMI. Polymer surface modification by atomic layer deposition. 2011. Diss.

462. KOCHURA, ALEKSEY. Growth, magnetic and transport properties of InSb and II-IV-As2 semiconductors doped with manganese. 2011. Diss.

463. PUTKIRANTA, ANTERO. Possibilities and challenges of longitudinal studies in operations management. 2011. Diss.

464. HAPPONEN, ARI. Muuttuvaan kysyntään sopeutuva varastonohjausmalli. 2011. Diss.

465. VASAVA, PARITOSH. Application of computational fluid dynamics in modelling blood flow in human thoracic aorta. 2011. Diss.

466. PURO, LIISA. Identification of extractives and polysaccharides as foulants in membrane filtration of pulp and paper mill effluents. 2011. Diss.

467. LAPPALAINEN, PIA. Socially Competent Leadership - predictors, impacts and skilling in engineering. 2012. Diss. 
